\title{
Sensoriamento de ambiente utilizando o padrão ZigBee
}

\author{
Ferdinando Monsignore
}

Dissertação apresentada à Escola de Engenharia de São Carlos da Universidade de São Paulo, como parte dos requisitos para a obtenção do título de Mestre em Engenharia Elétrica.

Orientadora: Profa. Dra. Maria Stela Veludo de Paiva

São Carlos 
Dedico este trabalho aos meus amados pais, Vera Teresa Moretti Monsignore e Simplicio Monsignore. 


\section{Agradecimentos}

Ao Pai Celestial, pela proteção e luz dada durante todo o desenvolvimento deste trabalho;

A minha orientadora Profa. Dra. Maria Stela Veludo de Paiva, por me ensinar e por sua amizade durante todo o percurso;

A todos os amigos de república, por sua amizade e presença em todas as horas;

A N3E, que teve papel muito importante na realização deste trabalho;

Aos meus avós, pais e irmãos, pelo apoio irrestrito e carinho em todos os momentos desde sempre;

Em especial a minha namorada Mônica C. Miranda, por seu amor, companheirismo e incansável apoio durante a realização deste trabalho. 


\section{Resumo}

MONSIGNORE, F. (2007), Sensoriamento de ambiente utilizando o padrão ZigBee. Dissertação (Mestrado) - Escola de Engenharia de São Carlos, Universidade de São Paulo, São Carlos, 2007. 74p.

A comunicação sem fio (wireless) vem sofrendo uma enorme expansão nos últimos anos. Para esse tipo de comunicação foram criados alguns padrões, destacando-se o Wi-Fi, o Bluetooth e mais recentemente o ZigBee. Este último, o ZigBee, engloba aplicações de monitoração e sensoriamento de sistemas, o que o torna adequado para aplicações residenciais. Essa característica do ZigBee motivou o desenvolvimento desse trabalho, cujo objetivo foi o de avaliar o padrão ZigBee através de uma aplicação de monitoração e sensoriamento para uso residencial, utilizando um kit de desenvolvimento da Microchip. Esse trabalho consiste em dois nós se comunicando via ZigBee, onde um nó possui um sensor de movimento, uma lâmpada e um LED (que simula um aparelho de ar condicionado) e um segundo nó, que pode ser conectado a um PC via USB utilizando um hardware externo desenvolvido. Esse nó ainda possui um sensor de temperatura, um sensor de luminosidade(LDR) e um sinalizador acústico.

Os resultados obtidos mostram que o ZigBee é um padrão eficiente para aplicações de monitoração e sensoriamento de ambientes.

Palavras-chave: ZigBee; Domótica; Sensoriamento; USB 


\begin{abstract}
MONSIGNORE, F. (2007), Environment sensing using ZigBee standard. M.Sc. Dissertation Escola de Engenharia de São Carlos, Universidade de São Paulo, São Carlos, 2007. 74p.

A huge expansion has occurred in wireless communication in the last few years. Some wireless standards were created, like Wi-Fi, Bluetooth and more recently the ZigBee standard, that includes monitoring and sensing systems application. This characteristic makes the ZigBee standard appropriate for residencial applications. This ZigBee characteristic motivated the development of this work, wich objective was evaluate the ZigBee standard through a monitoring and sensing application for residencial use, using a development kit by Microchip. This application has two nodes communicating through ZigBee. One node has a motion sensor, a lamp and a LED (that simulates an air conditioner device) and the second one can be connected to a PC through USB using a developed external hardware. This node also has a temperature sensor, a light dependent resistor (LDR) and a beep.
\end{abstract}

The reached results shows that ZigBee is an efficient standard for environment monitoring and sensing.

Keywords: ZigBee; Smart building; Sensing; USB 


\section{SUMÁRIO}

Lista de abreviaturas e siglas

vii

Lista de símbolos

xi

Lista de Figuras

Lista de Tabelas

$\mathbf{X V}$

1 Introdução

1.1 Contextualização . . . . . . . . . . . . . . . . . . . . . . 1

1.2 Motivação . . . . . . . . . . . . . . . . . . . . 2

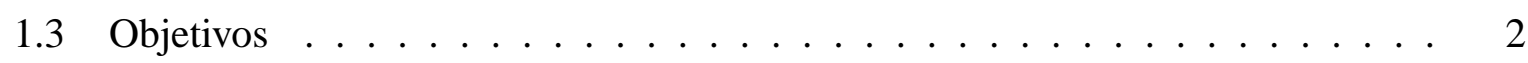

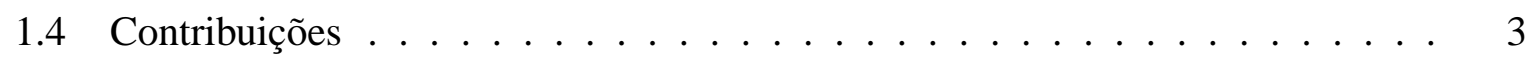

1.5 Estrutura do trabalho . . . . . . . . . . . . . . . . . 3

2 Comunicação Wireless 5

2.1 Considerações Iniciais $\ldots \ldots \ldots \ldots$

2.2 Comunicação Wireless: Introdução . . . . . . . . . . . . . . . 5

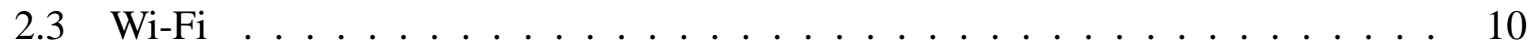

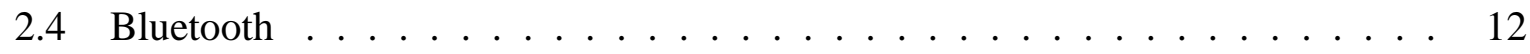

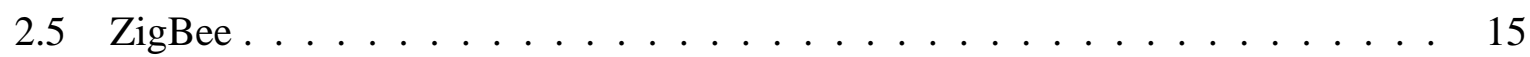


2.6 Considerações Finais . . . . . . . . . . . . . . . . . . . . . . 17

3 A norma 802.15.4 e o padrão ZigBee 19

3.1 Considerações Iniciais $\ldots \ldots \ldots$

3.2 O Padrão ZigBee . . . . . . . . . . . . . . . . . . . . . . . . . . . . . . . . . 19

3.2.1 Topologias de Rede . . . . . . . . . . . . . . . . . . . . . . . . 19

3.2 .2 Pilha Protocolar . . . . . . . . . . . . . . . . . 21

3.2 .3 Camada PHY . . . . . . . . . . . . . . . . . . . 21

3.2 .4 Camada MAC . . . . . . . . . . . . . . . . 23

3.2.5 Camada de Rede . . . . . . . . . . . . . . . . . . 26

3.2 .6 Camada de Aplicação . . . . . . . . . . . . . . . . . . . . . . 27

3.2.7 Binding e Binding Table . . . . . . . . . . . . . . . . 27

3.3 Considerações Finais $\ldots \ldots \ldots$. . . . . . . . . . . . . . . 30

4 Trabalho Desenvolvido $\quad 31$

4.1 Considerações Iniciais $\ldots \ldots \ldots$. . . . . . . . . . . . . . . . 31

4.2 Funções Implementadas . . . . . . . . . . . . . . . . . . . . . . . . 31

4.3 Metodologia . . . . . . . . . . . . . . . . . 32

4.3 .1 Comunicação Entre os Nós . . . . . . . . . . . . . . . . . . . . . . 33

4.3.2 Implementação e Validação do Hardware . . . . . . . . . . . . . . . . 34

4.4 Ferramentas de Desenvolvimento . . . . . . . . . . . . . . . 35

4.5 Considerações Finais $\ldots \ldots$. . . . . . . . . . . . . . . . . . . 36

5 Descrição, Resultados e Discussões 37 
5.1 Considerações Iniciais $\ldots \ldots$. . . . . . . . . . . . . . . . . 37

5.2 Descrição da Lógica dos Sensores e da USB . . . . . . . . . . . . . . . . . . 37

5.2.1 Sensor de Temperatura . . . . . . . . . . . . . . . 38

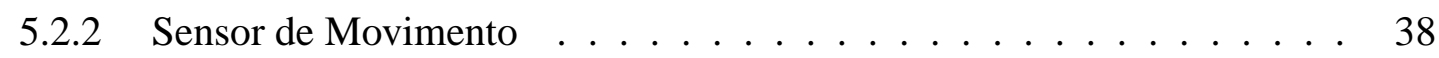

5.2.3 Sensor de Luminosidade . . . . . . . . . . . . . . . . . 38

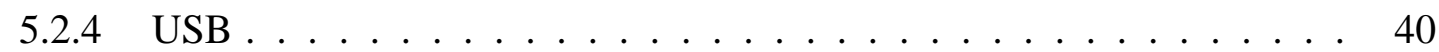

5.3 Descrição do Hardware . . . . . . . . . . . . . . . . . . . . . . 40

$5.3 .1 \quad \operatorname{PICDEM} Z \ldots \ldots \ldots \ldots \ldots$

5.3 .2 Sensor de Temperatura . . . . . . . . . . . . . . . . 42

5.3.3 Sensor de Luminosidade e Sinalizador Acústico . . . . . . . . . . . . . 43

$5.3 .4 \quad$ USB $\ldots \ldots \ldots \ldots \ldots \ldots \ldots$

5.3.5 Sensor de Movimento _. . . . . . . . . . . . . . . . . 45

5.3 .6 Led . . . . . . . . . . . . . . . . . 47

5.3 .7 Lâmpada . . . . . . . . . . . . . . . . . . . . 48

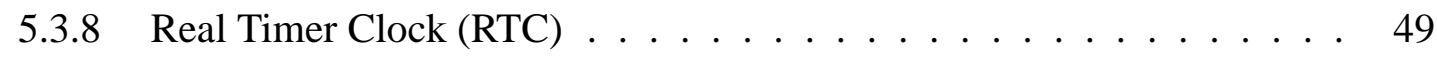

5.4 Descrição do Software . . . . . . . . . . . . . . 51

5.4 .1 Pilha ZigBee ...................... 51

5.4 .2 Software Desenvolvido . . . . . . . . . . . . . 52

5.5 Resultados e Discussões . . . . . . . . . . . . . . . . . . 52

6 Conclusões $\quad 55$

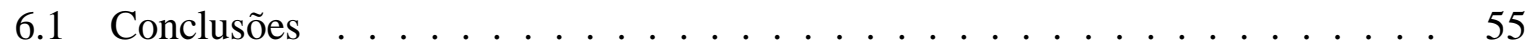

6.2 Contribuições ............................... 56 
6.3 Proposta para Trabalhos Futuros . . . . . . . . . . . . . . 56

$\begin{array}{ll}\text { Referências Bibliográficas } & 59\end{array}$

Apêndice A - Códigos Fonte $\quad 63$

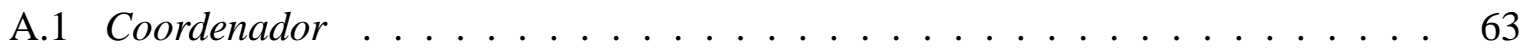

A.1.1 Inicialização . . . . . . . . . . . . . . 63

A.1.2 Sensor de Temperatura . . . . . . . . . . . . . . . 63

A.1.3 Sensor de Luminosidade (LDR) . . . . . . . . . . . . . . . 67

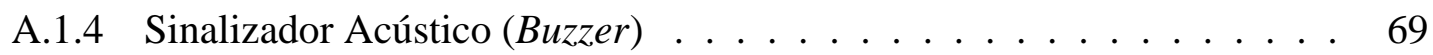

A.2 End Device $(\mathrm{RFD}) \ldots \ldots \ldots \ldots \ldots \ldots$

A.2.1 Inicialização . . . . . . . . . . . . . . . . . 70

A.2.2 Sensor de Movimento f . . . . . . . . . . . . . . 71

A.2.3 Lâmpada . . . . . . . . . . . . . . . . . . . 73

A.2.4 LED . . . . . . . . . . . . . . . . . . . . . . 74 


\section{LISTA DE ABREVIATURAS E SIGLAS}

\begin{tabular}{|c|c|}
\hline $\mathrm{AC}$ & Alternate Current \\
\hline Ack & Acknowledgment \\
\hline $\mathrm{ADC}$ & Analogic Digital Conversor \\
\hline AES & Advanced Encryption Standard \\
\hline $\mathrm{AF}$ & Application Framework \\
\hline APS & Applications Support \\
\hline CAP & Contention Access Period \\
\hline $\mathrm{CD}$ & Compact Disc \\
\hline $\mathrm{CE}$ & Chip Enable \\
\hline CLK & Clock \\
\hline $\mathrm{CNPq}$ & Conselho Nacional de Desenvolvimento Científico e Tecnológico \\
\hline CSMA-CA & Carrier Sense Multiple Access with Collision Avoidance \\
\hline DSSS & Direct Sequence Spread Spectrum \\
\hline FDM & Frequency Division Multiplexing \\
\hline FFD & Full-Function Device \\
\hline FHSS & Frequency Hopping Spread Spectrum \\
\hline GND & Ground \\
\hline GPRS & General Packet Radio Service \\
\hline GSM & Global System for Mobile Communications \\
\hline GTS & Guaranteed Time Slots \\
\hline HAN & House Area Network \\
\hline IEEE & Institute of Electrical and Electronics Engineers \\
\hline
\end{tabular}


IP Internet Protocol

ISM Industrial, Scientific and Medical

KVP Key-Value Pair

LAN Local Area Network

LCD Liquid Crystal Display

LDR Luminosity Dependent Resistor

LQI Link Quality Indication

MAC Medium Access Control

MAN Metropolitan Area Network

MSG Message Service Type

NWK Network

PAN Personal Area Network

PC Personal Computer

PCI Placa de Circuito Impresso

PDA Personal Digital Assistant

PHY Physical

QoS Quality of Service

RF Rádio Frequiência

RFD Reduced-Function Device

RS232 RETMA Standard 232

RTC Real Time Clock

SDI Serial Data In

SDI/O Serial Data In/Out

SDO Serial Data Out

SNR Sinal Noise Relation

SPI Serial Peripheral Interface 
TTL Transistor - Transistor Logic

UART Universal Assynchronous Receiver Transmitter

USB Universal Serial Bus

UWB Ultra Wide Band

WAN Wide Area Network

Wi-Fi Wireless Fidelity

ZDO ZigBee Device Object 


\title{
LISTA DE SÍMBOLOS
}

\author{
$\Omega \quad$ Ohm \\ ${ }^{o} \mathrm{C} \quad$ Graus Celsius \\ A Ampere \\ $B \quad$ Byte \\ bps Bits Por Segundo \\ $G \quad$ Giga \\ $\mathrm{Hz} \quad$ Hertz \\ $k \quad$ Kilo \\ M Mega \\ V Volts
}




\section{LISTA DE FIGURAS}

2.1 Posicionamento das tecnologias wireless. Fonte: (FRIAS, 2004) . . . . . . 6

2.2 Comparação de redes "Wireless". Fonte: (BRANQUINHO; REGGIANI; AN-

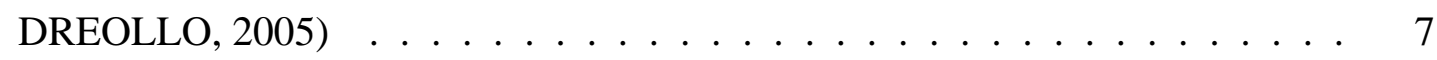

2.3 Tecnologias sem fio LAN/PAN. Fonte: $($ FRENZEL, 2004) $\ldots \ldots \ldots$

3.1 Topologias de Rede. Fonte: (MALAFAYA; TOMÁS; SOUSA, 2005) . . . . . . 20

3.2 Modelo de camadas da pilha protocolar ZigBee. . . . . . . . . . . . . . . 22

3.3 Estrutura de canais do IEEE 802.15.4. Fonte:(LEE, 2005) . . . . . . . . . . . . 23

3.4 Estrutura Superframe, Fonte: (ONDREJ et al., 2006) . . . . . . . . . . . . . 24

3.5 Transmissão direta em redes (a) beacon habilitado, e (b) beacon não habilitado. Fonte: $($ LEE, 2005) . . . . . . . . . . . . . . . . . . . . 25

3.6 Transmissão indireta em redes (a) beacon habilitado, e (b) beacon não habilitado. Fonte: $($ LEE, 2005) . . . . . . . . . . . . . . . . . 26

3.7 Formato da mensagem ZigBee $\ldots \ldots \ldots \ldots \ldots$

3.8 Binding e Tabela de Binding. Fonte: (ZIGBEE-ALLIANCE, 2005) . . . . . . . 29

4.1 Diagrama de blocos do nó do tipo coordenador. . . . . . . . . . . . . . 32

4.2 Diagrama de blocos do nó do tipo RFD. . . . . . . . . . . . . . . 33

4.3 Placa PICDEM Z com placa de RF acoplada. Fonte: (MICROCHIP, 2006b) . . 36

5.1 Trabalho Desenvolvido . . . . . . . . . . . . . . . . 37

5.2 PICDEM $Z$ adequado para o desenvolvimento. . . . . . . . . . . . . 41 
5.3 Parte inferior do PICDEM Z após adequação. . . . . . . . . . . . . . . . 41

5.4 Circuito do Sensor de Temperatura. Fonte: (MICROCHIP, 2004e) . . . . . . . 42

5.5 Localização do TC77 no kit PICDEM Z . . . . . . . . . . . . . . . . . 42

5.6 (a) Circuito do LDR implementado, (b) Circuito do Sinalizador Acústico im-

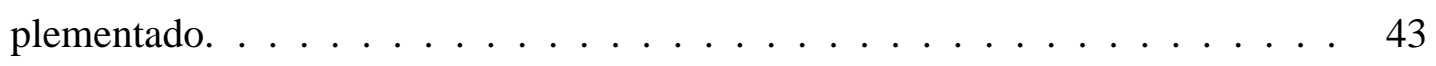

5.7 Sensor de Luminosidade e Sinalizador Acústico. . . . . . . . . . . . . . . . . . 44

5.8 Placa USB-RS232-TTL desenvolvida. . . . . . . . . . . . . . . . 45

5.9 Conexão da placa USB no modo USB - TTL. . . . . . . . . . . . . . . 46

5.10 Circuito implementado para leitura do sensor de movimento. . . . . . . . . . 46

5.11 Sensor de Movimento da ICCEA. . . . . . . . . . . . . . . . 46

5.12 Circuito do Sensor de Movimento implementado. . . . . . . . . . . . . . . 47

5.13 Circuito do LED implementado. . . . . . . . . . . . . . . . . . . 47

5.14 Circuito de acionamento da lâmpada. . . . . . . . . . . . . . . . 48

5.15 Circuito de referência para o comparador. . . . . . . . . . . . . . 48

5.16 Circuito do RTC implementado. . . . . . . . . . . . . . . . . . . 49

5.17 Real Timer Clock. . . . . . . . . . . . . . . . . . . . 50

5.18 Fluxograma do nó do tipo coordenador. . . . . . . . . . . . . 53

5.19 Fluxograma do nó do tipo RFD . . . . . . . . . . . . . . . . . 54

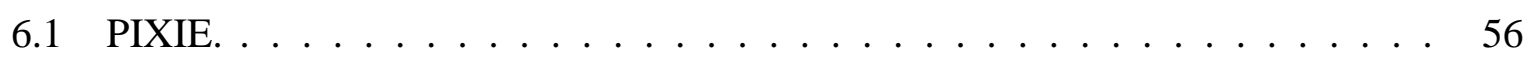




\section{LISTA DE TABELAS}

1.1 Comparação de tecnologias sem fio. Fonte: (MALAFAYA; TOMÁS; SOUSA, 2005) . . . . . . 2

2.1 Comparação de características desejáveis entre Bluetooth e ZigBee. Fonte: (BAKER, 2005) . 8 


\section{INTRODUÇÃO}

\subsection{Contextualização}

A comunicação wireless já está presente há algum tempo no cotidiano das pessoas, tendo sofrido uma enorme expansão nos últimos anos. Os mais difundidos padrões wireless são o Wi-Fi e o Bluetooth. Apenas recentemente começou a se pensar num padrão específico para se trabalhar com sistemas de monitoração e sensoriamento, tais como sistemas de automação doméstica, segurança, controle de iluminação e de acesso, etc. Os principais requisitos deste tipo de sistema são baixa latência, otimização para baixo consumo de energia, possibilidade de implementação de redes com elevado número de dispositivos e baixa complexidade dos nós de rede.

O padrão ZigBee (ZIGBEE-ALLIANCE, 2006) é um padrão mais recente, criado com o objetivo de suprir esses requisitos, e juntamente com o padrão IEEE ${ }^{1}$ 802.15.4 (GUTIERREZ et al., 2001), visa a uniformização das redes pessoais (PAN) e das redes domésticas (HAN) de última geração, garantindo a confiabilidade, a segurança na comunicação e a maximização do tempo de vida útil das baterias.

Cabe lembrar que o Zigbee não foi idealizado para substituir o Bluetooth. Cada um é específico para um tipo de aplicação. A tabela 1.1 apresenta a comparação entre as duas tecnologias sem fio. O ZigBee engloba aplicações de monitoração e sensoriamento de sistemas, enquanto que o Bluetooth é mais apropriado para sistemas de transmissão de áudio ou dados ponto a ponto, sistemas que exigem uma taxa de transferência mais alta.

\footnotetext{
${ }^{1}$ Institute of Electrical and Electronics Engineers
} 


\begin{tabular}{ccccccc}
\hline Especificação & $\begin{array}{c}\text { Camada } \\
\text { Física }\end{array}$ & Taxa & $\begin{array}{c}\text { Duração das } \\
\text { Baterias }\end{array}$ & Recursos & Nós & Alcance \\
\hline Bluetooth & 802.15 .1 & $1 \mathrm{Mbps}$ & 1 a 7 dias & $\approx 250 \mathrm{~KB}$ & 7 & 1 a $10 \mathrm{~m}$ \\
ZigBee & 802.15 .4 & $250 \mathrm{Kbps}$ & 100 a 1000 dias & 4 a $32 \mathrm{~KB}$ & 65535 & $100 \mathrm{~m}$ \\
\hline
\end{tabular}

Tabela 1.1: Comparação de tecnologias sem fio. Fonte: (MALAFAYA; TOMÁs; SOUSA, 2005)

O ZigBee é o mais apropriado para aplicações que envolvam dispositivos remotos alimentados por baterias, sensores e atuadores, já que permite baixo consumo, taxas de transferência adequadas para este tipo de aplicação (de 20 a 250kbps) e possui uma pilha protocolar mais simples que possibilita a sua implementação em sistemas com recursos limitados.(MALAFAYA; TOMÁS; SOUSA, 2005)

\subsection{Motivação}

Este trabalho é parte de um projeto do CNPq em conjunto com a N3E Nova Empresa, que tem por objetivo a implementação de um sistema para monitoração e sensoriamento de ambientes residenciais utilizando comunicação sem fio.

A busca por um padrão de comunicação sem fio, específico para esse fim, levou à implementação desse presente trabalho, que visa principalmente avaliar o padrão ZigBee para tal aplicação.

\subsection{Objetivos}

O objetivo deste trabalho é avaliar o protocolo de comunicação sem fio ZigBee através de uma aplicação para uso residencial utilizando um kit de desenvolvimento da Microchip. 


\subsection{Contribuições}

Uma rede de comunicação sem fios minimiza a utilização de cabos na instalação elétrica de uma residência. Os cabos que hoje fazem o papel de retorno para lâmpadas, e os cabos que ligam e alimentam os sensores espalhados pelas casas, entre outros, poderão ser substituídos por módulos ZigBee com alimentação por baterias, que podem durar vários anos.

Esse é o maior diferencial desse trabalho, pois já existem aplicações para uso residenciais que visam conforto, segurança e economia para os usuários, como pode ser visto em Home-Control (2006), mas a maioria possui cabeamento para tal.

Um outro aspecto muito importante é a utilização da interface $\mathrm{USB}^{2}$ na coleta dos dados. Nos últimos anos vem ocorrendo uma substituição gradativa das interfaces seriais no padrão RS232 pela do padrão USB nos PCs, e visto que a tendência aponta para um total desaparecimento das interfaces seriais do padrão RS232, torna-se de suma importância a presença de uma conexão USB no nó ZigBee que se comunicará com um PC para descarga de dados.

\subsection{Estrutura do trabalho}

Este trabalho está dividido em 6 capítulos e 1 apêndice.

No primeiro capítulo foi apresentada a introdução, destacando a aplicabilidade, importância, e o objetivo do trabalho.

No capítulo 2 é apresentada uma breve descrição da comunicação wireless e de alguns tipos de implementações existentes, enfatizando as que se encaixam no conceito de rede de área pessoal (PAN).

No capítulo 3 são apresentados mais detalhadamente os padrões ZigBee e 802.15.4.

No capítulo 4 é apresentada a metodologia e as ferramentas utilizadas para o desenvolvimento do trabalho proposto.

\footnotetext{
${ }^{2}$ Universal Serial Bus
} 
No capítulo 5 é apresentada a descrição da lógica, do hardware e software implementados, os resultados e as discussões.

No capítuo 6 são apresentados as conclusões, as contribuições deste trabalho e as propostas para trabalhos futuros.

No apêndice A é apresentado o código fonte utilizado na implementação proposta. 


\section{COMUNICAÇÃO WIRELESS}

\subsection{Considerações Iniciais}

Neste capítulo é realizada uma revisão dos trabalhos mais recentes na literatura sobre comunicação wireless e sobre alguns dos padrões mais difundidos.

\subsection{Comunicação Wireless: Introdução}

A tecnologia wireless descreve os sistemas de telecomunicação em que as ondas eletromagnéticas carregam o sinal sobre parte ou todo o trajeto de comunicação sem a utilização de cabos (JINDAL; JINDAL; GUPTA, 2005).

As redes wireless mantêm a promessa do acesso à informação em qualquer lugar. Esta promessa conduziu à distribuição difundida dos serviços de voz e dados baseados em tecnologia wireless, exemplificado por redes de celulares e por redes de área local sem fio (WLAN) (NUGGEHALLI; SRINIVASAN; RAO, 2006).

É apresentado a seguir um breve histórico da comunicação wireless:

- 1839 - $1^{\mathrm{a}}$ mensagem telegráfica em código morse - o $1^{\circ} \mathrm{SMS}$ !

- 1867 - Fundação da indústria telefônica, a Bell, precursora da AT\&T.

- 1900 - $1^{\text {a }}$ Transmissão Wireless - MARCONI, ondas de rádio.

- 1972 - $1^{\text {a }}$ Demonstração de telefonia celular - MOTOROLA

- 1999 - Criação da Wi-Fi Alliance.

- 1999 - Formalizado o Bluetooth Special Interest Group (SIG). 
- 2000 - Revolução de voz \& dados na telefonia celular.

- 2002 - Revolução de banda larga - CableModem, xDSL, VoiceIP...

- 2004 - ZigBee Alliance termina primeira versão do padrão ZigBee em Dezembro.

A Figura 2.1 ilustra o posicionamento do padrão ZigBee no mercado de tecnologias wireless, levando em consideração o alcance e a taxa de transmissão. Apesar do padrão ZigBee ter sido projetado para ter um alcance de até 10 metros, ele pode chegar a algumas dezenas de metros, ultrapassando um pouco o limite de uma PAN e entrando na região de alcance de uma rede de área local (LAN).

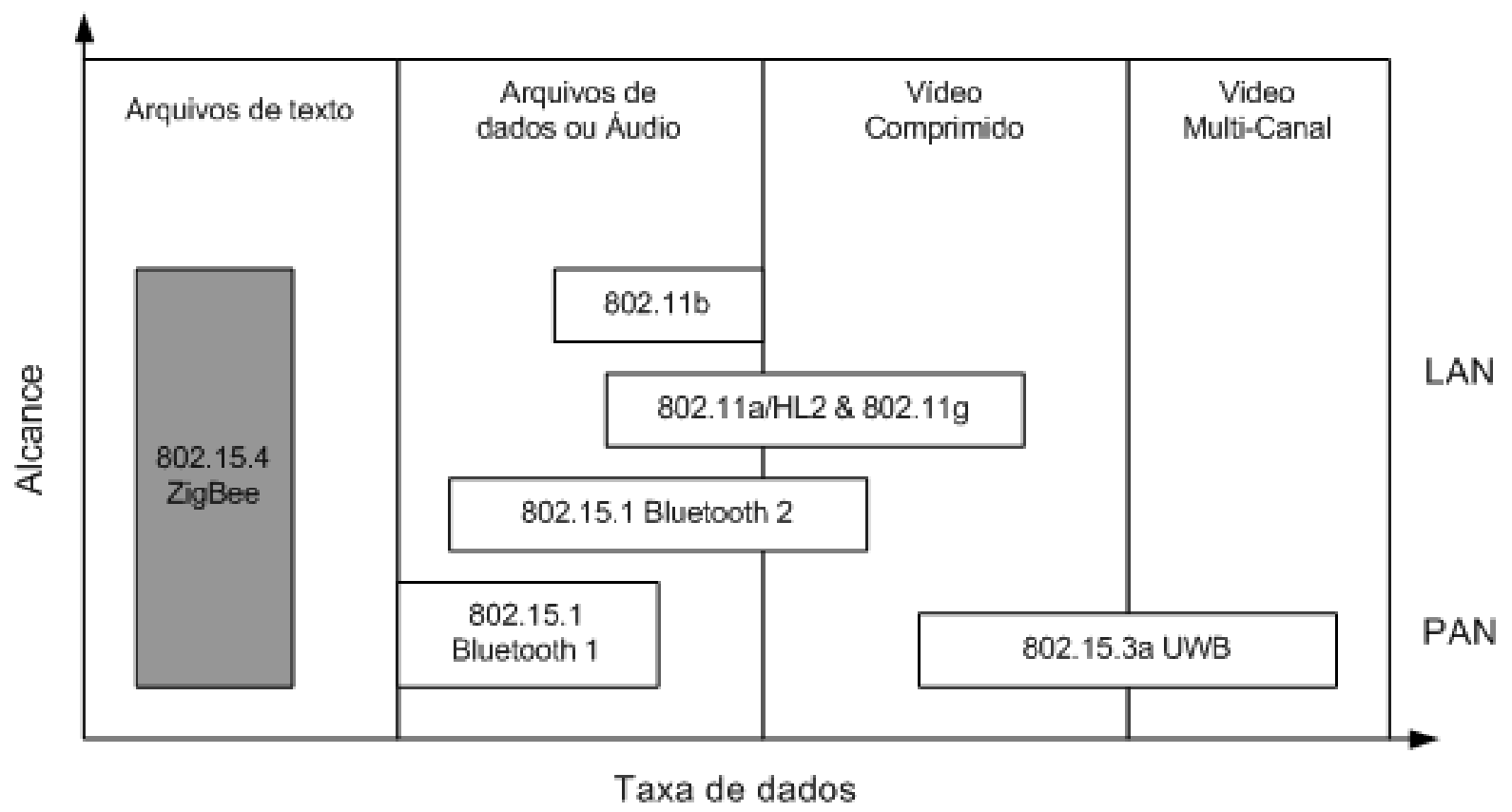

Figura 2.1: Posicionamento das tecnologias wireless. Fonte: (FRIAS, 2004)

Conforme já mencionado na introdução, o ZigBee veio preencher uma lacuna referente às aplicações de monitoração e sensoriamento.

Como pode ser visto na Figura 2.2, existem vários tipos de redes, classificadas de acordo com a distância de alcance de cada uma delas como segue:

\section{- PAN}

Esse tipo de rede geralmente tem alcance bem restrito, da ordem de alguns metros. 
- LAN

Esse tipo de rede já possui um alcance de algumas dezenas de metros.

- MAN (Metropolitan Area Network)

O alcance desse tipo de rede já é da ordem de dezenas de quilômetros.

- WAN (Wide Area Network)

A proposta deste tipo de rede é ter um alcance global, a exemplo do que acontece com a tecnologia GSM (Global System for Mobile Communications) .

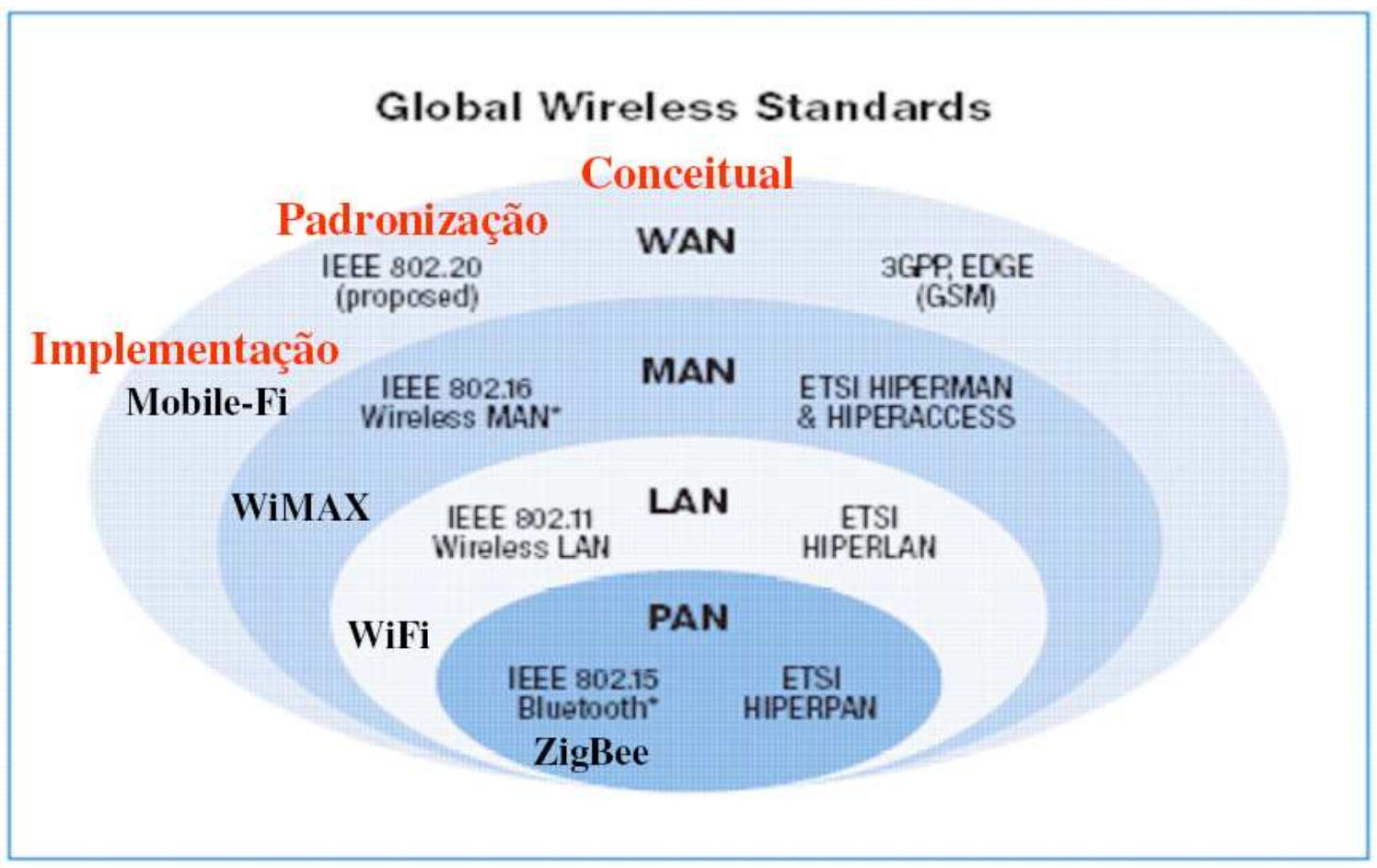

Figura 2.2: Comparação de redes "Wireless". Fonte: (BRANQUINHO; REGGIANI; ANDREOLLO, 2005)

O padrão ZigBee, juntamente com os padrões Bluetooth e Ultra Wide Band (UWB) pertencem ao mesmo tipo de rede, a PAN, que possui um alcance restrito, da ordem de até 10 metros para o UWB, de 10 metros para o Bluetooth e de 10 a 100 metros para o padrão ZigBee, conforme especificado na Figura 2.3. Também pode ser visto nessa figura o alcance do Wi-Fi, que é de 100 metros para os padrões 802.11 b e 802.11 g e de 50 metros para o padrão 802.11a.

\footnotetext{
${ }^{1}$ Depende do rádio
} 


\begin{tabular}{|c|c|c|c|c|c|c|c|c|}
\hline Property & $\begin{array}{l}802.11 \\
\mathrm{Wi}-\mathrm{Fi}\end{array}$ & Bluetooth & ZigBee & UWB & UHF & $\begin{array}{l}\text { Wireless } \\
\text { USB }\end{array}$ & $\begin{array}{l}\text { IR } \\
\text { Wireless }\end{array}$ & $\begin{array}{l}\text { Near Field } \\
\text { Magnetic }\end{array}$ \\
\hline $\begin{array}{l}\text { Operating } \\
\text { frequency }\end{array}$ & $\begin{array}{l}802.11 \mathrm{big} \\
2.4 \mathrm{GHz} \\
802.11 \mathrm{a} \\
5 \mathrm{GHz}\end{array}$ & $2.4 \mathrm{GHz}$ & $\begin{array}{l}868 \mathrm{MHz} \text { (Europe) } \\
902-928 \mathrm{MHz} \\
\text { (The Americas) } \\
2.4 \mathrm{GHz} \\
\text { (Weridwide) }\end{array}$ & $3.1-10.6 \mathrm{GHz}$ & $\begin{array}{l}260-470 \mathrm{MHz} \\
902-928 \mathrm{MHz}\end{array}$ & $2.4 \mathrm{GHz}$ & $\begin{array}{l}\text { Infrared } 800 \text { - } \\
900 \mathrm{~nm}\end{array}$ & $\begin{array}{l}\text { Magnetic } \\
\text { Coupling }\end{array}$ \\
\hline Data rate & $\begin{array}{l}11 \text { Mbits/s } \\
54 \text { Mbits/s }\end{array}$ & 1Mbits/s & $\begin{array}{l}20 \text { kbits's } \\
40 \text { kbits/s } \\
250 \text { kbits's } \\
\end{array}$ & $\begin{array}{l}100-500 \\
\text { Mbits/5 }\end{array}$ & $10-100 \mathrm{kbits} / \mathrm{s}$ & $62.5 \mathrm{kbits} / \mathrm{s}$ & $\begin{array}{l}20-40 \mathrm{kbits} / \mathrm{s} \\
115 \mathrm{kbits} / \mathrm{s} \\
4 \& 16 \mathrm{Mbits} / \mathrm{s} \\
\end{array}$ & $\begin{array}{l}64.384 \\
\mathrm{kbits} / \mathrm{s}\end{array}$ \\
\hline Range & $\begin{array}{l}100 \text { meters } \\
50 \text { meters }\end{array}$ & 10 meters & $10-100$ meters & $<10$ meters & $\begin{array}{l}10 \text { meters } \\
10 \text { miles }\end{array}$ & 10 meters & $\begin{array}{l}1-9 \text { meters } \\
\text { Line-of-sight }\end{array}$ & $1-3$ meters \\
\hline Networking & $\begin{array}{l}\text { Point-to- } \\
\text { Imultipoint }\end{array}$ & $\begin{array}{l}\text { Ad hoc } \\
\text { piconets }\end{array}$ & $\begin{array}{l}\text { Ad hoc, stat. } \\
\text { peer-to-peer, mesh }\end{array}$ & Point-to-point & Point-to-point & Point-to-point & Point-to-point & Point-to-point \\
\hline Complexity & High & High & Low & Medium & Lowest & Low & Low & Low \\
\hline $\begin{array}{l}\text { Power } \\
\text { consumption }\end{array}$ & High & Medium & Very low & Low & Low & Low & Low & Low \\
\hline Applications & WL AN hotspots & $\begin{array}{l}\text { Wireless } \\
\text { headsets, } \\
\text { PC-PDA-laptop } \\
\text { connections. }\end{array}$ & $\begin{array}{l}\text { Industrial monitoring } \\
\text { and control. Home } \\
\text { automation and con- } \\
\text { trod. Sensor newworks. } \\
\text { Toys, games, medical, } \\
\text { automotive. }\end{array}$ & $\begin{array}{l}\text { Home } \\
\text { entertainment } \\
\text { networks. } \\
\text { Streaming } \\
\text { video. }\end{array}$ & $\begin{array}{l}\text { Coded remote } \\
\text { control. Remote } \\
\text { keyless entry. } \\
\text { garage doors. }\end{array}$ & $\begin{array}{l}\text { PC } \\
\text { peripherals }\end{array}$ & $\begin{array}{l}\text { Remote control. } \\
\text { PC-PDA-laptop } \\
\text { links. }\end{array}$ & $\begin{array}{l}\text { Wirdess } \\
\text { headsets. } \\
\text { Autanotive. }\end{array}$ \\
\hline
\end{tabular}

Figura 2.3: Tecnologias sem fio LAN/PAN. Fonte: (FRENZEL, 2004)

\begin{tabular}{|c|c|c|}
\hline Característica & ZigBee & Bluetooth \\
\hline \multicolumn{3}{|l|}{ Alcance } \\
\hline Projetado & 10 a 100 metros & 10 metros \\
\hline $\begin{array}{l}\text { Kits especiais ou } \\
\text { ambiente externo }\end{array}$ & até 400 metros & acima de 100 metros $^{1}$ \\
\hline Taxa de transmissão & 20 a $250 \mathrm{kbps}$ & $1 \mathrm{Mbps}$ \\
\hline \multicolumn{3}{|l|}{ Latência (típica) } \\
\hline Inserção de novo escravo & $30 \mathrm{~ms}$ & $20 \mathrm{~s}$ \\
\hline $\begin{array}{l}\text { Mudança de estado do escravo } \\
\text { de sleep para ativo }\end{array}$ & $15 \mathrm{~ms}$ & $3 \mathrm{~s}$ \\
\hline Acesso de canal Escravo ativo & $15 \mathrm{~ms}$ & $2 \mathrm{~ms}$ \\
\hline \multirow[t]{2}{*}{ Perfil de Alimentação } & Anos & Dias \\
\hline & $\begin{array}{l}\text { Requer Alimentação } \\
\text { do escravo otimizada }\end{array}$ & $\begin{array}{l}\text { Funcionalidades } \\
\text { adhoc maximizadas }\end{array}$ \\
\hline Segurança & $\begin{array}{l}128 \text { bit AES e definível na } \\
\text { camada de aplicação de usuário }\end{array}$ & 64 bit, 128 bit \\
\hline Freqüência de Operação & $\begin{array}{c}868 \mathrm{MHz}, 902-928 \mathrm{MHz} \\
\text { 2,4 GHz ISM }\end{array}$ & 2,4 GHz ISM \\
\hline Complexidade & Simples & Complexo \\
\hline Topologias de Rede & $\begin{array}{l}\text { Adhoc, estrela, } \\
\text { malha híbrida }\end{array}$ & Adhoc piconets \\
\hline Número de dispositivos por rede & 2 a 65.000 & 8 \\
\hline Escalabilidade/ Extendabilidade & muito alta/ sim & baixa/não \\
\hline Flexibilidade & Muito alta & $\begin{array}{c}\text { Média, } \\
\text { dependente do perfil }\end{array}$ \\
\hline Elasticidade e confiabilidade & Muito alta & Média \\
\hline
\end{tabular}

Tabela 2.1: Comparação de características desejáveis entre Bluetooth e ZigBee. Fonte: (BAKER, 2005) 
A Tabela 2.1 mostra uma comparação feita por Baker (2005), entre os padrões ZigBee e Bluetooth, das características desejáveis em uma rede wireless, onde AES significa Advanced Encryption Standard e elasticidade seria o equivalente à mobilidade. A freqüência de operação industrial, científica e médica (ISM) é uma freqüência livre.

Sakuragui (2006) diz que:

Redes ad hoc são redes desprovidas de infra-estrutura ou organização central, compostas por dispositivos móveis sem fio que, dada sua mobilidade e liberdade, podem entrar ou sair da rede de modo aleatório.

Ainda na tabela 2.1 o termo Piconet refere-se a um tipo de rede ad hoc de dispositivos, que utiliza a tecnologia Bluetooth para permitir que o dispositivo mestre se conecte com até sete dispositivos escravos ativos.

De acordo com a Tabela 2.1 o ZigBee apresenta as seguintes diferenças mais marcantes em relação ao Bluetooth: tempo de inserção de um novo escravo na rede bem menor, uma complexidade bem menor e um número de dispositivos por rede bem mais elevado, entre outras.

No que se refere à alimentação é desejável, para o tipo de aplicação que o ZigBee engloba, que ela tenha uma longa duração.

O problema de eficiência energética em um ambiente wireless foi abordado em Nuggehalli, Srinivasan e Rao (2006), onde se considerou um transmissor wireless como sendo limitado por seu recurso de bateria finito. O objetivo deste artigo foi desenvolver um esquema de transmissão que maximizasse a vida útil da bateria sujeitando os delays a algumas restrições. Para tal foram exploradas duas idéias não conexas:

1. a codificação do canal pode ser usada para conservar energia, transmitindo em níveis de potência reduzidos, através de intervalos de tempo maiores;

2. uso de mecanismos eletro-químicos nas baterias, permitindo que elas recuperem energia durante os períodos de inatividade. 
Foi atingido um ganho de até $50 \%$ com a primeira estratégia e até $90 \%$ no segundo caso.

\subsection{Wi-Fi}

Em Lansford, Stephens e Nevo (2001) é apresentada uma introdução sobre a coexistência entre Bluetooth e Wi-Fi (dado que os dois operam na mesma banda de frequiência de 2,4GHz), com uma atenção especial para cenários que requerem uma operação simultânea. O artigo contém também uma explicação básica sobre os mecanismos de interferência e quantifica seu impacto através de medidas atuais e simulações. O resultado chave desse trabalho é que enquanto a performance dos dois sistemas pode degradar quando eles são co-alocados, um número de técnicas pode ser empregado para eliminar virtualmente os problemas, tais como buscar uma banda de freqüência alternativa $(5 \mathrm{GHz})$, ou promover alterações nas camadas de controle de acesso ao meio (MAC) ou física (PHY).

Em Jindal, Jindal e Gupta (2005) o termo WI FI é encontrado com o significado de wireless fidelity (fidelidade sem fio) e geralmente se refere a qualquer tipo de rede que usa o padrão 802.11 , entre eles o 802.11 b, o 802.11a e o 802.11 g. WI-FI é uma tecnologia sem fio que usa freqüências de radio para transmitir dados.

Em Ferro e Potortì (2005) é feita uma comparação entre os padrões Wi-Fi e Bluetooh. Segundo o artigo, o objetivo do padrão IEEE 802.11 é fornecer a conectividade sem fio aos dispositivos que requerem uma instalação rápida, tal como computadores portáteis, PDAs (Personal Digital Assistant), ou dispositivos geralmente móveis dentro de uma rede de área local sem fio (WLAN). A comparação foi feita em termos de capacidade, topologias de rede, segurança, suporte a qualidade de serviço (QoS) e consumo de potência. Algumas das características, como tipos de conexão de dados, performance, topologias, e MAC, estão estáveis e bem definidas pelos padrões. Outras, como consumo de potência, QoS, e segurança, são desafios ainda em aberto, onde a tecnologia está melhorando continuamente. 
Os três tipos de rede citados acima $(802.11 \mathrm{~b}, 802.11 \mathrm{a}$ e $802.11 \mathrm{~g})$ apresentam as seguintes características:

- $802.11 b$

- É o tipo de rede de maior alcance, bem suportado, estável e de melhor relação custo benefício. Opera na banda de $2.4 \mathrm{GHz}$, o que o deixa mais propenso a sofrer interferência de outros dispositivos (fornos de microondas, telefones sem fio, etc) e também possui desvantagens de segurança;

- O número de pontos de acesso se limita a três;

- Composto de 11 canais, com 3 não sobrepostos, e possui taxas de 1 a $11 \mathrm{Mbps}$;

- Usa a tecnologia DSSS² (PETERSON; ZIEMER; BORTH, 1995).

- $802.11 \mathrm{~g}$

- É uma extensão do 802.11b, com as mesmas desvantagens (segurança e interferência);

- Possui um alcance menor que o do 802.11b;

- É compatível com o 802.11b, permitindo uma transição suave do $11 \mathrm{~b}$ para o $11 \mathrm{~g}$;

- É flexível, pois vários canais podem ser combinados para uma rápida transferência, mas limitado a apenas um ponto de acesso;

- Suporta taxas de 54Mbps;

- Usa a tecnologia de multiplexação por divisão de frequiência (FDM) (PROAKIS, 2001).

- $802.11 \mathrm{a}$

- É completamente diferente do $11 \mathrm{~b}$ e do $11 \mathrm{~g}$;

- É flexível porque vários canais podem ser combinados para uma rápida transferência e mais de um canal pode ser utilizado;

\footnotetext{
${ }^{2}$ Direct Sequence Spread Spectrum
} 
- O alcance é menor que o do $11 \mathrm{~b}$ e do $11 \mathrm{~g}$;

- Opera na banda de 5GHz, sofrendo uma menor interferência de outros dispositivos;

- Possui 12 canais, sendo 8 não sobrepostos, e suporta taxas de 6 a 54 Mbps;

- Usa a tecnologia de multiplexação por divisão de freqüência.

Em Ferrari et al. (2006) é apresentada a implementação de uma rede de sensores utilizando o 802.11. Uma rede mestre-escravo foi proposta, para permitir que vários sensores pudessem se conectar com dispositivos Wi-Fi genéricos, como PCs. Foram desenvolvidos para este estudo um protocolo de comunicação sobre $\mathrm{IP}^{3}$ e alguns protótipos de baixo custo para testar a performance do comportamento na rede quanto às características de tempo de latência e à potência dissipada. Os resultados para as características de tempo foram satisfatórios, mas o consumo de potência mostrou-se especialmente alto, tornando-se uma grande desvantagem na rede de sensores utilizando o 802.11.

\subsection{Bluetooth}

O nome Bluetooth tem sua origem no nome do rei Harald Bluetooth Gormson (911986), conhecido como Harald I of Denmark, que foi um rei do século 10 que se ocupou com a diplomacia, facilitando a negociação entre diferentes grupos.

"Bluetooth" agora mais comumente, refere-se à especificação sem fio Bluetooth, projetada para permitir conexões livres de cabos entre computadores, telefones móveis, PDAs, impressoras e outros equipamentos eletrônicos. O logo de Bluetooth consiste das runas nórdicas para suas iniciais, H e B (WIKIPEDIA, 2006a).

Um transceptor Bluetooth é um dispositivo FHSS ${ }^{4}$ (PETERSON; ZIEMER; BORTH, 1995) que usa a freqüência ISM não licenciada de 2,4 GHz. Na maioria dos países existem 79 canais disponíveis, mas alguns países permitem o uso de apenas 23. A largura de banda nominal para cada canal é de $1 \mathrm{MHz}$.

\footnotetext{
${ }^{3}$ Internet Protocol

${ }^{4}$ Frequency Hopping Spread Spectrum
} 
Segundo Haartsen (1998), Bluetooth é uma interface de rádio que permite que dispositivos eletrônicos portáteis possam se conectar e se comunicar sem fio, com um alcance limitado em redes ad hoc. Cada unidade pode comunicar simultaneamente com até sete outras unidades por piconet. Além disso, cada unidade pode simultaneamente pertencer a várias piconets.

McDermott-Wells (2004-2005) explica o conceito de piconet, ja mencionado na seção 2.2. A especificação do Bluetooth define uma piconet como sendo um agrupamento espontâneo e específico de dispositivos Bluetooth, ou seja, os dispositivos se conectam automaticamente, criando uma rede sem a necessidade do usuário criá-la. Nessa rede, um dispositivo assume o papel de mestre, enquanto que os outros dispositivos são escravos, podendo haver um número máximo de sete escravos ativos na piconet.

Salonidis et al. (2001) apresenta uma maneira de construir topologias distribuídas para redes PANs do tipo Bluetooth, através de um protocolo de construção de topologias Bluetooth. É um protocolo distribuído assíncrono para a construção de scatternets que começam com nós que não possuem conhecimento da sua vizinhança e termina com a formação de uma rede conectada satisfazendo todas as restrições de conectividade propostas pela tecnologia Bluetooth.

Segundo Zheng e Feng (2002), a tecnologia Bluetooth é bastante complexa por ser principalmente baseada no padrão 802.11 e por utilizar o modo ad-hoc. Isto significa que cada estação deve observar e dar a todas as outras unidades um acesso equivalente à mídia sem fios. Além disso, Bluetooth é uma tecnologia complexa que incorpora tanto hardware quanto software. Embora dispositivos Bluetooth prometem ser simples e transparentes aos usuários, eles são completamente complexos e caros para seus programadores. Para criar uma aplicação Bluetooth completa, programadores precisam desenvolver ou adquirir tanto o hardware quanto o software. O artigo conclui que o padrão Bluetooth deveria ser simplificado para poder tornar o desenvolvimento de uma interface Bluetooth mais simples e de menor custo. 
Cordeiro et al. (2003a) apresenta um método para fornecer acesso global a WPANs Bluetooth utilizando WLANs 802.11. Para isso, faz uso de uma nova arquitetura Bluetooth, denominada BLUESTAR, segundo a qual são selecionados dispositivos Bluetooth, chamados Bluetooth Wireless Gateways (BWGs), que também possuem o padrão IEEE 802.11. Assim esses BWGs servem de pontos de conexão entre as redes sem fio do padrão 802.11 (Wi-Fi) e Bluetooth.

Cordeiro, Agrawall e Sadok (2003b) fez um estudo sobre a modelagem da interferência e a performance do protocolo MAC Bluetooth. Utilizando várias piconets numa mesma vizinhança trabalhando na mesma banda de freqüência, empregou um modelo de captura de sinais para estudar a performance da camada MAC da piconet. Os resultados obtidos indicam que o rendimento do Bluetooth é afetado pela interferência de várias piconets.

Um dos problemas do Bluetooth é que opera na mesma banda de frequiência do microondas. Surgiu então o receio de interferência do forno de microondas sobre redes Bluetooth. Para esclarecer essa questão, Rondeau, D’Souza e Sweeney (2004) fez um estudo com o intuito de caracterizar o comportamento do forno de microondas e entender seus efeitos sobre as redes Bluetooth. Os resultados obtidos foram os seguintes: com dois dispositivos Bluetooth em uma mesma piconet, a um metro de distância do forno de microondas, os dados da rede obtiveram um rendimento de 50\% devido à interferência. Já a mesma piconet a 10 metros de distância do forno não apresentou nenhuma perda devido à interferência no sinal. Aproximando a piconet do forno, a interferência no sinal começa a ser percebida apenas a partir de 5 metros, mas mesmo a um metro de distância a rede manteve a conexão e apresentou um rendimento aproveitável.

Em Chakrabarti et al. (2004) é apresentado um método de controle de dispositivos presentes em um ambiente, com Bluetooth habilitado remotamente, na casa ou escritório, e em qualquer parte do mundo conectado à internet. Para controlar os parâmetros dos dispositivos no ambiente remoto Bluetooth, foi utilizado um applet Java para poder ser acessado por qualquer navegador que estivesse conectado à internet e com Java habilitado. 
Em Marsan, Chiasserini e Nucci (2006) é apresentado um estudo sobre a determinação de uma topologia ótima para as redes PAN baseadas no protocolo Bluetooth. Os resultados mostraram que topologias otimizadas podem ser muito robustas a mudanças na forma do tráfego. Os resultados também podem ser usados para encontrar um ponto ótimo entre a complexidade do sistema e a eficiência da rede.

\subsection{ZigBee}

Segundo Norris (2005), ZigBee é um novo padrão para redes de telemetria sem fio, otimizadas para baixo consumo de potência e um longo período de operação da bateria. A pilha protocolar ZigBee tem suporte a rede auto organizável de dispositivos nas topologias árvore, malha e estrela, permitindo uma instalação rápida de um sistema de telemetria sem fio interno.

ZigBee é um padrão de comunicação wireless que provê uma rede de curto alcance e boa relação custo benefício. Foi desenvolvido com ênfase em aplicações de baixo custo alimentadas por bateria, tais como automação predial, controle industrial e comercial, marinha sem fio, assistência médica pessoal e sistemas de tag avançados.

Com um décimo dos requisitos de memória do Bluetooth e uma fração do poder de processamento necessário aos dispositivos de rede 802.11, ZigBee está sendo considerado como a melhor solução para sistemas de comunicação de baixa taxa de dados (20 a 250 kbps) e curto alcance (10 a 100 metros) (STREETON; STANFIELD, 2005).

Segundo Streeton e Stanfield (2005), ZigBee também oferece:

- Baixo consumo de potência - otimizado para operação com baterias;

- Operação nas bandas não licenciadas de 2.4GHz, 868MHz e 915MHz;

- Protocolo simples - pode ser implementado em microcontroladores de baixo custo;

- Centenas de dispositivos por rede;

- Flexibilidade de rede - configurações Estrela, Árvore ou Malha; 
- Taxa de dados de até 250kbps;

- Tamanho do hardware reduzido.

Em Aakvaag, Mathiesen e Thonet (2005) são apresentados os resultados de um experimento feito com uma rede ZigBee, em uma instalação de automação industrial em uma companhia de mineração sueca, com o intuito de demonstrar que o novo padrão ZigBee se comporta bem mesmo em ambientes industriais pesados. Umas das principais observações feitas foi que a rede de sensores wireless aparentava estar funcionando satisfatoriamente, mesmo além da máxima distância especificada no padrão ZigBee $(30 \mathrm{~m})$. O ambiente industrial hostil a rádio aparentemente não estava prejudicando a performance a um grau perceptível. Um modelo de sincronização de tempo simples mostrou ser suficiente para o ciclo ativo da rede. Isto permitiu um melhor gerenciamento de energia ao custo da redução do rendimento de toda a rede.

Norris (2005) descreve um sistema de telemetria interno experimental, capaz de monitorar tags móveis e prover uma assistência local comum. A pilha ZigBee possui suporte à redes de dispositivos auto-organizáveis em todas suas topologias, permitindo uma instalação rápida de um sistema de telemetria interno. O sistema é baseado em uma rede ZigBee semiestática contendo uma mistura de nós wireless estáticos e móveis. A rede estática é utilizada para monitorar os nós móveis, que podem ser associados a pacientes em hospital ou equipamentos de alto valor em um sistema prático. As características de auto organização e auto recuperação presentes na pilha ZigBee são aproveitadas para traçar as posições dos tags móveis e reorganizar as rotas de dados conforme os tags vão se movendo pelo prédio.

Zhao e Cui (2005) utilizou sensores ZigBee em conjunto com GPRS ${ }^{5}$, com o intuito de realizar medidas de sinais vitais de pacientes e enviar esses sinais a um centro médico onde os dados seriam analisados. A concentração de oxigênio no sangue foi medida através de um nó desenvolvido e o resultado foi transmitido sem fios até uma estação base, onde a curva em função do tempo foi plotada em uma tela $\mathrm{LCD}^{6}$. O padrão mostrou-se eficiente para esse tipo de aplicação.

\footnotetext{
${ }^{5}$ General Packet Radio Service

${ }^{6}$ Liquid Crystal Display
} 


\subsection{Considerações Finais}

Este capítulo descreve alguns trabalhos relacionados aos padrões Bluetooth e ZigBee para redes sem fio do tipo PAN, e também trabalhos relacionados ao padrão Wi-Fi para redes do tipo LAN.

Poucos trabalhos foram encontrados sobre a utilização do padrão Wi-Fi no sensoriamento, dado que esse padrão não foi criado com esta finalidade. Nesses trabalhos, fica claro que o consumo de potência inviabilizaria a utilização deste padrão com a finalidade de sensoriamento.

O padrão Bluetooth mostrou ser complexo e de alto custo de implementação, além de sofrer interferências até mesmo de outras redes Bluetooth colocadas num mesmo ambiente.

Os trabalhos relacionados, ao padrão ZigBee, apesar de serem poucos por esse ser um padrão recente, confirmaram que o ZigBee se comporta bem mesmo para ambientes industriais pesados. O tamanho reduzido do hardware, a flexibilidade da rede e a elevada autonomia de bateria foram fatores amplamente citados nos trabalhos como pontos positivos do padrão ZigBee. 


\section{A NORMA 802.15.4 E O PADRÃO ZIGBEE}

\subsection{Considerações Iniciais}

Neste capítulo é realizada uma revisão aprofundada dos padrões ZigBee e 802.15.4 (IEEE-STANDARDS, 2003).

\subsection{O Padrão ZigBee}

\subsubsection{Topologias de Rede}

Segundo Streeton e Stanfield (2005), a especificação do ZigBee permite que três topologias de rede diferentes possam ser implementadas (Figura 3.1), dependendo da aplicação. São elas: Star (Estrela), Cluster tree (Árvore) e Mesh (Malha). Estas topologias são discutidas a seguir.

- Estrela

Na configuração Estrela um dispositivo atua como o coordenador da PAN, o qual se encarrega de toda a comunicação em um dado canal de rádio. O coordenador da PAN deve ser capaz de se comunicar com qualquer outro dispositivo na rede. Essa funcionalidade é existente em um dispositivo de funções completas (FFD) e é implementada usando uma pilha de software de aproximadamente 30 Kbytes. Um coordenador de PAN deve estar no modo de recepção quando ele não estiver transmitindo. Esta unidade provavelmente irá consumir muita potência para permitir operação com bateria, e provavelmente deverá ter uma fonte principal de alimentação. Um dispositivo de funções reduzidas (RFD) pode 
ser implementado utilizando um microcontrolador de baixo custo e pequena quantidade de memória. O RFD pode apenas se comunicar com um FFD. Ele deverá receber ou transmitir por um curto período de tempo para se tornar adequado para operação com bateria.

- Árvore

A topologia Árvore é formada apenas modificando a topologia Estrela. Um ou mais dos RFDs conectados ao coordenador da PAN é substituído por um FFD, e destes FFDs, mais RFDs ou FFDs podem ser conectados. Uma vantagem desta topologia é que ela pode ser usada para aumentar a cobertura geográfica da rede.

- Malha

A terceira topologia suportada pelo ZigBee é a Malha. Nessa configuração existe muita conectividade de uma das FFDs, que está atuando como o coordenador da PAN, com todas as outras FFDs participantes da rede. As RFDs também podem participar da rede, mas estarão conectadas apenas ao seu FFD pai, e não participam no roteamento. A principal vantagem da topologia malha é a confiança e rendimento da rede provido através do amplo número de caminhos.

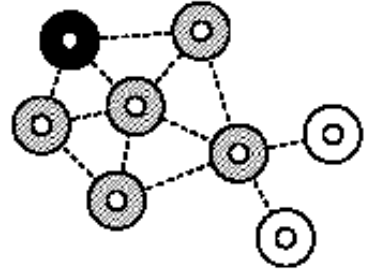

MALHA

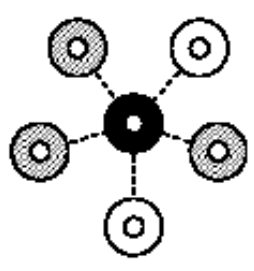

ESTRELA

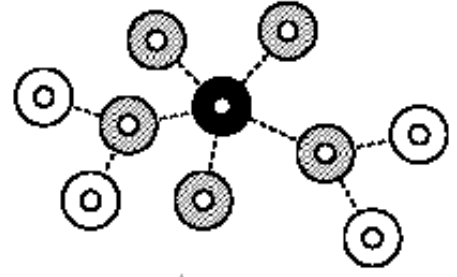

ARVORE

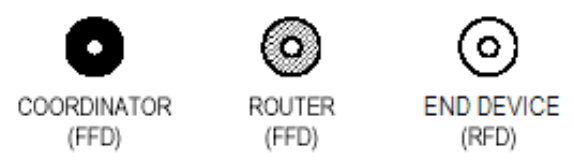

Figura 3.1: Topologias de Rede. Fonte: (MALAFAYA; TOMÁS; SOUSA, 2005) 
Os nós podem ser de três tipos distintos:

\section{Coordenador}

O nó do tipo coordenador é o maior entre os três, e é o que possui uma maior complexidade, dado que ele é o responsável por indicar a ligação entre os nós através da Binding Table, que será abordada na seção 3.2.7. Este nó é do tipo FFD.

2. Roteador

Este tipo de nó tem uma função muito importante, a de ampliar o alcance entre determinados End Devices, fazendo com que os mesmos possam se encontrar a uma distância maior que a permitida entre dois nós. Este nó também é do tipo FFD.

\section{End Device}

Os End Devices são os nós que apenas possuem os End Points, que são os atuadores propriamente ditos, podendo-se citar como exemplo as lâmpadas, chaves, sensores de temperatura, umidade, movimento, dependendo de qual é a aplicação. Apenas este tipo de nó é RFD.

\subsubsection{Pilha Protocolar}

A pilha protocolar ZigBee é formada pelas camadas PHY e MAC, especificadas conforme o padrão 802.15.4 da IEEE, pela camada de rede (NWK) e pela camada de aplicação, que contém as sub camadas de suporte à aplicação (APS) e ZigBee Device Object (ZDO). Na estrutura também são adicionados os objetos de aplicação definidos pelo usuário. A estrutura completa é mostrada na Figura 3.2 (ONDREJ et al., 2006).

\subsubsection{Camada PHY}

A camada mais baixa da pilha protocolar, a camada física, é definida pelo padrão 802.15.4 da IEEE, e é implementada em silício. 


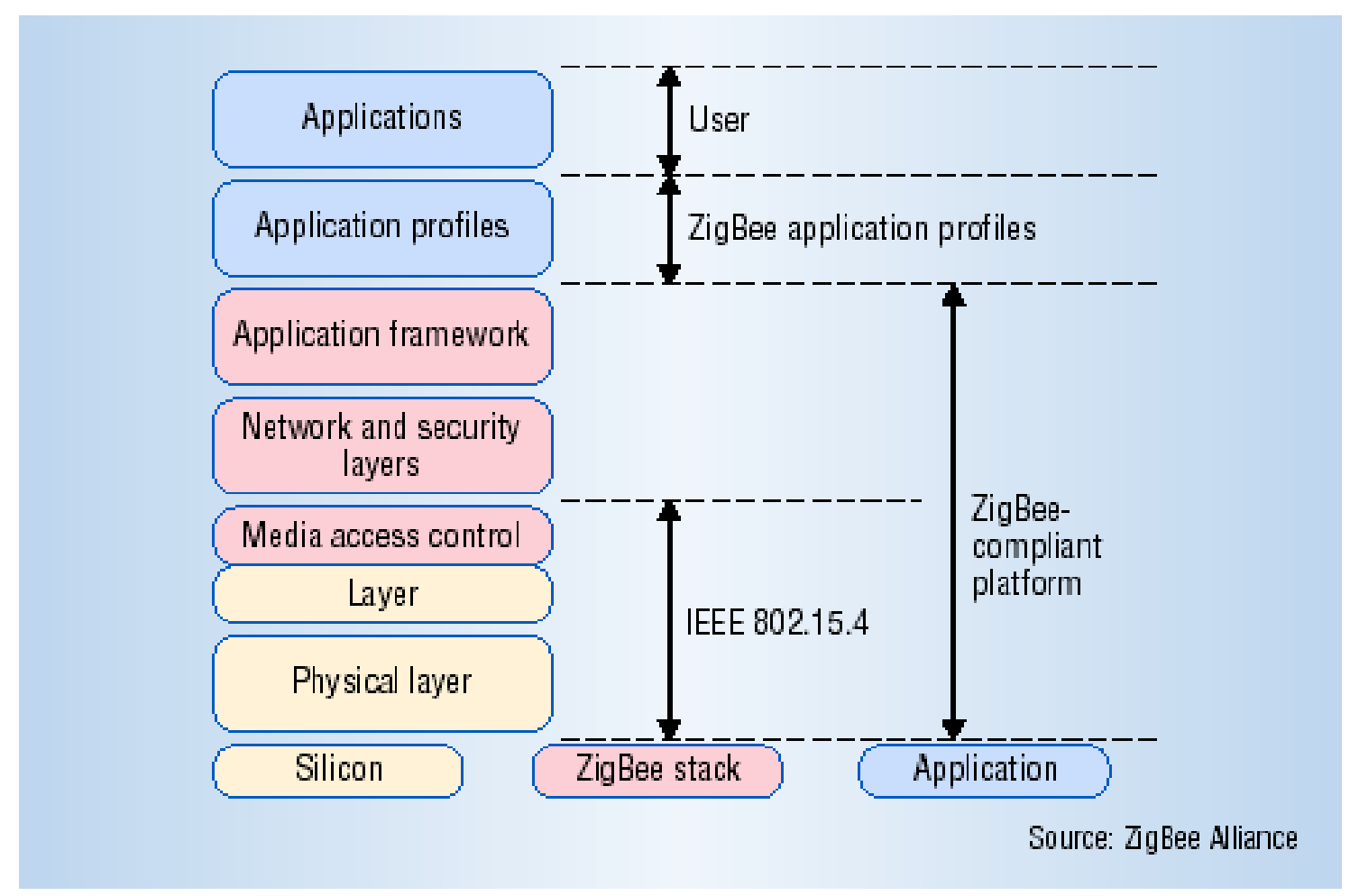

Figura 3.2: Modelo de camadas da pilha protocolar ZigBee.

A camada física codifica os bits que são enviados e decodifica os que são recebidos. Parte da informação disponível na camada física é fornecida para a camada MAC, como por exemplo, a estimativa de canal livre, a indicação da qualidade da conexão e a indicação da potência do sinal recebido.

Segundo Ding et al. (2005) a norma IEEE 802.15.4 define 27 canais na camada PHY distribuídos da seguinte forma:

- 16 canais com taxa de 250kbps na banda livre ISM 2,4 - 2,4835 GHz disponível globalmente;

- 10 canais com taxa de 40kbps na banda ISM 902 - 928 MHz, disponível na América do Norte

- 1 canal com taxa de 20kbps na banda 868,0 - 868,6 MHz, disponível na Europa.

Na Figura 3.3 pode-se ver a estrutura dos canais nas 3 bandas diferentes. 


\section{$868 / 915 \mathrm{MHz}$ PHY}

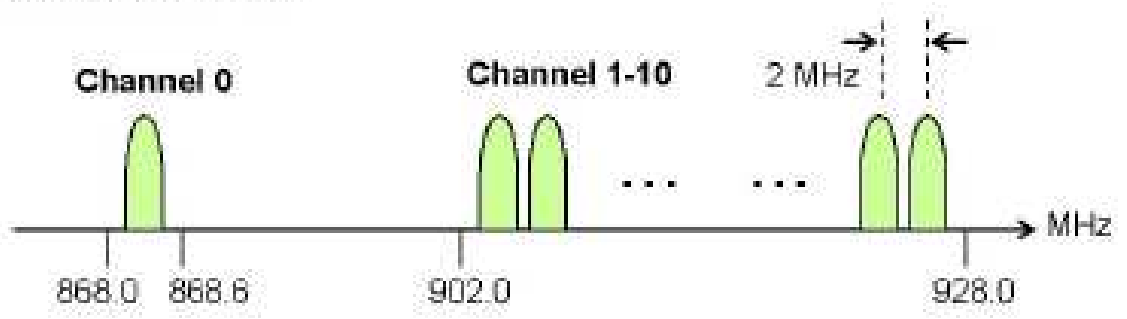

$2.4 \mathrm{GHz}$ PHY

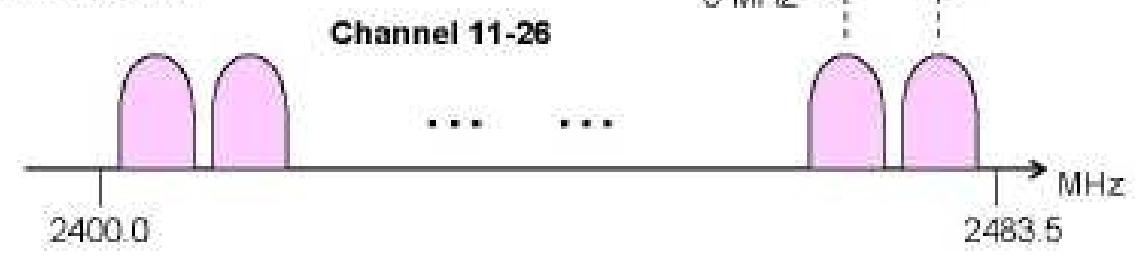

Figura 3.3: Estrutura de canais do IEEE 802.15.4. Fonte:(LEE, 2005)

A camada PHY fornece um parâmetro, o indicador de qualidade do link (LQI), que caracteriza a qualidade do sinal recebido. Pode ser a potência recebida, a relação sinal ruído (SNR) estimada, ou a combinação dos dois. O LQI é passado para a camada MAC e finalmente disponibilizado para as camadas superiores da rede. Outras características da camada PHY incluem a ativação e desativação do transceptor do rádio, seleção do canal e transmitir/receber os pacotes através do meio físico.

\subsubsection{Camada MAC}

A camada MAC controla o acesso ao canal de rádio compartilhado. Ela gera e reconhece os endereços, e verifica as sequiências das estruturas de controle (frame check).

A camada MAC também é responsável por sincronizar as transmissões dos frames no modo non-beacon ${ }^{1}$, usando o método CSMA-CA ${ }^{2}$, onde um nó verifica a ausência de tráfego antes de iniciar uma transmissão, com o intuito de diminuir a possibilidade de transmissões simultâneas. Depois que o canal é encontrado e determinado como livre, o nó inicia a transmissão. Quando o nó suspeita de uma colisão, ele imediatamente para de transmitir e espera um tempo aleatório antes de tentar novamente.

\footnotetext{
${ }^{1}$ Não sinalizado

${ }^{2}$ Carrier Sense Multiple Access with Collision Avoidance
} 
No modo beacon ${ }^{3}$ existe uma estrutura de superframe (Figura 3.4) opcional, empregada quando uma garantia de acesso ao canal é obrigatório. O superframe inicia com um beacon e é seguido por 16 intervalos de tempo iguais. Os primeiros nove intervalos (CAP) podem ser usados por qualquer dispositivo, e os sete intervalos seguintes (denotados como GTS) são reservados e podem ser alocados por um dispositivo através de um pedido.

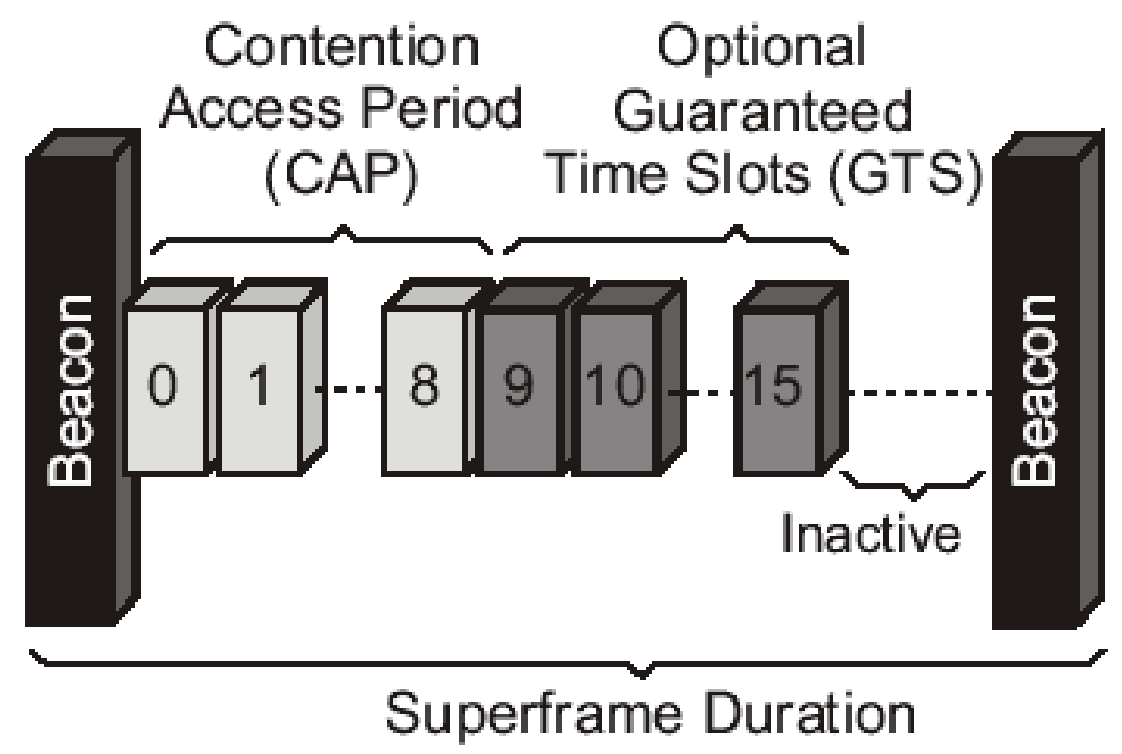

Figura 3.4: Estrutura Superframe, Fonte: (ONDREJ et al., 2006)

Na topologia árvore, os beacons nos nós filhos são atrasados, e a retransmissão dos beacons a partir dos nós filhos é feita com uma compensação no tempo de transmissão. Na topologia malha, os beacons não são suportados e não podem ser usados como meios de sincronização.

Segundo Lee (2005) o mecanismo para transferência de dados depende se a rede suporta ou não a transmissão de beacons. Uma rede com beacon habilitado é usada para dispositivos de baixa latência, tais como periféricos de PC. Se a rede não necessita estar preparada para este tipo de dispositivo, pode-se optar por não utilizar o beacon para transferências normais.

Há dois modos de transferência de dados:

- Transmissão de dados direta: Este tipo de transferência de dados é o mecanismo para transferir dados do dispositivo para o coordenador. Na rede com o beacon habilitado,

\footnotetext{
${ }^{3}$ Sinalizado
} 
quando um dispositivo deseja transferir dados ao coordenador, ele primeiro espera receber um beacon da rede, como mostrado na Figura 3.5 (a). Quando o beacon é recebido, o dispositivo sincroniza-se com a estrutura de superframe. Na hora apropriada, o dispositivo transmite seu frame de dados ao coordenador. O coordenador confirma a recepção do dado com sucesso, transmitindo um frame de confirmação. Por outro lado, em redes com beacon não habilitado, quando um dispositivo deseja transferir dados, ele simplesmente transmite seu frame de dados ao coordenador. O coordenador confirma a recepção do dado com sucesso, transmitindo um frame de confirmação, como mostrado na Figura 3.5 (b).

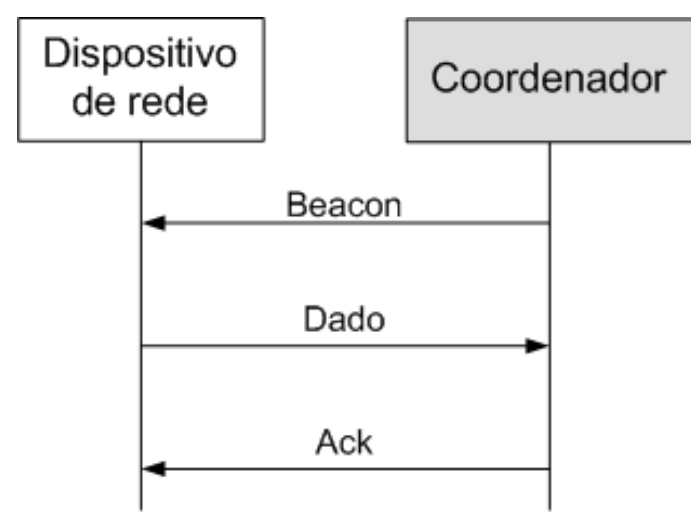

(a)

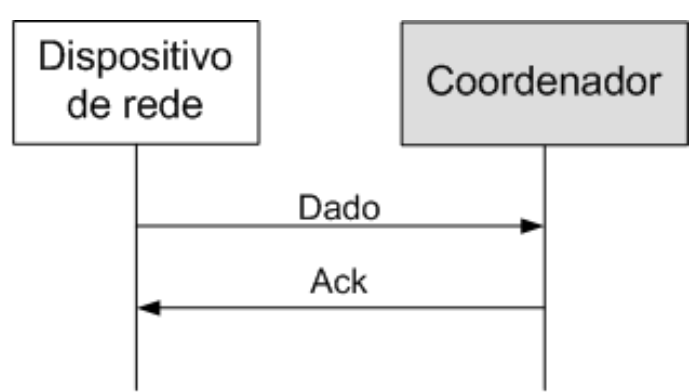

(b)

Figura 3.5: Transmissão direta em redes (a) beacon habilitado, e (b) beacon não habilitado. Fonte: (LEE, 2005)

- Transmissão de dados indireta: Este tipo de transferência de dados é o mecanismo para transferir dados do coordenador para o dispositivo. Em uma rede com o beacon habilitado, quando o coordenador deseja transferir dados para um dispositivo, ele indica no beacon da rede que existe uma mensagem pendente. O dispositivo periodicamente ouve o beacon da rede e, se houver mensagem pendente, transmite um comando MAC pedindo o dado. O coordenador confirma a recepção da requisição do dado com sucesso, transmitindo um frame de confirmação. O frame de dado pendente é então enviado. O dispositivo confirma a recepção do dado com sucesso, transmitindo um frame de confirmação. Assim que a confirmação é recebida, a mensagem é removida da lista de mensagens pendentes no beacon. Esta sequiência é mostrada na Figura 3.6 (a). Por outro lado, em uma rede com o beacon não habilitado, o dado é armazenado até que o dispositivo apropriado faça 
contato e requisite o dado. Um dispositivo pode fazer contato enviando um comando MAC, requisitando o dado ao coordenador, em uma taxa de pooling ${ }^{4}$ definida pela aplicação, como mostrado na Figura 3.6 (b). O coordenador confirma a recepção do frame de dados com sucesso, transmitindo um frame de confirmação. Se o dado está pendente, o coordenador transmite o frame de dados para o dispositivo. Se o dado não está pendente, o coordenador transmite um frame de dados com um cabeçalho de comprimento zero, para indicar que não existem dados pendentes. O dispositivo confirma o sucesso da recepção dos dados transmitindo um frame de confirmação.

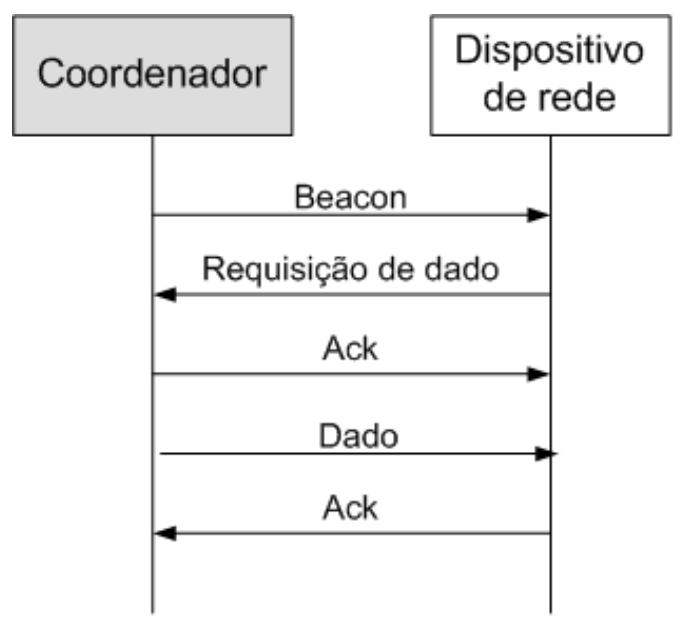

(a)

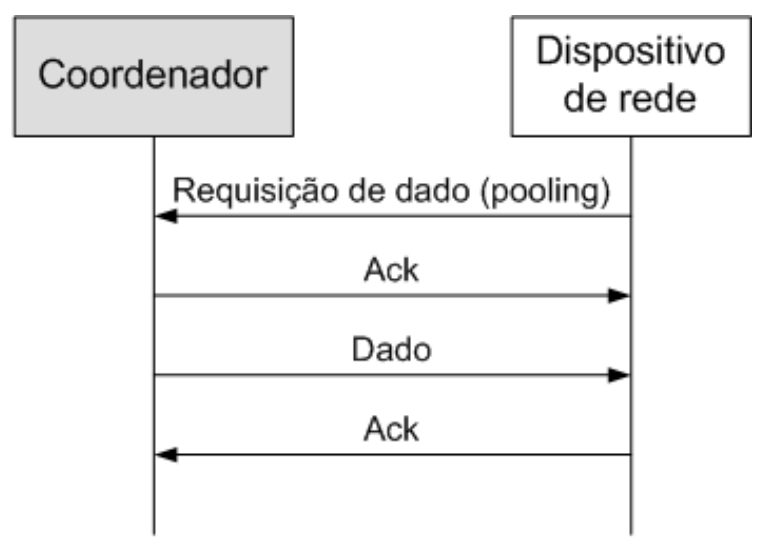

(b)

Figura 3.6: Transmissão indireta em redes (a) beacon habilitado, e (b) beacon não habilitado. Fonte: (LEE, 2005)

\subsubsection{Camada de Rede}

A camada de rede (NWK) cuida do nível de rede relativo à comunicação. Controla a estrutura de rede e cuida do roteamento e das funções de segurança das mensagens transmitidas. A rede ZigBee é uma rede dinâmica e a camada de rede precisa manter as informações sobre os nós dentro da rede. As propriedades e parâmetros da rede são especificados na aplicação como configurações de pilha da camada de rede. Isto inclui a topologia, segurança, etc.

\footnotetext{
${ }^{4}$ verificação
} 


\subsubsection{Camada de Aplicação}

A camada de aplicação carrega o código de cada aplicação feita individualmente. De acordo com a especificação ZigBee, este código é escrito dentro do objeto do dispositivo ZigBee (ZDO) e a função do dispositivo é especificada. Aqui é definido se o dispositivo será do tipo FFD ou RFD, as funções de segurança de rede, as resposta e atos para cada evento do sistema.

A sub camada de suporte à aplicação (APS) forma o nível baixo da camada de aplicação. Aqui é onde as ligações (binding) e a descoberta da vizinhança dos dispositivos são feitas. A APS também é responsável por encaminhar as mensagens através dos dispositivos que não estão habilitados para se comunicarem diretamente, e habilita a funcionalidade de modificar a rede para uma rede do tipo malha.

\subsubsection{Binding e Binding Table}

Existem dois tipos de mensagem, as do tipo $\mathrm{KVP}^{5}$, onde cada nó conhece o endereço do nó destino, e a do tipo $\mathrm{MSG}^{6}$, onde é necessário que seja feita e armazenada uma ligação entre dois End Points.

Na Figura 3.7, onde AF significa Application Framework, pode-se ver como é montada a mensagem ZigBee.

\footnotetext{
${ }^{5}$ Key-Value Pair

${ }^{6}$ Message Service Type
} 


\section{ZigBee Protocol Frame Overview}

AF Frame

(Spec 1.3.4)

APS Frame

(Spec 1.2.5)

NWK Frame

(Spec 2.4.1)

MAC Frame

(IEEE 7.2.1)

PHY Frame

(IEEE 6.3.1)

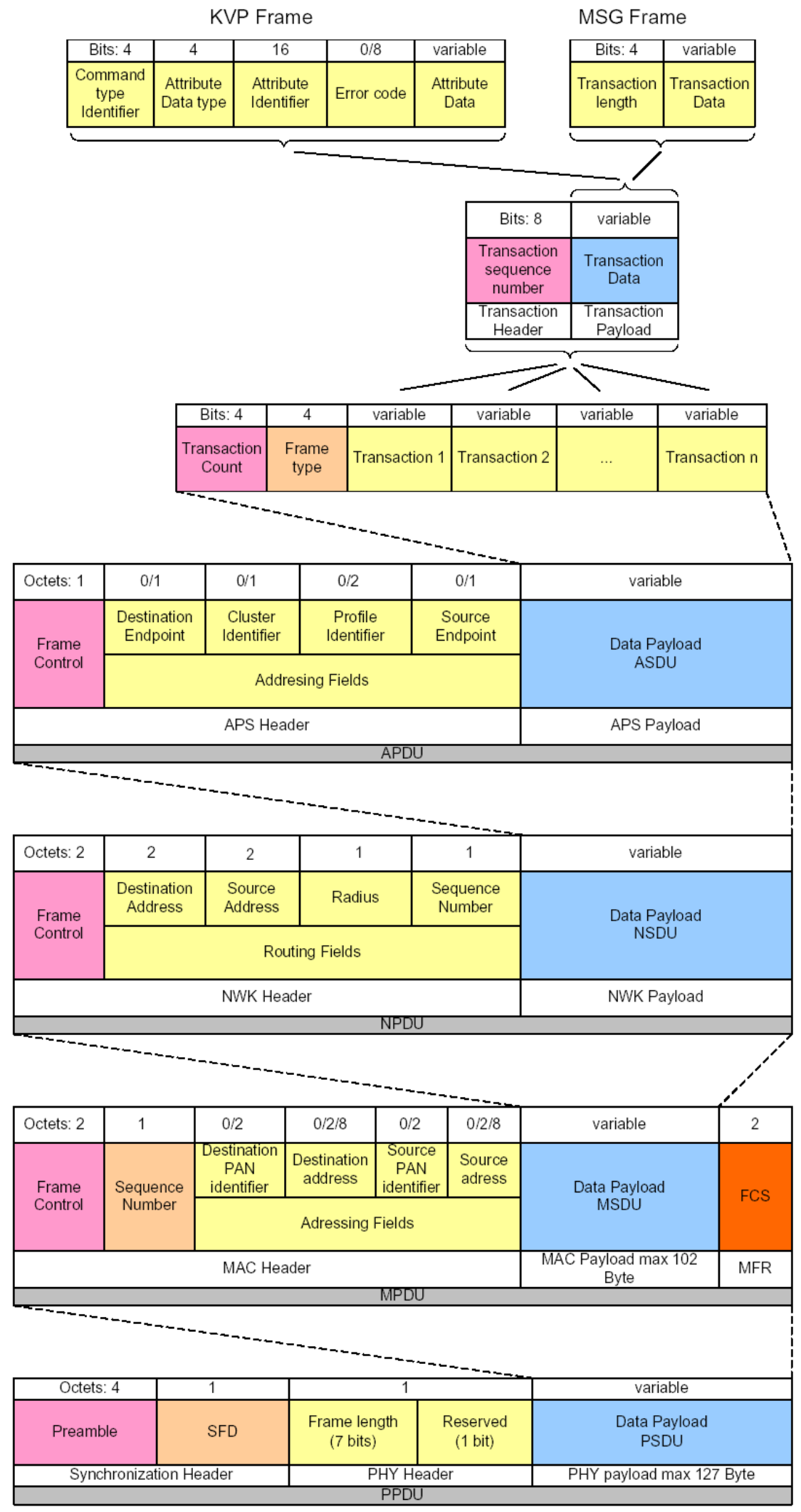

Source: ZigBee Spec. V1.0 and IEEE 802.15.4 - 2003 A. Pötsch 08 2006, University Linz Austria ICIE

Figura 3.7: Formato da mensagem ZigBee 
É importante lembrar que os End Points podem ser lâmpadas, sensores de movimento ou temperatura, entre outros. Um nó pode ter mais de um End Point, como pode ser visto na Figura 3.8 (ZIGBEE-ALLIANCE, 2005).

O nó Z1 possui duas chaves (switchs), que na rede são os End Points EP3 e EP21, enquanto que o nó Z2 possui 4 lâmpadas, EP5, EP7, EP8 e EP17.

A Binding Table é responsável por fazer a conexão entre os End Points. Ainda na Figura 3.8, nota-se que a chave 1 (EP3) está ligada às lâmpadas 1(EP5), 2(EP7) e 3(EP8), enquanto que a chave 2 (EP21) está ligada à lâmpada 4(EP17).

Existem também nós ZigBee que possuem chaves e lâmpadas, ou lâmpadas e sensores. Nem sempre o nó ZigBee possuirá apenas sensores ou atuadores, ele pode ser de várias formas diferentes, dependendo da aplicação em que ele estiver inserido.

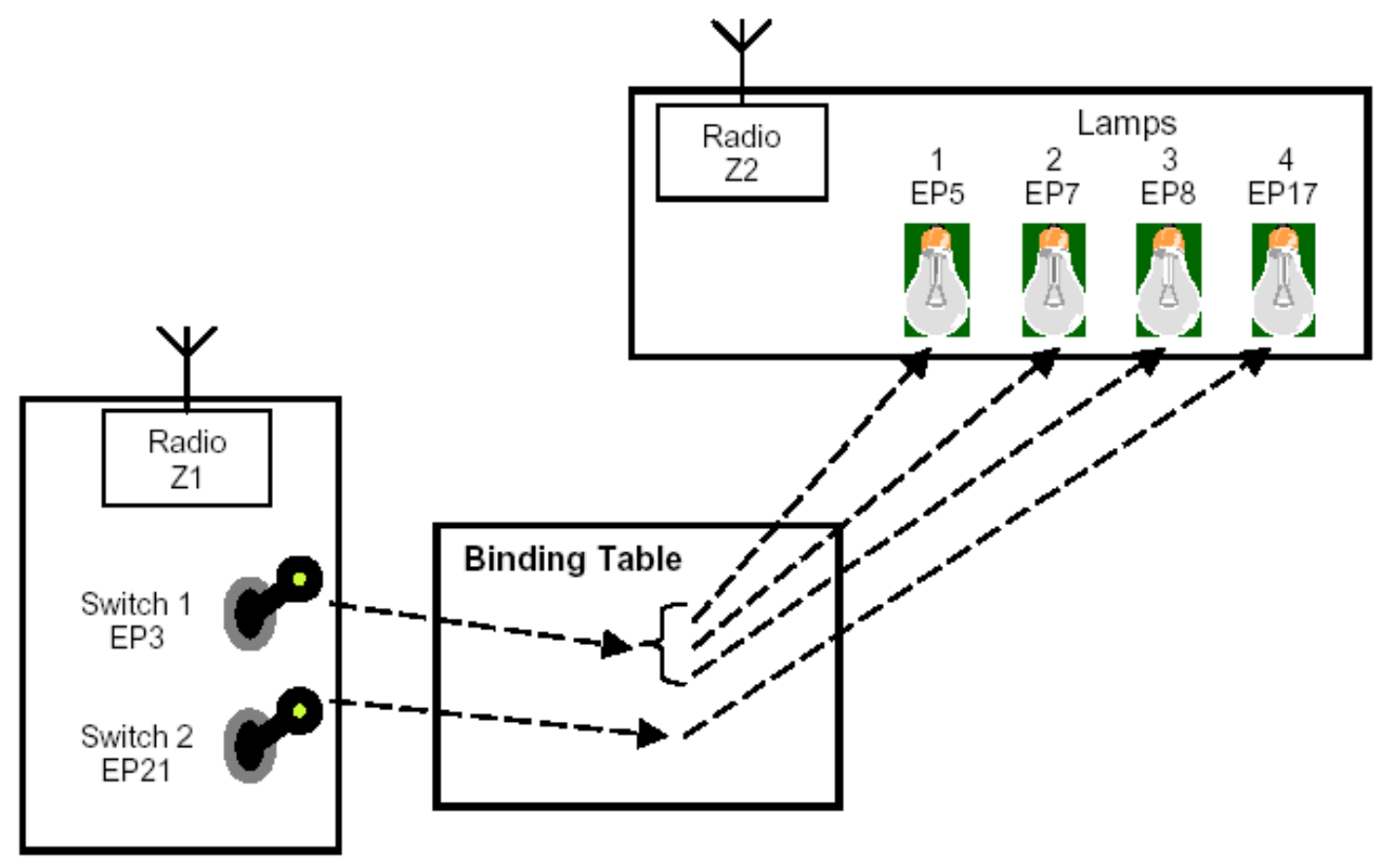

Figura 3.8: Binding e Tabela de Binding. Fonte: (ZIGBEE-ALLIANCE, 2005) 


\subsection{Considerações Finais}

As opções de configuração disponíveis em uma rede ZigBee é um de seus pontos fortes, o que a deixa à parte de alguns dos padrões competidores, cujos protocolos torna-os menos flexíveis. Dessa forma o ZigBee satisfaz a necessidade de muitas aplicações existentes e certamente de outras que surgirão, mas sempre haverá lugar para soluções mais customizadas em áreas mais específicas (STREETON; STANFIELD, 2005). 


\section{TRABALHO DESENVOLVIDO}

\subsection{Considerações Iniciais}

Nesse capítulo são apresentadas as funções implementadas no projeto de sensoriamento, a metodologia que foi adotada e uma breve descrição das ferramentas que foram utilizadas na criação e validação do software.

\subsection{Funções Implementadas}

No desenvolvimento do hardware e do software do projeto de sensoriamento foram implementadas as quatro funções seguintes:

1. Leitura de um sensor de movimento em um nó, enviando ao outro uma mensagem. Esse segundo nó aciona um sinalizador acústico, indicando que o sensor foi acionado;

2. Leitura de um sensor de temperatura em um nó e, dependendo do intervalo de temperatura selecionado, é enviada uma mensagem ao outro nó indicando se deve ligar ou desligar um aparelho de ar condicionado (LED);

3. Leitura de um sensor de luminosidade (LDR) e, dependendo do valor encontrado, enviar uma mensagem indicando se uma lâmpada no outro nó deve ser apagada, acesa a 40\%, acesa a $60 \%$ ou acesa a $100 \%$ de sua carga máxima;

4. No Hyperterminal é mostrado o valor medido da temperatura e o valor lido pelo sensor de luminosidade (LDR), comunicando-se com o PC via USB, através da placa de circuito impresso (PCI) extra desenvolvida. 
Os desafios do trabalho foram: desenvolver o software que faz o controle dos sensores e atuadores e implementar e validar o hardware referente a cada uma das quatro etapas de desenvolvimento citadas anteriormente.

Foram utilizados dois nós ZigBee. Um deles (Figura 4.1) possui interface USB para se comunicar com um PC, um sensor de luminosidade (LDR), um sinalizador acústico, que simula uma sirene e um sensor de temperatura, através do qual o nó decide a hora de ligar ou desligar o aparelho de ar condicionado.

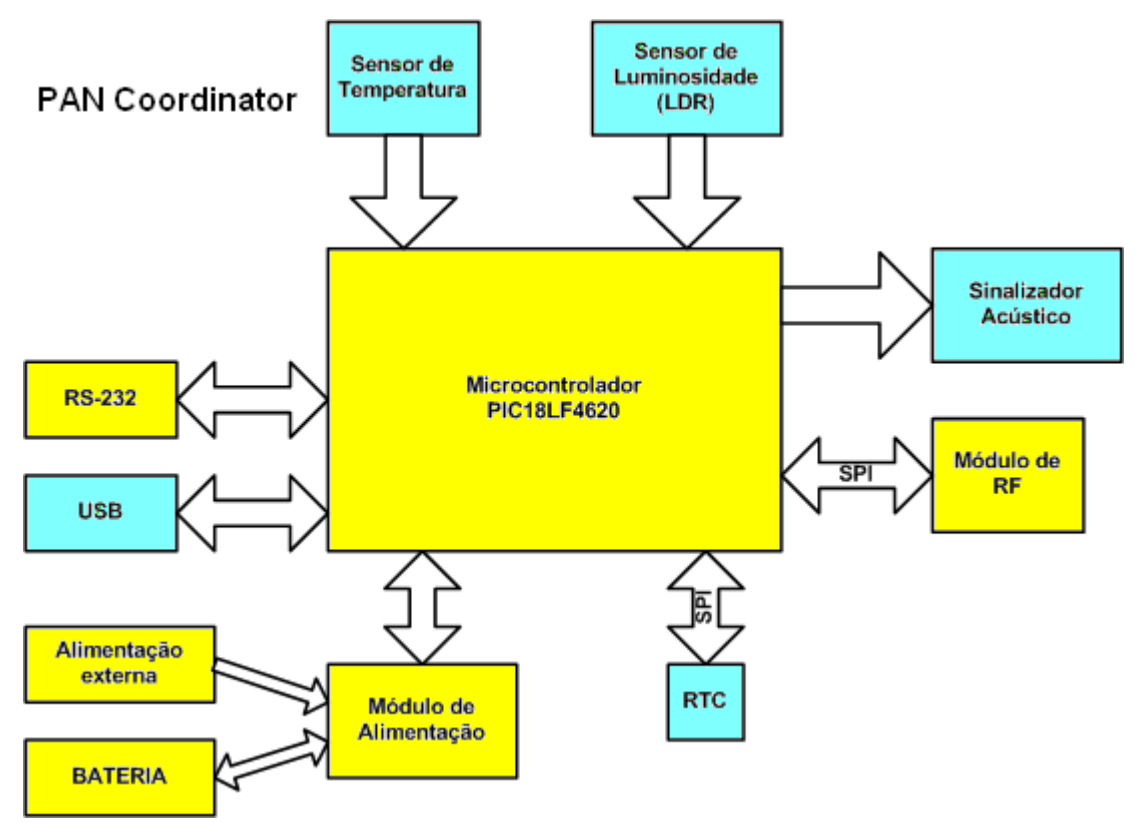

Figura 4.1: Diagrama de blocos do nó do tipo coordenador.

Um segundo nó ZigBee (Figura 4.2) possui uma lâmpada, que é acionada de acordo com o sinal obtido no LDR do primeiro nó, um LED, que simula um aparelho de ar condicionado, apenas para indicar que ele foi acionado ou não, e um sensor de movimento, que quando acionado faz com que o sinalizador acústico do outro nó dispare.

\subsection{Metodologia}

A primeira fase desse trabalho consistiu no estudo da pilha protocolar ZigBee, pelo fato deste ser um padrão de comunicação wireless recente e pouco estudado. 


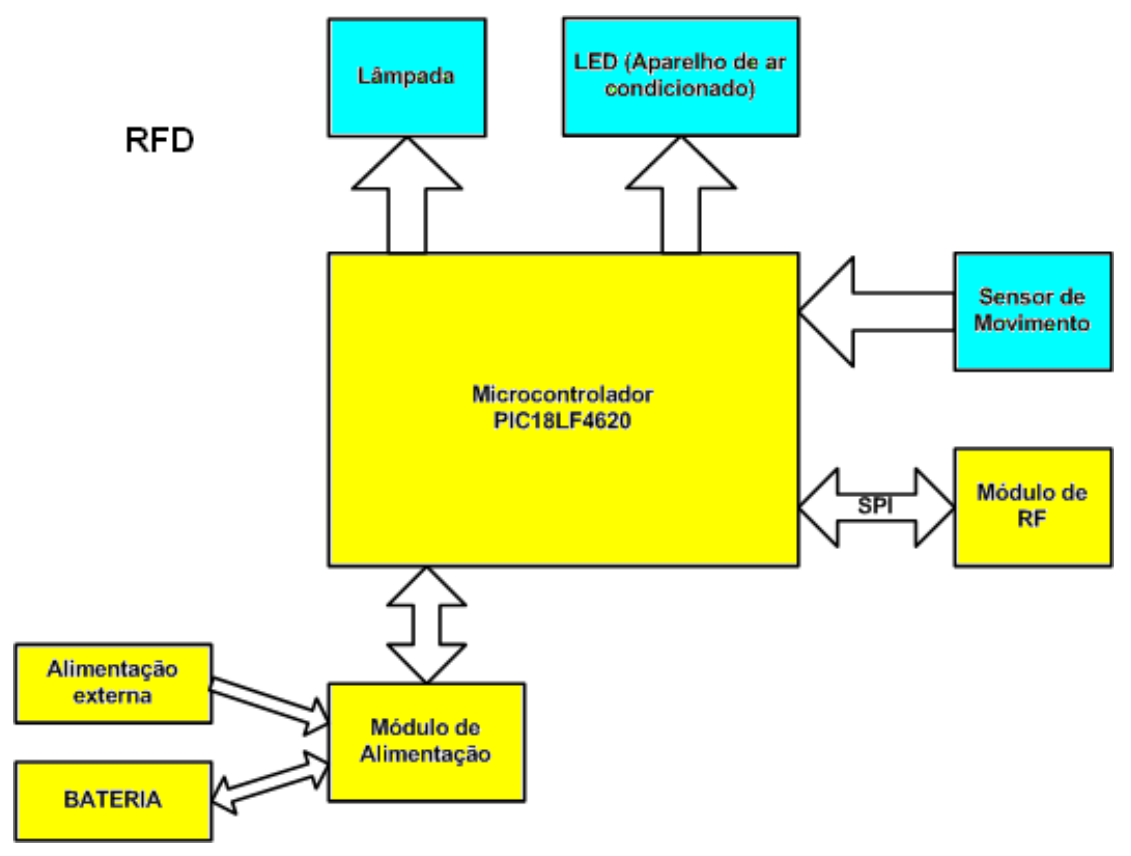

Figura 4.2: Diagrama de blocos do nó do tipo RFD.

A segunda fase deste trabalho constituiu na implementação e validação dos hardwares descritos no item 4.2 e na implementação e validação da parte de comunicação e do software implementado para realizar as funções descritas.

\subsubsection{Comunicação Entre os Nós}

Para a comunicação entre os nós foi desenvolvido um software, onde foram utilizadas funções desenvolvidas pela Microchip (2006a), que fazem parte da chamada ZigBee Stack, ou pilha ZigBee. Algumas da funções utilizadas são:

- HardwareInit()

Inicializa o hardware. Seleciona quais portas serão utilizadas como entrada ou saída, qual o estado de cada uma delas na inicialização, inicializa o barramento de comunicação SPI (Serial Peripheral Interface), entre outras coisas.

- ZigBeeInit()

Inicializa a pilha ZigBee. Inicializa as camadas MAC, NWK, APS e ZDO.

- ConsoleInit() 
Inicializa a UART (Universal Assynchronous Receiver Transmitter).

O formato de mensagem utilizado foi o KVP, onde cada nó sabe o endereço do outro, consequentemente não foi utilizada a tabela de ligações (binding table). Também não foi utilizado o beacon na comunicação.

\subsubsection{Implementação e Validação do Hardware}

Foi inserido em cada placa do kit de desenvolvimento, na área disponível para montagens, um hardware extra, que nas Figuras 4.1 e 4.2 é ilustrado como módulos adicionais conectados ao microcontrolador. Abaixo segue uma breve descrição do hardware que foi implementado e testado.

\section{- USB}

O chip utilizado nesse item foi o FT232BL. Optou-se por criar uma PCI separada para o hardware USB devido principalmente ao tamanho dos componentes.

- RTC (Real Time Clock)

O chip utilizado foi o DS1305. Este item possui duas implementações, o hardware e o software. O hardware foi montado e validado, mas o software não funcionou como era esperado em conjunto com a pilha ZigBee. A discussão é feita no item 5.3.8.

- Sensor de temperatura

Foi utilizado um sensor de temperatura digital acessado serialmente, que já estava presente no próprio kit de desenvolvimento da Microchip, o TC77.

- Sensor de movimento

Foi utilizado um sensor de movimento que detecta a variação de infravermelho, desenvolvido pela empresa ICCEA.

- Sensor de luminosidade (LDR)

Foi utilizado um LDR de 200k $\Omega$. 
- Sinalizador acústico

Foi escolhido um sinalizador acústico da marca HXD de 5V, mas que funcionou bem em $3 \mathrm{~V} 3$.

- LED (simulando um aparelho de ar condicionado)

- Lâmpada

O acionamento da lâmpada foi implementado com um triac. Para evitar algum dano a uma das placas do kit, optou-se por montar o circuito em um protoboard.

\subsection{Ferramentas de Desenvolvimento}

Foi utilizado para o desenvolvimento do projeto, um kit da Microchip, denominado PICDEM Z Demonstration Kit (MICROCHIP, 2006b), mostrado na Figura 4.3. Este kit é composto por duas PCIs PICDEM Z, onde cada uma delas contém:

- Um microcontrolador PIC18LF4620 com tecnologia nanoWatt, 64 KB de memória Flash e periféricos integrados;

- Transceptor de rádio freqüência (RF) e interface de antena em uma placa separada visando flexibilidade;

- Interface serial no padrão RS232;

- Regulador de tensão de 9V para 3.3V;

- Sensor de temperatura (Microchip TC77), LEDs e chaves de pulso para permitir demonstrações.

Foram adquiridas duas fontes de $9 \mathrm{~V}$ para serem utilizadas com as placas do kit PICDEMZ, pois devido ao alto consumo de corrente durante a gravação dos PICs, as baterias tiveram uma vida útil muito reduzida, da ordem de uma semana. 


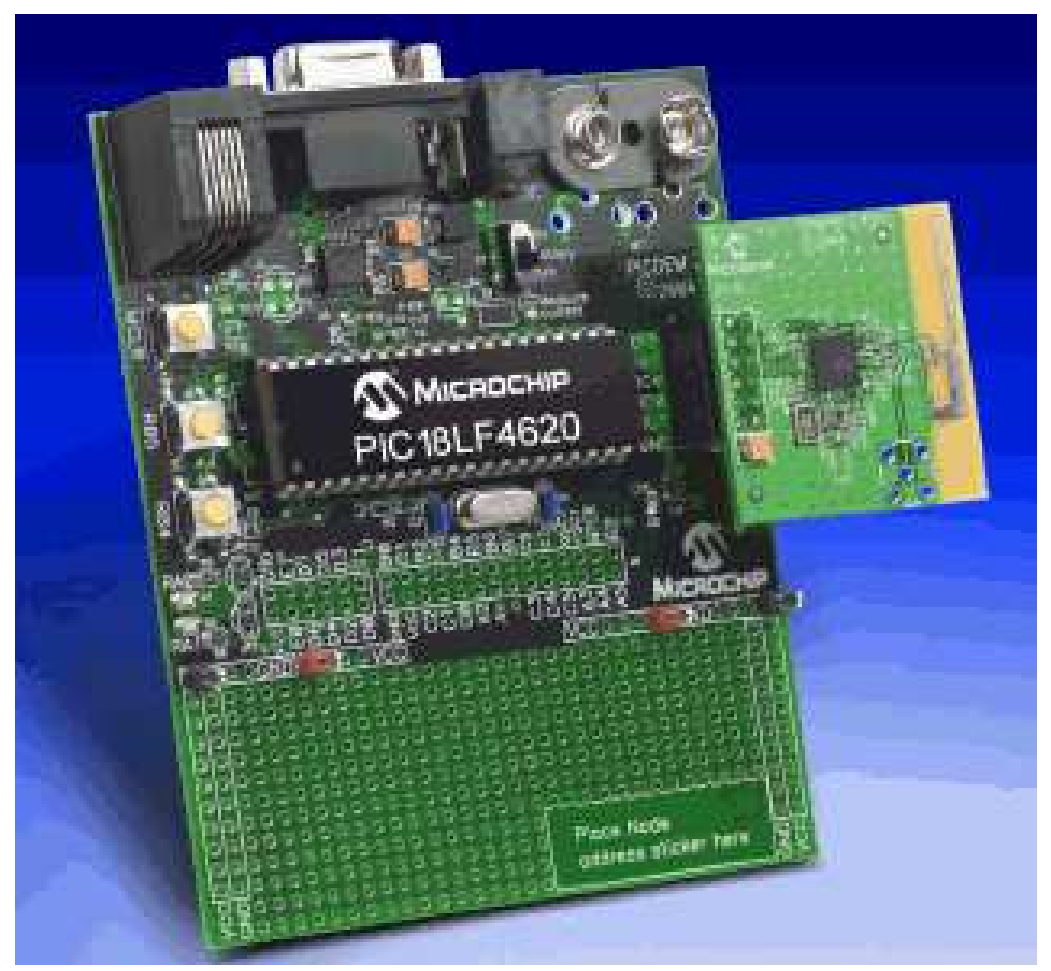

Figura 4.3: Placa PICDEM Z com placa de RF acoplada. Fonte: (MICROCHIP, 2006b)

Além do kit descrito acima, foi utilizado o ambiente de desenvolvimento integrado da própria Microchip, denominado MPLAB IDE (MICROCHIP, 2006c). Neste ambiente foi desenvolvido o software que foi gravado nas memórias internas aos microcontroladores dos kits de desenvolvimento (PIC18LF4620).

O software foi escrito em linguagem $\mathrm{C}$.

O compilador utilizado foi o C18 (MICROCHIP, 2006d), também da Microchip, específico para os microcontroladores PIC da família 18.

Para a gravação dos microcontroladores foi utilizado o gravador/depurador ICD2BR, comercializado pela LabTools (LABTOOLS, 2006).

\subsection{Considerações Finais}

Com as funções implementadas é possível simular sensores e atuadores utilizados em uma residência. A metodologia foi elaborada de forma a assegurar o funcionamento do hardware e do software. 


\section{DESCRIÇÃO, RESULTADOS E DISCUSSÕES}

\subsection{Considerações Iniciais}

Nesse capítulo é apresentada a descrição do projeto de sensoreamento, os resultados e as discussões.

Será feita uma descrição da lógica dos sensores e da USB, do hardware e do software implementados.

\subsection{Descrição da Lógica dos Sensores e da USB}

A Figura 5.1 dá uma visão melhor de qual sensor é responsável por qual atuador, onde as setas indicam a direção de propagação da informação.

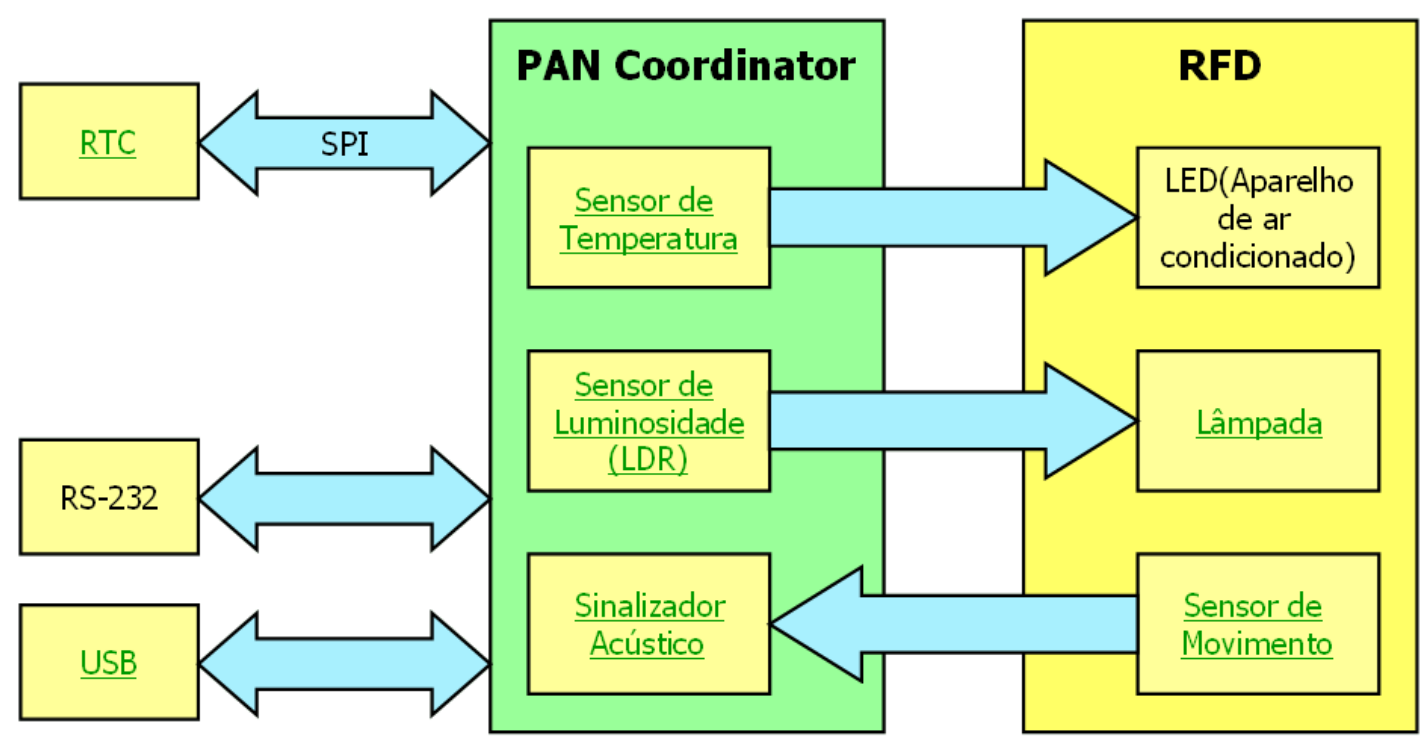

Figura 5.1: Trabalho Desenvolvido 


\subsubsection{Sensor de Temperatura}

A lógica para o acionamento do ar condicionado (LED) é a seguinte: foram delimitados dois patamares de temperatura, $35^{\circ} \mathrm{C}$ e $45^{\circ} \mathrm{C}$. Quando a temperatura mensurada no sensor de temperatura (TC77) do nó do tipo coordenador está acima do patamar superior $\left(45^{\circ} \mathrm{C}\right)$, o nó do tipo coordenador envia uma mensagem para o nó do tipo RFD indicando que o ar condicionado deve ser ligado. $\mathrm{O}$ ar condicionado permanece ligado até que a temperatura fique abaixo $\operatorname{dos} 35^{\circ} \mathrm{C}$. Quando a temperatura estiver abaixo do patamar inferior, o nó do tipo coordenador envia uma mensagem ao nó do tipo RFD indicando que o ar condicionado deve ser desligado. $\mathrm{O}$ ar condicionado só é religado quando a temperatura passar novamente $\operatorname{dos} 45^{\circ} \mathrm{C}$.

Os valores de $35^{\circ} \mathrm{C}$ e $45^{\circ} \mathrm{C}$ foram escolhidos para testes e são pré-estabelecidos em software, mas nada impede que futuramente se crie um modo de alterar esses valores, utilizando o software hyperterminal, por exemplo, para a entrada desses valores.

\subsubsection{Sensor de Movimento}

O tempo de inicialização do sensor de movimento varia de 40 a 60 segundos. Devido a isso, o nó do tipo RFD deve aguardar 60s antes de entrar em sua rotina de funcionamento normal. Isso deve ser feito para garantir que o sensor de movimento tenha sido inicializado corretamente.

Após essa inicialização, quando o sensor de movimento é acionado, o nó do tipo RFD envia uma mensagem ao nó do tipo coordenador, indicando que o sinalizador acústico deve ser acionado. Quando o sensor não mais detecta movimento, é enviada uma mensagem ao nó do tipo coordenador indicando que o sinalizador acústico deve deixar de ser acionado.

\subsubsection{Sensor de Luminosidade}

O sensor de luminosidade funciona da seguinte forma: 
Ou seja, quanto menor a luminosidade no ambiente, maior o valor da resistência do sensor de luminosidade, e consequentemente menor a tensão lida pelo conversor analógico digital(ADC) da porta RA3.

Com os valores de tensão ( $0 \mathrm{~V}$ e $3 \mathrm{~V} 3$ ) e resistência $(200 \mathrm{k} \Omega$ para o LDR e $33 \mathrm{k} \Omega$ para o resistor) utilizados, chegamos aos seguintes valores digitalizados lidos pelo conversor AD:

- 993

Este valor foi lido quando obtida a maior luminosidade possível no ambiente.

- 0

Este valor foi lido com a menor luminosidade possível no ambiente.

Para a lógica utilizada no acionamento da lâmpada, foram estipulados três patamares:

- 300;

- 500;

- 700 .

E criados quatro estados para a lâmpada:

- apagado;

- aceso a $40 \%$;

- aceso a $60 \%$;

- aceso a $100 \%$.

De posse desses valores, foi criada a lógica a ser utilizada no algoritmo. Se a leitura do conversor $\mathrm{AD}$ for maior que 700, a lâmpada deve estar apagada. Se a leitura for um valor 
entre 500 e 700, a lâmpada deve estar acesa a $40 \%$ de sua carga máxima. Se a leitura for um valor entre 300 e 500, a lâmpada deve estar acesa a 60\%, e finalmente, caso a leitura do conversor $\mathrm{AD}$ for um valor abaixo de 300 , a luz deve estar acesa a $100 \%$ de sua carga máxima. Sendo assim, quanto menor a luminosidade no ambiente lido pelo conversor $\mathrm{AD}$, maior o grau de luminosidade da lâmpada.

\subsubsection{USB}

O intuito inicial foi desenvolver um hardware para a USB equivalente ao hardware para RS232 existente na placa do kit PICDEM Z. Esse hardware seria montado no nó do tipo coordenador. Na busca pelo hardware, foi encontrado apenas um transceptor RS232-USB com encapsulamento SMD. Devido à dificuldade de manuseio de componentes SMD, surgiu a idéia de se criar uma PCI externa que tivesse a funcionalidade de comunicação USB e que pudesse ser facilmente conectada ao hardware do kit PICDEM Z. Foi então concebida essa PCI, de forma a permitir a seleção entre três modos diferentes. Dentre eles, o principal é o USB-TTL. Neste modo, pode-se conectar os fios RX, TX e GND na placa USB desenvolvida e comunicar com o PC através da porta USB. O funcionamento desta placa será melhor descrito na seção 5.3.4.

\subsection{Descrição do Hardware}

\subsubsection{PICDEM Z}

Para iniciar a montagem do hardware extra nas placas do kit de desenvolvimento, foram colocados algumas barras de pino torneado a fim de transformar a área livre em algo mais parecido com um protoboard. As Figuras 5.2 e 5.3 mostram, respectivamente, as partes superior e inferior de uma das placas do kit após a adequação para a utilização no desenvolvimento.

Os componentes agora podem ser apenas encaixados na placa, ao invés de soldados, o que além de deixar a montagem mais rápida e simples ainda aumenta a vida útil da área de montagem, evitando a necessidade de soldas a cada troca de componente e consequentes danos às ilhas, que seriam inevitáveis. 


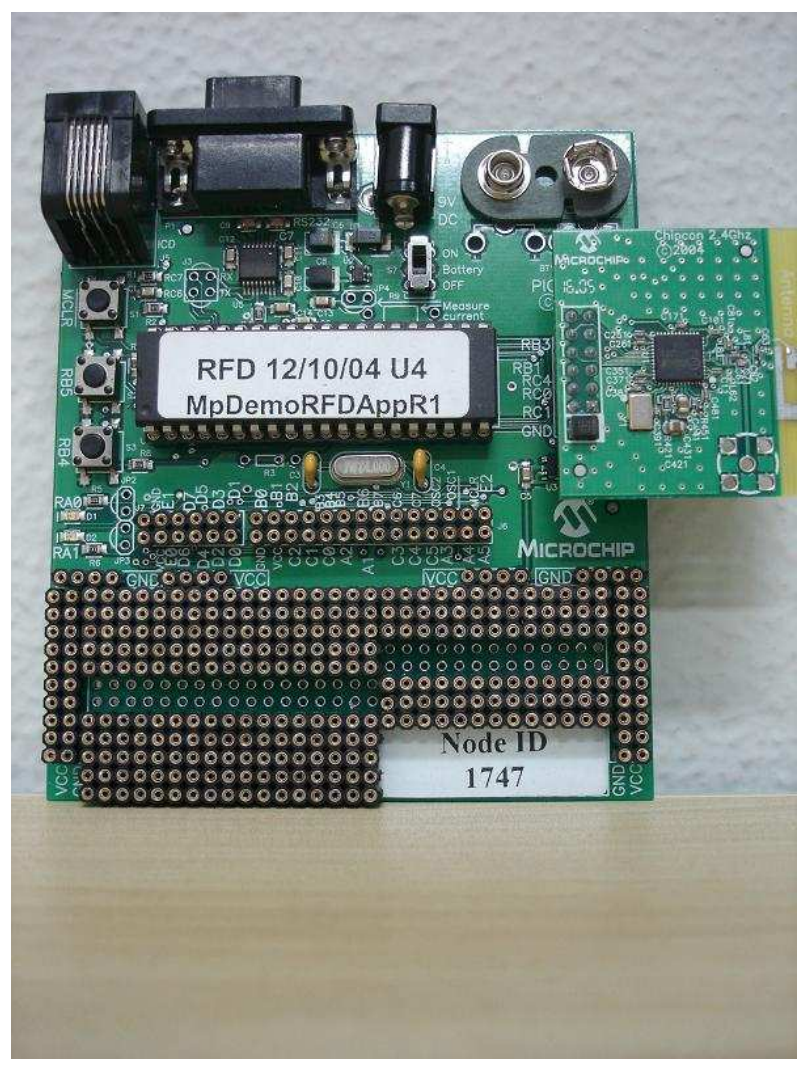

Figura 5.2: PICDEM $Z$ adequado para o desenvolvimento.

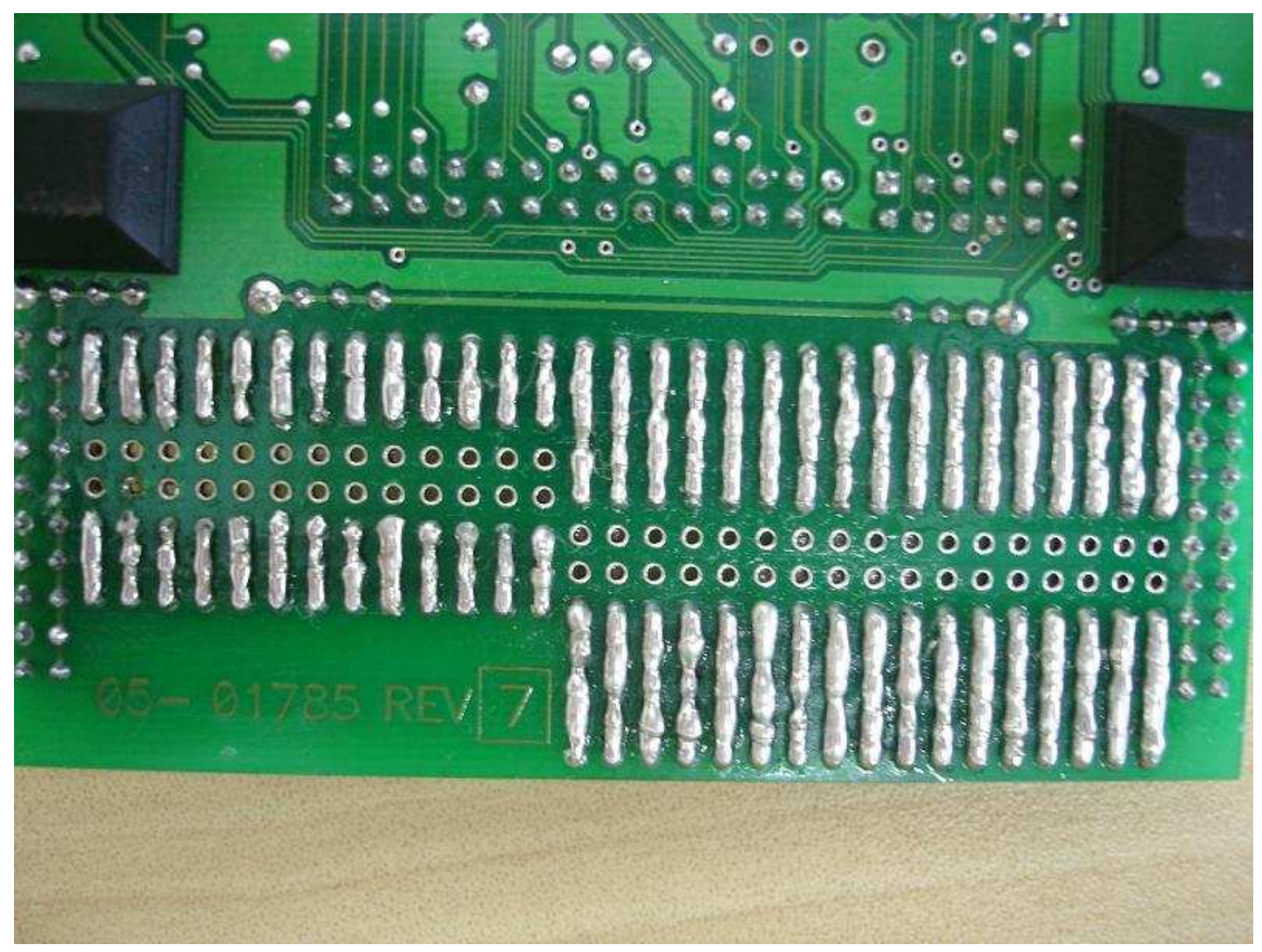

Figura 5.3: Parte inferior do PICDEM Z após adequação. 


\subsubsection{Sensor de Temperatura}

O sensor de temperatura utilizado foi o TC77, por já fazer parte do hardware do kit. Este sensor se comunica com o PIC via barramento de comunicação SPI. A Figura 5.4 mostra o esquema elétrico do sensor de temperatura. A Figura 5.5 mostra o sensor de temperatura implementado pela microchip no kit PICDEM Z.

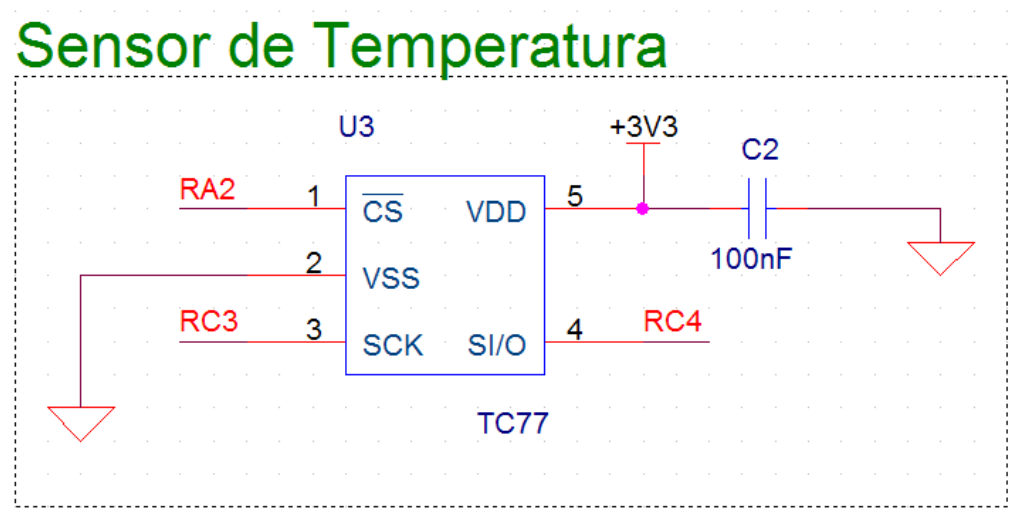

Figura 5.4: Circuito do Sensor de Temperatura. Fonte: (MICROCHIP, 2004e)

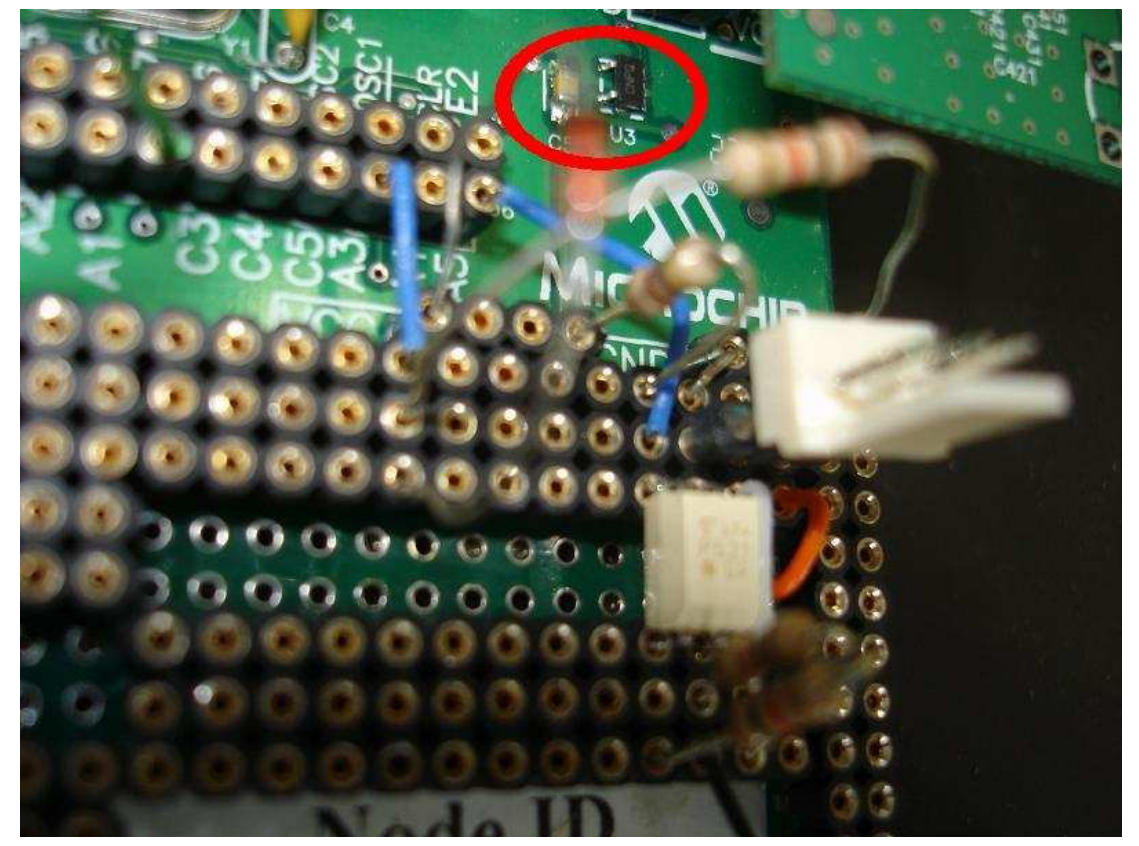

Figura 5.5: Localização do TC77 no kit PICDEM Z. 


\subsubsection{Sensor de Luminosidade e Sinalizador Acústico}

O esquema elétrico do circuito implementado para o sensor de luminosidade pode ser visto na Figura 5.6(a), enquanto que o esquema elétrico do circuito implementado para o sinalizador acústico pode ser visto na Figura 5.6(b). Na Figura 5.7 pode-se ver o hardware implementado para o sensor de luminosidade (LDR) e para o sinalizador acústico.

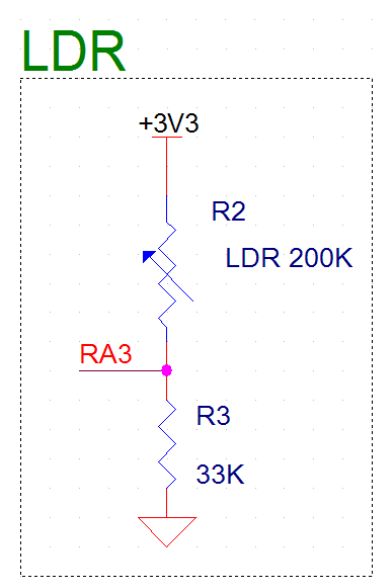

(a)

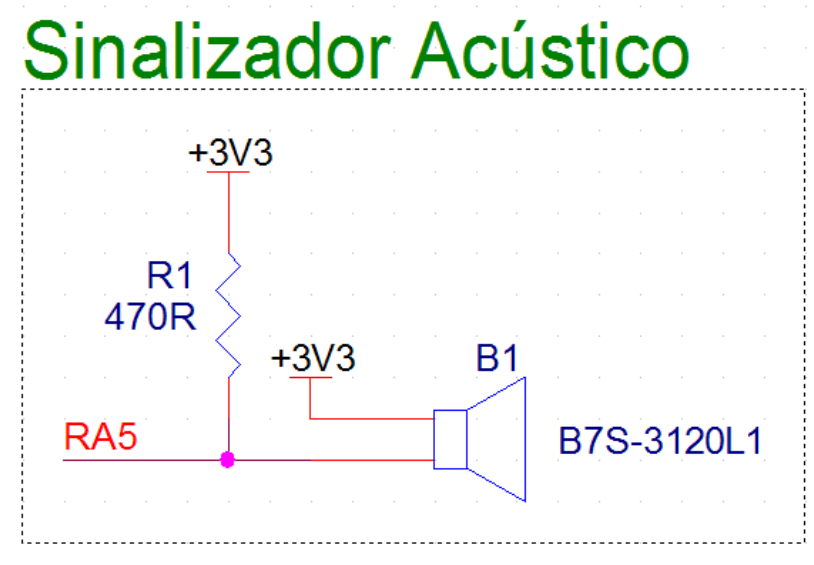

(b)

Figura 5.6: (a) Circuito do LDR implementado, (b) Circuito do Sinalizador Acústico implementado.

O circuito do LDR é um circuito simples e consiste apenas de um LDR de 200k $\Omega$ e um resistor de 33k $\Omega$. A porta do PIC do nó do tipo coordenador utilizada foi a entrada analógica RA3.

O circuito do sinalizador acústico é ainda mais simples, como pode ser visto na Figura 5.6(b). Uma das extremidades do sinalizador acústico é conectada à tensão de referência positiva do circuito (no caso $3,3 \mathrm{~V}$ ), e a outra extremidade é conectada à porta RA5 do PIC do nó do tipo coordenador, utilizada como saída digital. Nessa mesma extremidade é conectado um resistor (R1) de $470 \Omega$. A outra extremidade desse resistor é conectada em 3,3V. Esse resistor é denominado resistor de pull up. Esse resistor serve para manter a tensão na porta do PIC em nível lógico alto, evitando que a porta fique com um valor desconhecido e, provocando eventuais acionamentos indevidos do hardware que está conectado na porta do PIC, nesse caso, o sinalizador acústico. O sinalizador acústico é acionado quando a porta RA5 do PIC estiver em nível lógico baixo (no caso 0V). 


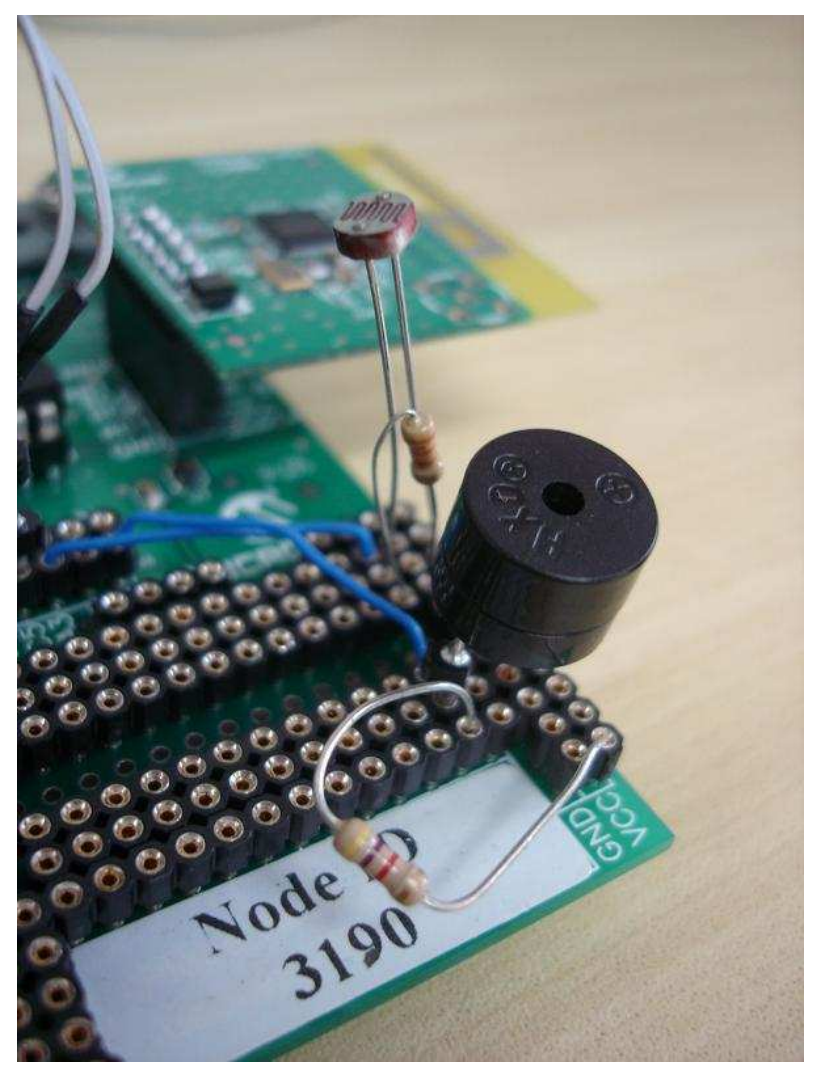

Figura 5.7: Sensor de Luminosidade e Sinalizador Acústico.

\subsubsection{USB}

Como o transceptor USB-RS232 escolhido (FT232) possui encapsulamento SMD, optou-se por criar uma placa onde houvesse um conector que pudesse ser ligado diretamente aos pinos de RX e TX do PIC e o GND do circuito da PCI do PICDEM Z, de modo a permitir a comunicação do PIC com o PC através do transceptor FT232, equivalente ao que já é feito com o transceptor MAX3221 no kit PICDEM Z.

Pode-se ver na Figura 5.8 a placa que foi desenvolvida. Na parte superior direita da placa existem três leds, onde o primeiro (superior) indica se a placa está alimentada (via USB ou RS232), o segundo indica o fluxo de dados recebidos através da USB e o último indica o fluxo de dados enviados através da USB.

Para um melhor aproveitamento de tempo e recursos, a placa foi desenvolvida com o intuito de permitir três modos distintos de operação, que são os seguintes: 


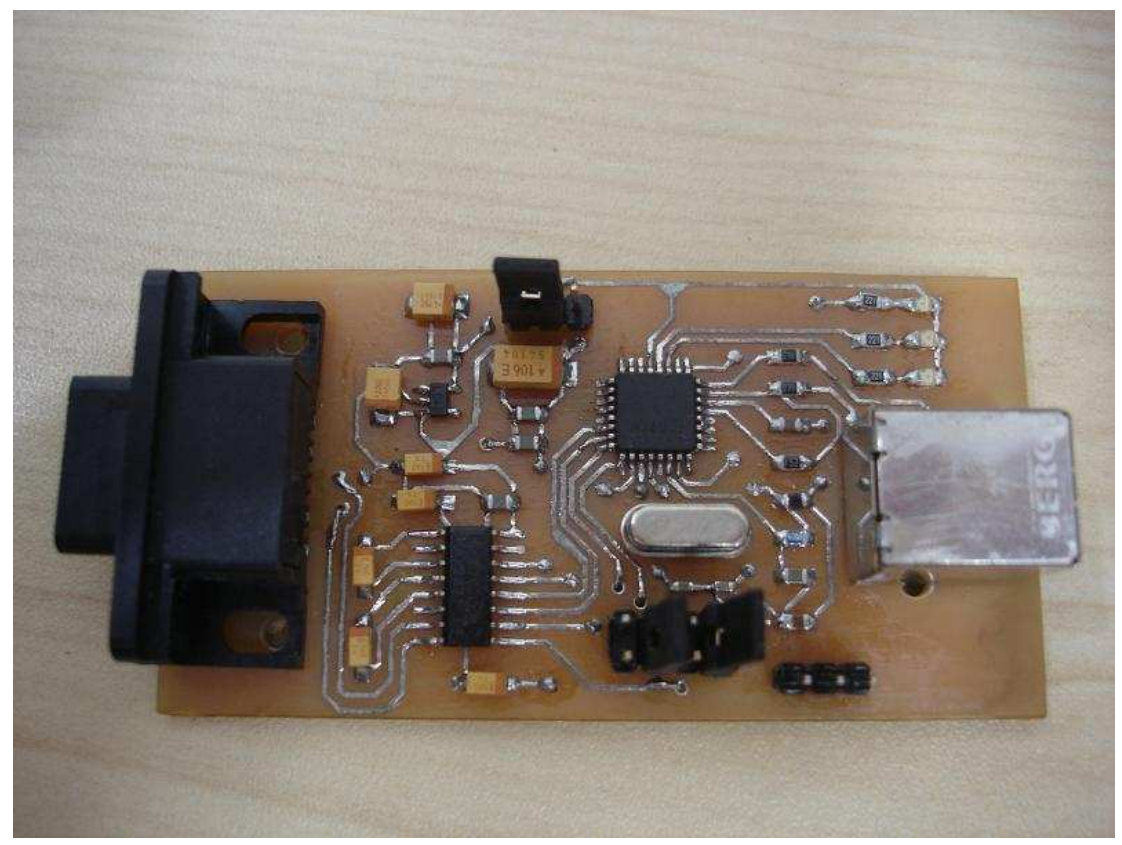

Figura 5.8: Placa USB-RS232-TTL desenvolvida.

\section{USB - RS232}

Este modo é o mesmo utilizado nos cabos comerciais USB-Serial encontrados em lojas de informática.

2. USB - TTL

Este modo dispensa um transceptor RS232, conectando diretamente o PIC ao PC através do transceptor USB (FT232), como pode ser visto na Figura 5.9.

3. RS232 - TTL

Este modo é equivalente ao que já está implementado no kit PICDEM Z, que faz com que o PIC comunique-se com o PC através de um transceptor RS232 (MAX3221).

\subsubsection{Sensor de Movimento}

A Figura 5.10 mostra o circuito que foi montado para poder isolar o sensor de movimento do resto do circuito, de modo a não deixar que o sensor causasse algum tipo de interferência. Na Figura 5.11 pode-se ver um sensor de movimento desenvolvido pela ICCEA. 


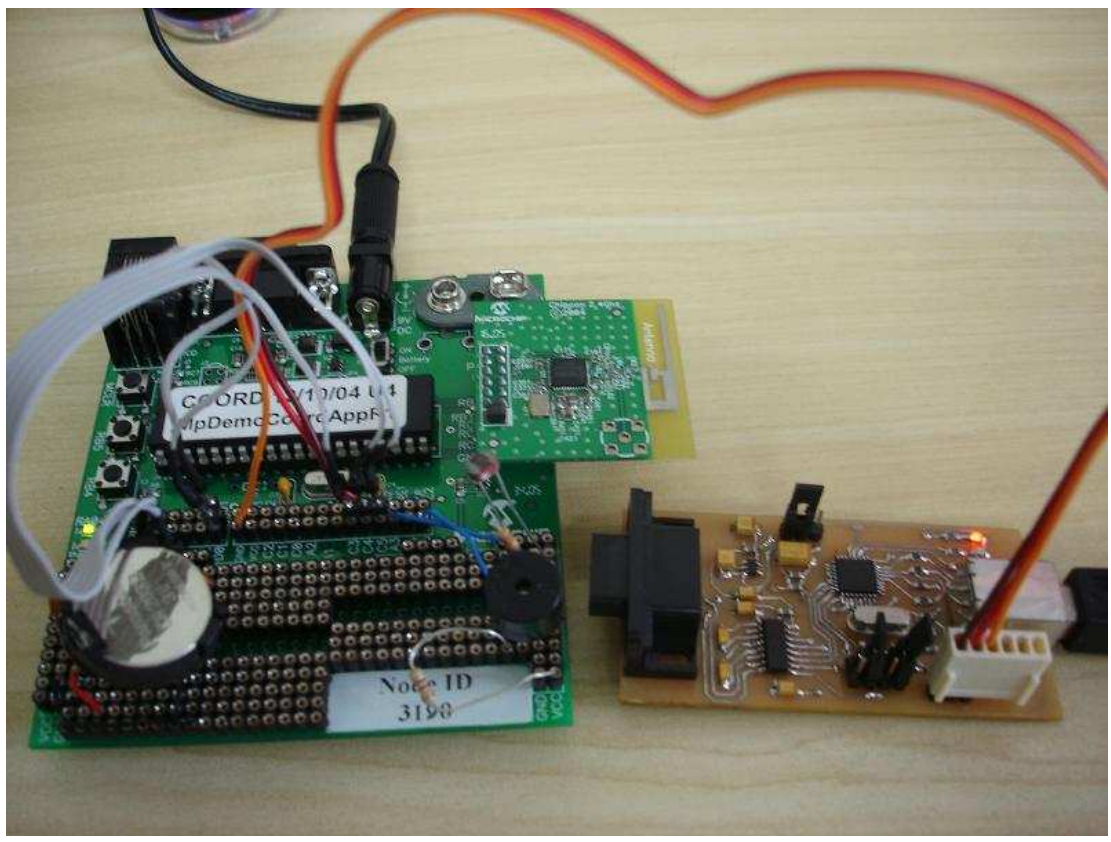

Figura 5.9: Conexão da placa USB no modo USB - TTL.

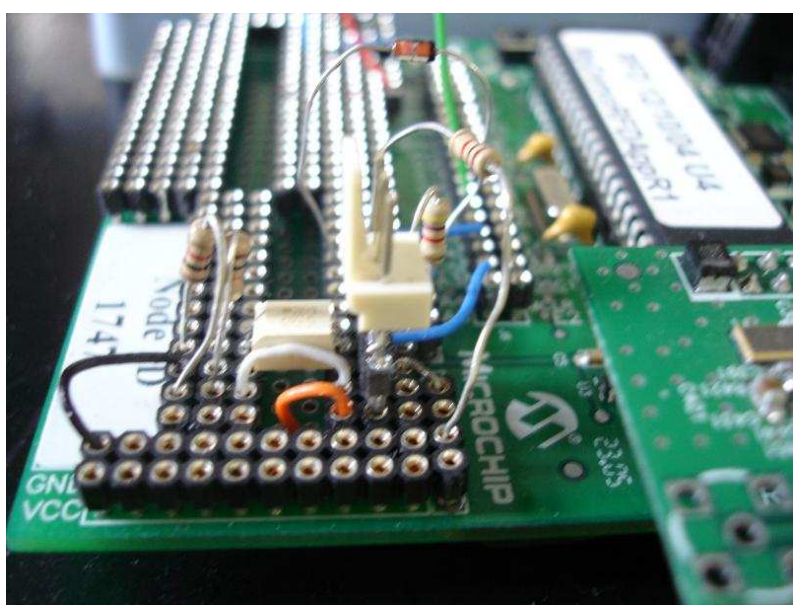

Figura 5.10: Circuito implementado para leitura do sensor de movimento.

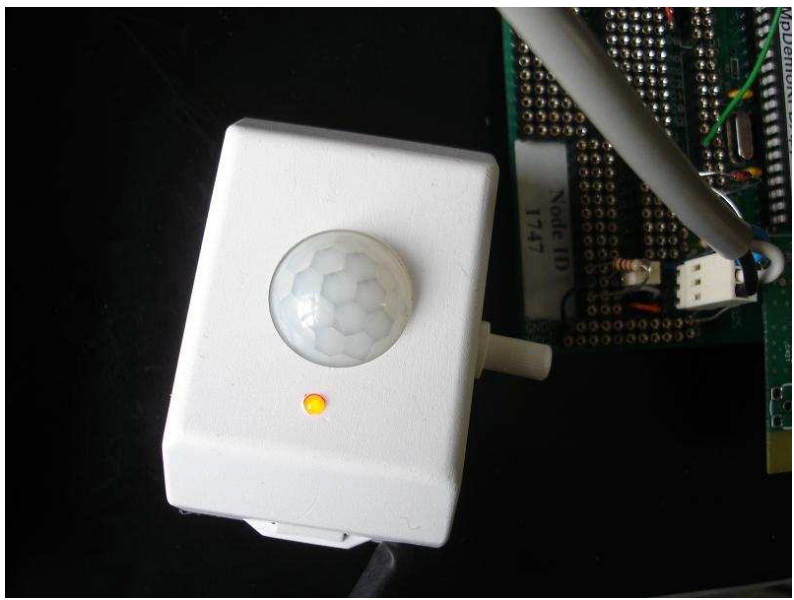

Figura 5.11: Sensor de Movimento da ICCEA. 
Ainda na Figura 5.11 pode-se ver que o sensor de movimento da ICCEA possui um led externo com a função de indicar o acionamento do sensor de movimento. O sensor de movimento está na porta RA5 do nó do tipo RFD, como pode ser visto no esquema elétrico do sensor de movimento na Figura 5.12.

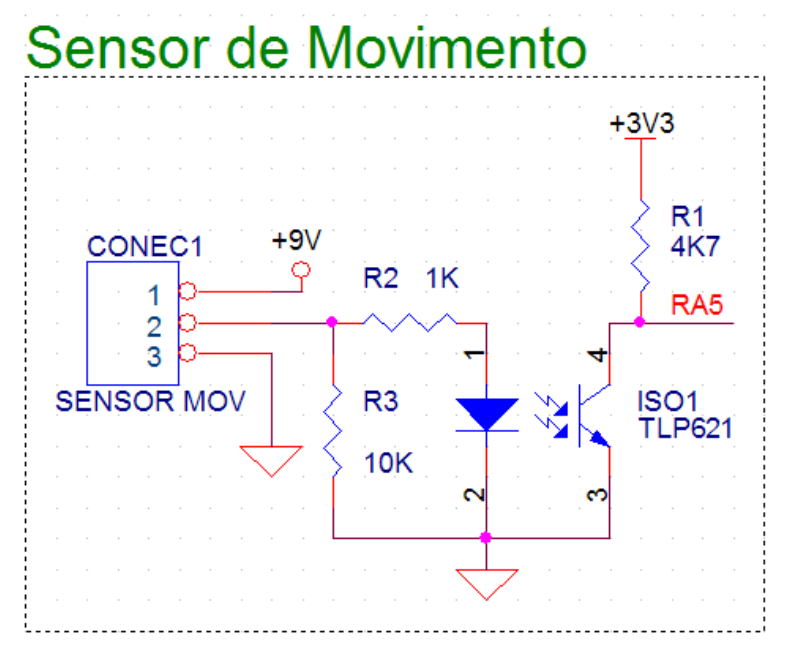

Figura 5.12: Circuito do Sensor de Movimento implementado.

\subsubsection{Led}

Devido à utilização do comparador no nó do tipo RFD, não foi possível utilizar os dois leds já implementados na placa do kit PICDEM Z utilizada. Portanto foi necessário conectar um LED à porta RD0, cuja funcionalidade é servir de referência visual, ao invés de se criar um acionamento de um ar condicionado. A Figura 5.13 mostra o circuito utilizado para a implementação.

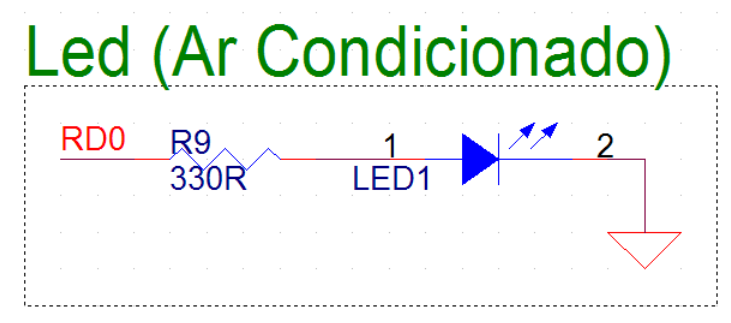

Figura 5.13: Circuito do LED implementado. 


\subsubsection{Lâmpada}

No caso de acionamento de uma lâmpada, por se tratar de uma tensão AC e elevada, a fim de evitar algum dano a alguma das placas do kit de desenvolvimento, o circuito de acionamento da lâmpada foi montado em um protoboard que foi conectado ao nó do tipo RFD. A Figura 5.14 mostra o circuito implementado para o acionamento da lâmpada.

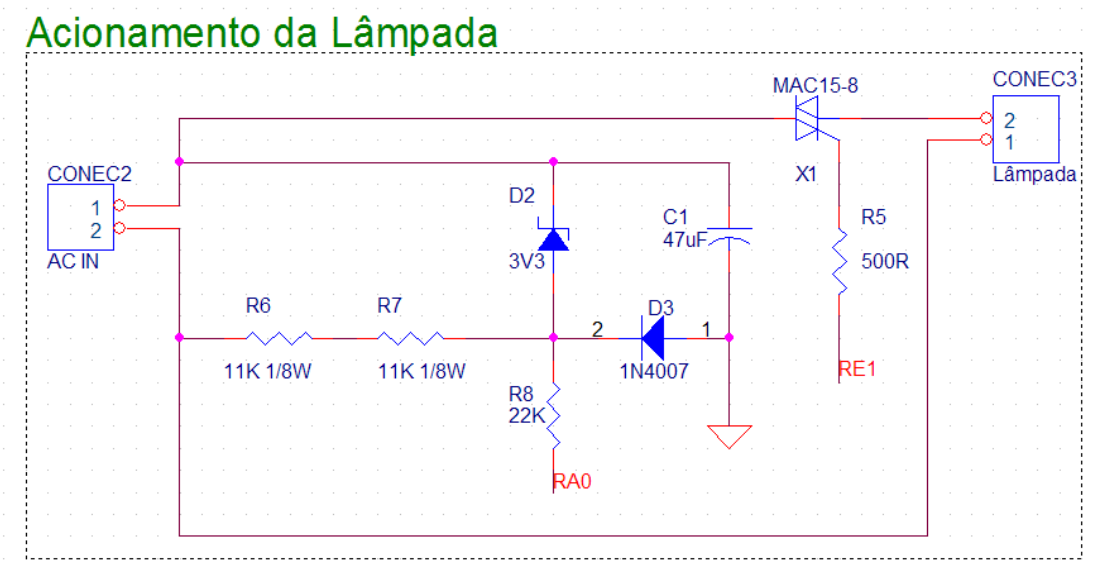

Figura 5.14: Circuito de acionamento da lâmpada.

O triac (componente X1 da Figura 5.14) é o responsável pelo acionamento da lâmpada. É necessário enviar um pulso no gate do triac para que o acionamento seja realizado (pino RE1 do PIC). Para que esse pulso fosse dado no momento certo, foi necessário implementar um detector de zero do sinal de tensão da rede (pino RA0 do PIC) que, na Figura 5.14, é composto pelos componentes C1, D2, D3, R6, R7 e R8. A Figura 5.15 mostra o circuito que foi utilizado como referência para o comparador (pino RA3 do PIC).

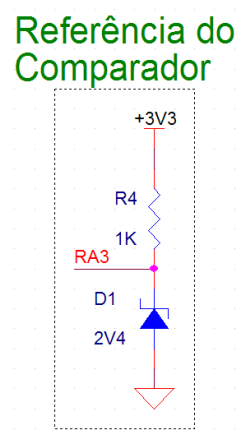

Figura 5.15: Circuito de referência para o comparador. 


\subsubsection{Real Timer Clock (RTC)}

Na Figura 5.16 pode-se ver o esquema elétrico do circuito implementado para o RTC. Já a Figura 5.17 abaixo mostra uma foto do hardware implementado para o Real Timer Clock no nó do tipo coordenador.

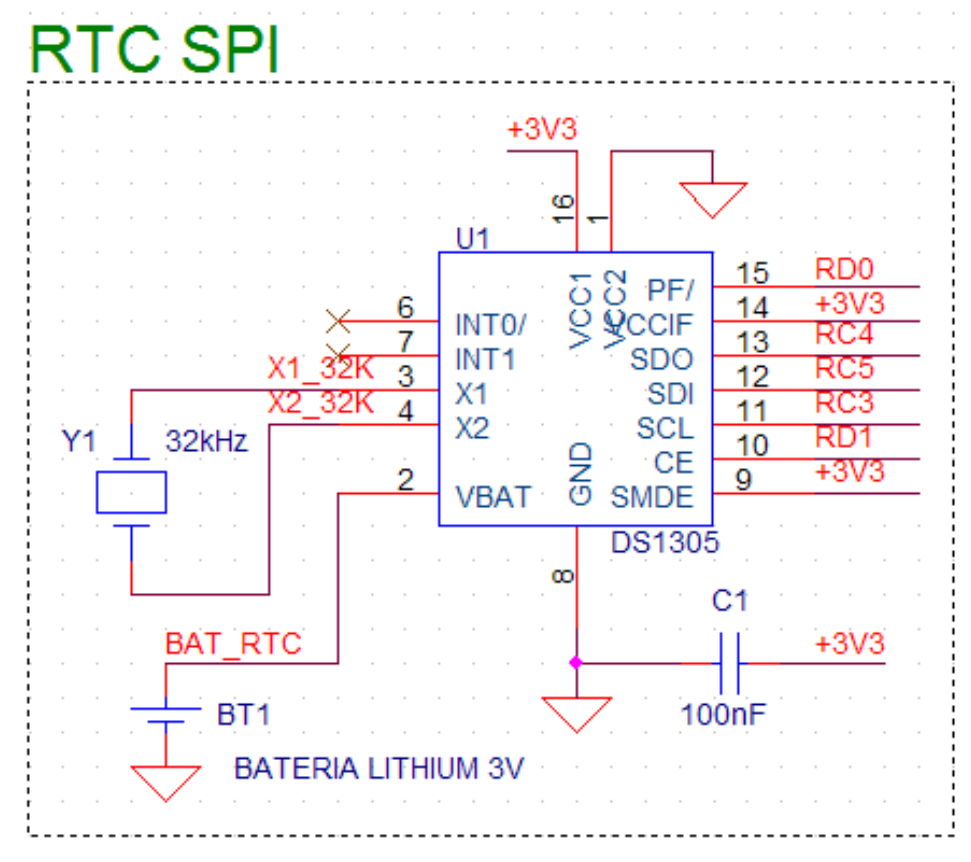

Figura 5.16: Circuito do RTC implementado.

O hardware do RTC funcionou muito bem com um software desenvolvido apenas para testar seu funcionamento. Ao tentar integrar este software com a pilha ZigBee, ocorreu uma certa incompatibilidade no barramento de comunicação SPI. O barramento de comunicação SPI é utilizado pelo transceptor ZigBee (CC2420), pelo sensor de temperatura (TC77) e pelo RTC (DS1305).

O transceptor ZigBee funciona a quatro fios, ou seja, o transceptor utiliza os pinos de clock (CLK), chip enable (CE), serial data in (SDI) e serial data out (SDO), enquanto que o Real Timer Clock (DS1305) pode funcionar de duas formas distintas: 


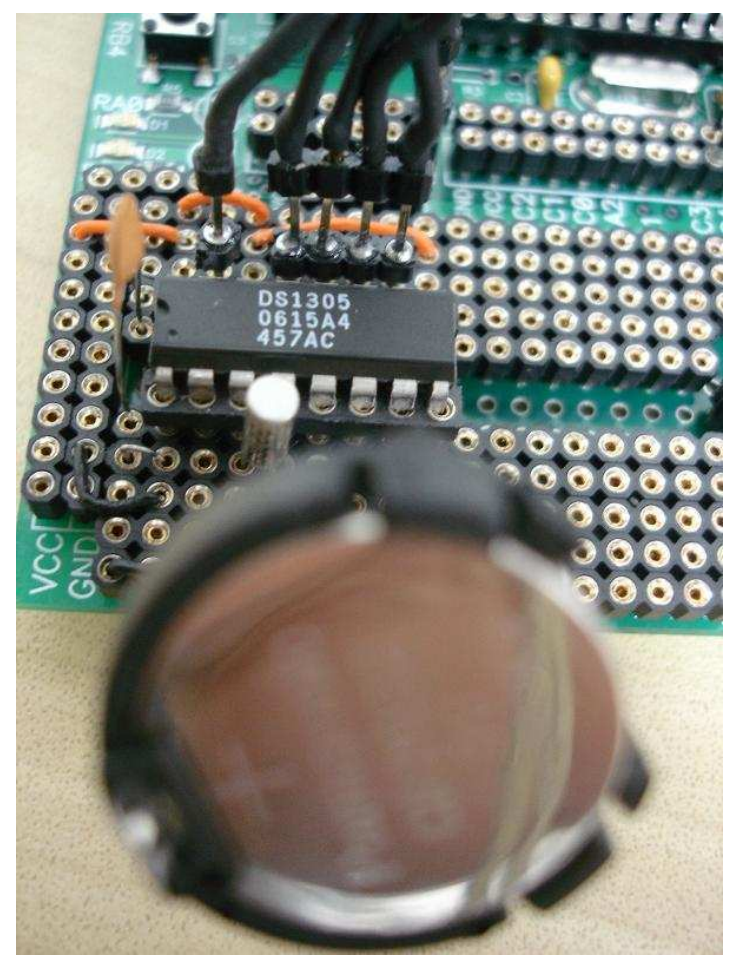

Figura 5.17: Real Timer Clock.

- 3 fios

Os três fios são o clock, o chip enable e o pino de entrada e saída de dados (SDI/O), ou seja, o DS1305 teria seus pinos de entrada e saída de dados (SDI e SDO respectivamente) curto circuitados. Para tal funcionamento, deveriam ser também curto circuitados os pinos de entrada e saída de dados do PIC18LF4620, e caso isso fosse feito, o transceptor não funcionaria corretamente.

\section{- SPI Motorola}

Esta segunda forma foi a testada, como mencionado anteriormente, e funcionou como o esperado sem a pilha ZigBee. Em conjunto com a pilha ZigBee apresentou algumas falhas no funcionamento. Para que o RTC funcionasse corretamente seria necessário que o transceptor fosse inibido e o RTC habilitado quando fosse realizar a leitura do RTC, e após a leitura, o RTC teria de ser inibido e o transceptor habilitado novamente. Isto também não seria possível, pois a cada vez que o transceptor do nó do tipo coordenador fosse inibido, a rede entraria em colapso, pois para a rede seria como se o coordenador não estivesse presente. 
Desta forma observa-se que não há como utilizar o RTC no nó do tipo coordenador. Poderia se utilizar, ao invés disso, o RTC no nó do tipo RFD, mas o funcionamento seria o mesmo descrito anteriormente, e isso iria sem dúvida desgastar bastante a bateria do nó.

O sensor de temperatura (TC77) funciona com o barramento SPI a 3 fios, mas como não é necessário enviar nenhum dado ao sensor na aplicação, e apenas ler dados, os pinos de entrada e saída de dados do sensor de temperatura foram conectados apenas ao pino de entrada de dados do microcontrolador (SDI).

\subsection{Descrição do Software}

\subsubsection{Pilha ZigBee}

Foi utilizado no trabalho, a versão 1.0-3.6 da pilha ZigBee fornecida pela Microchip para download gratuito (MICROCHIP, 2006a). Nessa versão algumas funções foram melhor organizadas e, para inicializar a pilha ZigBee, basta chamar a seguinte função:

// Initialize the ZigBee Stack.

ZigBeeInit();

A função ZigBeeInit() está localizada no arquivo ZigBeeTasks.c, e entre outras inicializações, chama as seguintes funções:

MACInit ();

NWKInit ();

APSInit ();

ZDOInit();

As funções acima são responsáveis por inicializar, respectivamente, as camadas MAC, NWK, APS e ZDO. Algumas das funções que existiam em versões anteriores da pilha ZigBee da Microchip mantiveram sua funcionalidade. Abaixo são citados alguns exemplos. 
As funções acima, na coluna da direita, por possuirem a mesma funcionalidade que as funções da esquerda em versões antigas da pilha ZigBee, podem ser chamadas do modo antigo (coluna da esquerda), de modo a facilitar a migração do software para uma nova versão da pilha. Isto é o que faz as linhas de comando \#define acima, retiradas do arquivo zAPL.h.

\subsubsection{Software Desenvolvido}

A Figura 5.18 representa o diagrama em blocos do funcionamento do arquivo principal do nó do tipo coordenador, enquanto que a Figura 5.19 representa o digrama em blocos do arquivo principal do nó do tipo RFD.

O software desenvolvido está detalhado no apêndice A.

\subsection{Resultados e Discussões}

Quatro funções foram implementadas neste projeto de monitoração e sensoriamento. A primeira, que foi o sensor de movimento em conjunto com o Buzzer, funcionou sem problema algum. Cada vez que o sensor de movimento no nó do tipo RFD é acionado, a mensagem é enviada com sucesso para o nó do tipo coordenador, onde o Buzzer aciona, e quando o sensor de movimento deixa de detectar movimento, a mensagem que indica que o Buzzer deve deixar de ser acionado também é enviada com sucesso.

A segunda função, que coompreende o sensor de temperatura e o LED, também funcionou corretamente, acionando o LED quando a temperatura do nó do tipo coordenador supera o patamar superior de temperatura e desligando o LED quando a temperatura baixa do patamar inferior. A terceira função, que compreende o sensor de lumiosidade (LDR) e o acionamento da lâmpada também obteve êxito. Quanto menor o grau de luminosidade do ambiente, maior a porcentagem da carga da lâmpada utilizada. Essa porcentagem da carga máxima pode ser de $0 \%, 40 \%, 60 \%$ ou $100 \%$.

A quarta função funcionou corretamente no modo empregado (USB-TTL), mas possui dois erros de layout que precisam ser corrigidos, e só ocorrem no modo (RS232-TTL). O 
primeiro é que para se utilizar o hardware USB nesse modo, torna-se necessário que a alimentação venha via TTL, pois nesse caso o conector USB não estará conectado, e a tensão positiva não foi prevista no conector. O segundo erro é que da forma como o jumper de seleção foi concebido, ao selecionar o modo RS232-TTL, o pino de RX do PIC fica conectado onde deveria estar conectado o pino de TX, e vice-versa.

Uma quinta função que seria implementada e foi testada sem sucesso é a implementação de um Real Timer Clock no nó do tipo coordenador. Os componentes que utilizam o barramento de comunicação SPI são: o transceptor ZigBee, o sensor de temperatura e o RTC. O problema encontrado foi que o transceptor e o RTC não poderem trabalhar simultaneamente, no momento em que um estivesse sendo utilizado, o outro não poderia estar habilitado. Como o transceptor ZigBee do nó do tipo coordenador não pode ser desligado, torna-se impossível a utilização do RTC escolhido em conjunto com a pilha ZigBee utilizada, disponibilizada pela Microchip.

\section{Coordenador}
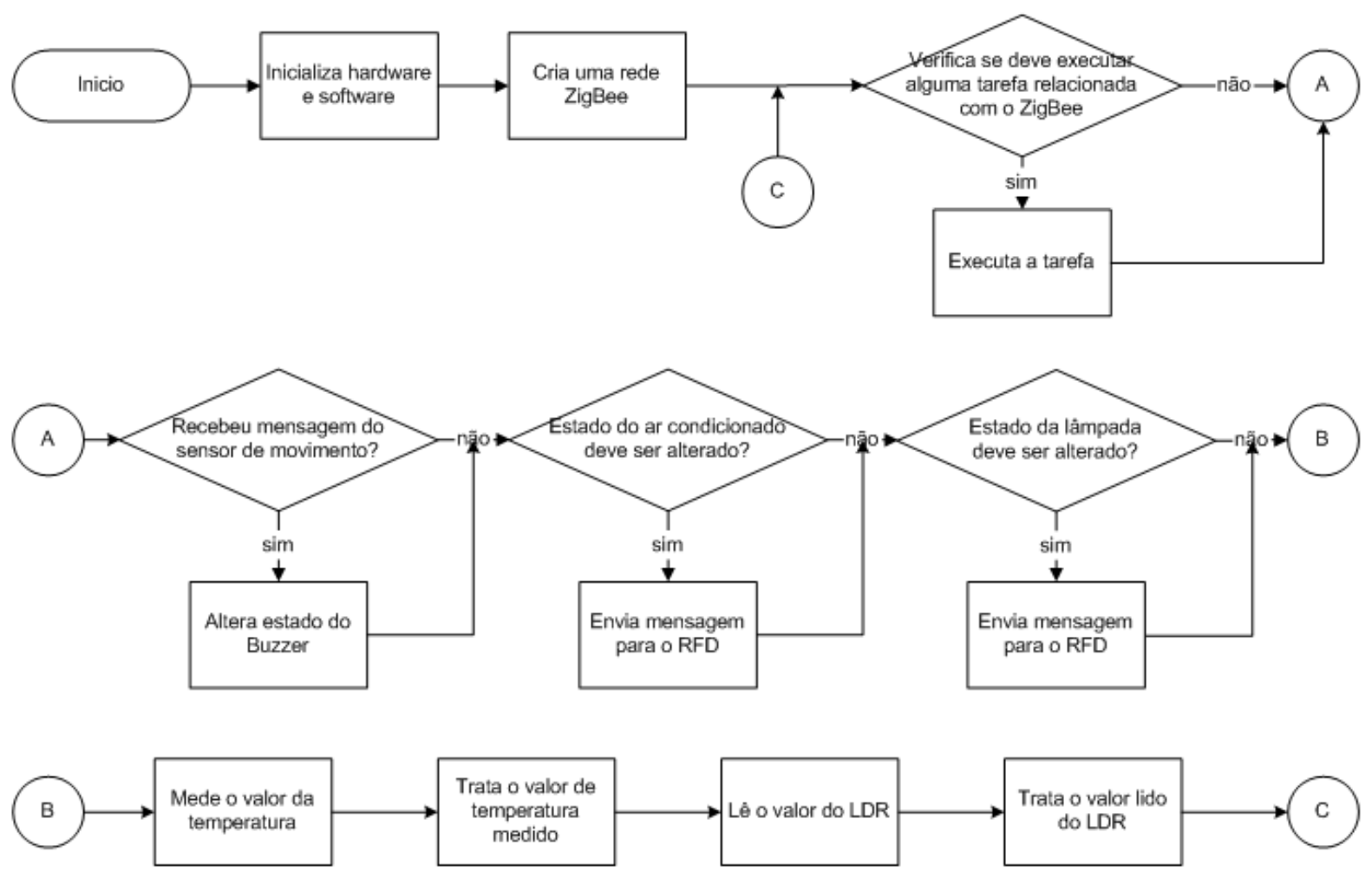

Figura 5.18: Fluxograma do nó do tipo coordenador. 


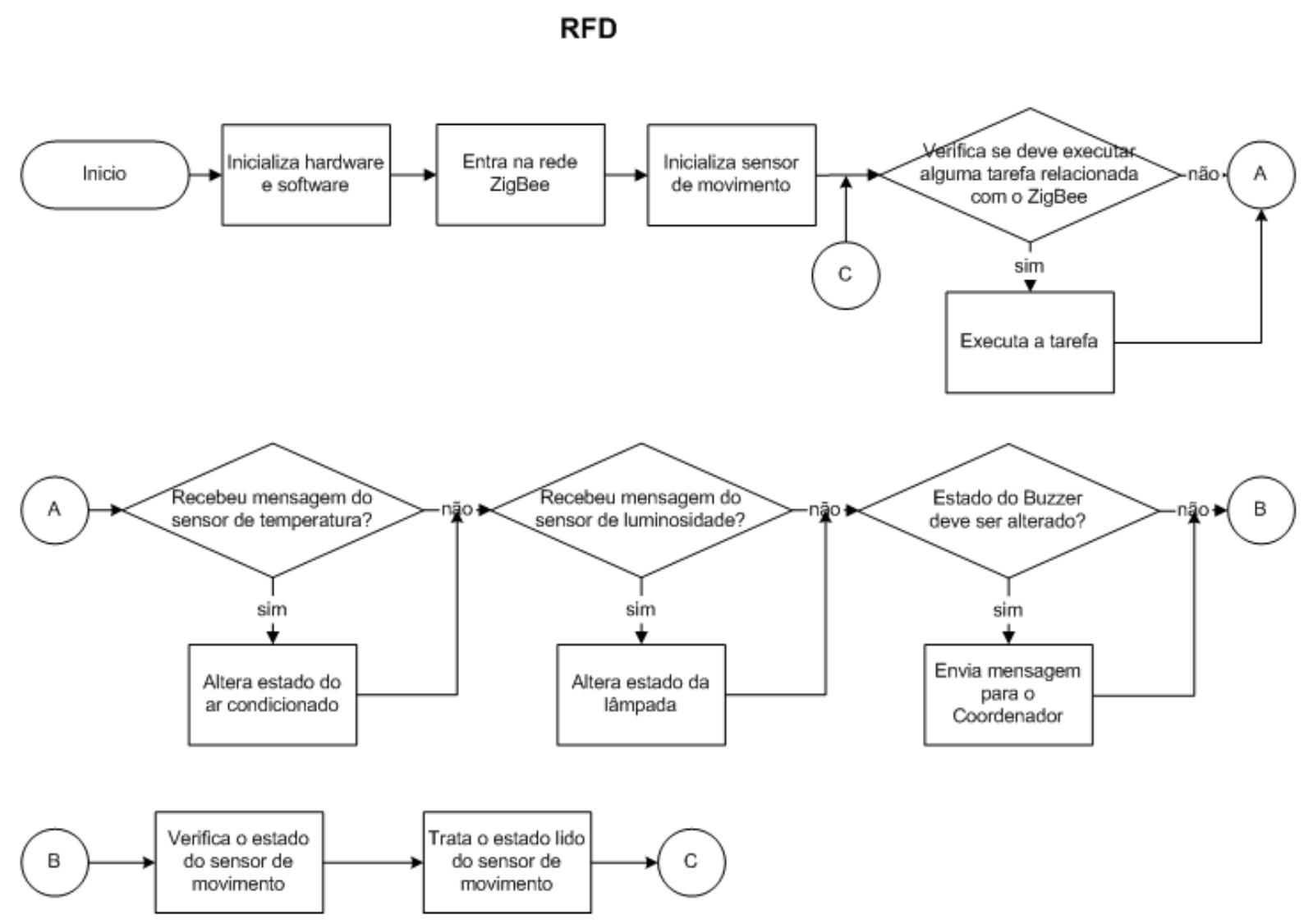

Figura 5.19: Fluxograma do nó do tipo RFD 


\section{CONCLUSÕES}

\subsection{Conclusões}

A proposta do projeto é avaliar o padrão sem fio ZigBee para sensoriamento de ambientes. Para tal foi implementada uma aplicação com o kit PICDEM Z contendo sensores e atuadores, baseados numa rede ZigBee. Essa implementação mostrou que o padrão ZigBee é eficiente para a monitoração e sensoriamento de ambientes.

Foi testado com sucesso a comunicação entre os dois nós a 15 metros de distância um do outro e com duas paredes entre eles, o que era esperado, pois a especificação diz que o padrão ZigBee possui um alcance de até $100 \mathrm{~m}$ em ambiente externo e até $30 \mathrm{~m}$ em ambiente fechado.

O consumo de corrente do nó do tipo coordenador não ultrapassou 30mA durante o funcionamento, o que está de acordo com o esperado. A corrente em modo de sleep não pode ser mensurada, pois o nó do tipo RFD não pode entrar neste modo, devido à maneira como o acionamento da lâmpada é realizado.

A quantidade de recursos necessária para implementar um nó ZigBee, apenas considerando a pilha ZigBee, foi $32 \mathrm{kB}$ no caso do nó do tipo coordenador e $14 \mathrm{kB}$ no caso do nó do tipo RFD.

O único imprevisto que ocorreu foi na implementação do RTC, que não funcionou corretamente quando foram incluídas as funções do RTC no programa que já estava funcionando com a pilha ZigBee. 


\subsection{Contribuições}

Como o ZigBee é um padrão recente e pouco estudado, este trabalho representa uma contribuição para aqueles interessados em desenvolver aplicações que utilizem esse padrão.

Outra contribuição importante está relacionada com o RTC. O RTC utilizado na aplicação foi o DS1305, que se comunica com o PIC via barramento SPI. Este RTC não funcionou corretamente devido ao modo como o barramento SPI é utilizado pelo transceptor ZigBee. A explicação se encontra na seção 5.3.8. Cabe ressaltar que o hardware implementado para o RTC foi testado e funcionou corretamente sem a pilha ZigBee. Essa informação é importante para aqueles que pretendem incluir um RTC em seu projeto.

\subsection{Proposta para Trabalhos Futuros}

Uma proposta é a de implementar um protótipo como produto final e realizar a avaliação deste em ambientes residenciais.

Outra proposta é utilizar, ao invés do kit PICDEM Z, um hardware chamado PIXIE, da Flexipanel (2006), cujo hardware é compatível com o do PICDEM Z e com a pilha ZigBee fornecida gratuitamente pela Microchip, de modo a reduzir consideravelmente o tamanho dos nós. Podemos ver uma foto do PIXIE na Figura 6.1.

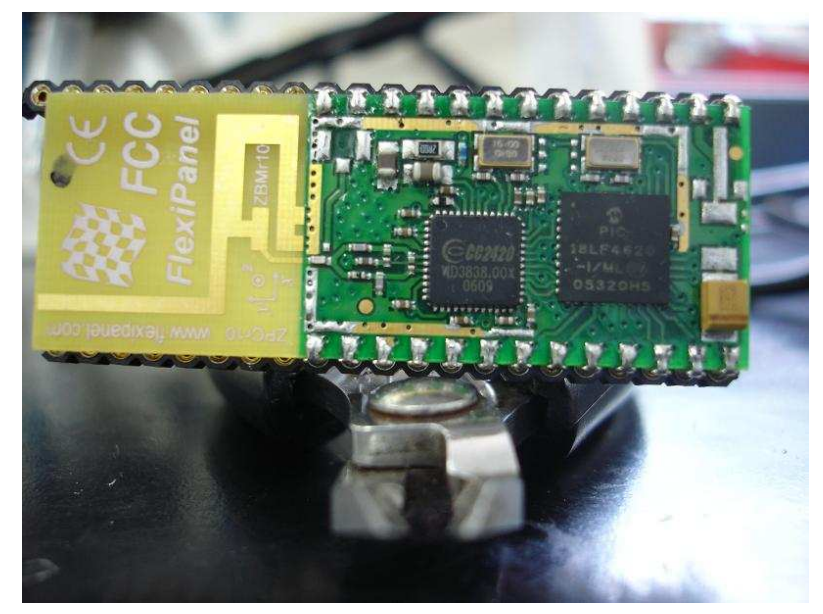

Figura 6.1: PIXIE. 
Pode-se utilizar também um outro microcontrolador PIC, no lugar do PIC18LF4620 utilizado, que já possua o hardware USB. Já existem PICs com saída USB, que dispensam o uso de um transceptor (FT232 ou qualquer equivalente), mas que não foram utilizados por não possuir memória de programa suficiente para a aplicação. O PIC com USB de maior memória disponível no mercado, na época da realização do trabalho, possui 32kBytes de memória de programa, quantidade que não seria suficiente para o coordenador, cuja pilha ZigBee é a mais complexa e com maior número de funções, e que somente ela já ocuparia algo da ordem de 32kBytes, e ainda seria necessário colocar no PIC as funções de USB e o código relativo à aplicação realizada.

Uma terceira proposta pode ser a utilização de PICs com saída USB de maior memória que estão para ser lançados pela Microchip, tornando assim desnecessária a utilização de um circuito externo para se comunicar com um PC através do barramento USB.

Estudos mais detalhados podem ser realizados com o RTC utilizado, o DS1305, ou pode-se tentar utilizar um outro tipo diferente. Pode-se tentar também implementar o RTC em um outro tipo de nó, por exemplo no nó do tipo RFD. 


\section{REFERÊNCIAS BIBLIOGRÁFICAS}

AAKVAAG, N.; MATHIESEN, M.; THONET, G. (2005). Timing and power issues in wireless sensor networks - an industrial test case. In: IEEE 34th International Conference Workshops on Parallel Processing. Oslo, Noruega: [s.n.], p. 419-426.

BAKER, N. (2005). Zigbee and bluetooth strengths and weaknesses for industrial applications. IEE Computing and Control Engineering Journal, 2, v. 16, n. 2, p. 20-25.

BRANQUINHO, O. C.; REGGIANI, N.; ANDREOLLO, A. G. (2005). Redes de comunicação de dados sem fio - uma análise de desempenho. In: ISA SHOW SOUTH AMERICA Feira Sul-Americana e 5 Congresso Internacional de Automação, Sistemas e Instrumentação. São Paulo, Brasil: [s.n.].

CHAKRABARTI, S.; WU, L.; VUONG, S.; LEUNG, V. C. M. (2004). A remotely controlled bluetooth enabled environment. In: 2004 IEEE Consumer Communications and Networking Conference. Caesar's Palace, Las Vegas, Nevada USA: [s.n.], p. 77-81.

CORDEIRO, C. D. M.; ABHYANKAR, S.; TOSHIWAL, R.; AGRAWAL, D. P. (2003). A novel architecture and coexistence method to provide global access to-from bluetooth wpans by ieee 802.11 wlans. In: IEEE. 22nd IEEE International Performance Computing and Communications Conference. Phoenix, Arizona, p. 23-30.

CORDEIRO, C. D. M.; AGRAWALL, D. P.; SADOK, D. H. (2003). Interference modeling and performance of bluetooth mac protocol. IEEE Transactions on wireless communications, v. 2 , n. 6, p. 1240-1246.

DING, G.; SAHINOGLU, Z.; BHARGAVA, B.; ORLIK, P.; ZHANG;, J. (2005). Reliable broadcast in zigbee networks. In: Second Annual IEEE Communications Society Conference on Sensor and Ad Hoc Communications and Networks, 2005. Santa Clara, California, USA: [s.n.], p. 510-520.

FERRARI, P.; FLAMMINI, A.; MARIOLI, D.; TARONI, A. (2006). Ieee802.11 sensor networking. IEEE Transactions on instrumentation and measurement, 2, v. 55, n. 2, p. 615-619.

FERRO, E.; POTORTÌ, F. (2005). Bluetooth and wi-fi wireless protocols: a survey and a comparison. IEEE Wireless Communications, v. 12, n. 1, p. 12-26.

FLEXIPANEL. (2006). Site Flexipanel. Disponível em: < http : //www.flexipanel.com >. Acesso em: 17 out. 2006.

FRENZEL, L. E. (2004). Wireless control that simply works. A Supplement to Electronic Design, p. 1-12. 
FRIAS, R. N. (2004). O que é ZigBee? Disponível em: $<$ http : $/ /$ www.teleco.com.br/tutoriais/tutorialzigbee/pagina 1. asp $>$. Acesso em: 23 jun. 2006.

GUTIERREZ, J. A.; NAEVE, M.; CALLAWAY, E.; BOURGEOIS, M.; MITTER, V.; HEILE, B. (2001). Ieee 802.15.4: a developing standard for low-power low-cost wireless personal area networks. IEEE Network, 5, v. 15, n. 5, p. 12-19.

HAARTSEN, J. (1998). Bluetooth - the universal radio interface for ad hoc, wireless connectivity. Ericsson Review, 3, v. 75, n. 3, p. 110-117.

HOME-CONTROL. (2006). Disponível em: $<$ http : //www.homecontrol.com.br/index_aplicacoes.htm >. Acesso em: 17 jul. 2006.

IEEE-STANDARDS. (2003)., IEEE Standard 802.15.4. [S.1.], Outubro 2003. 1-679 p.

JINDAL, S.; JINDAL, A.; GUPTA, N. (2005). Grouping wi-max, 3g and wi-fi for wireless broadband. In: The First IEEE and IFIP International Conference in Central Asia on Internet, 2005. Hyatt Regency Hotel, Bishkek, Kyrgyz Republic: [s.n.], p. 5.

LABTOOLS. (2006). Gravador e Depurador de PICs ICD2BR. Disponível em: $<$ http : $/ /$ www.labtools.com.br $/$ index.asp? area $=07 \&$ idioma $=$ por\&script $=$ produtos\&prod $=$ $681>$. Acesso em: 7 jun. 2006.

LANSFORD, J.; STEPHENS, A.; NEVO, R. (2001). Wi-fi (802.11b) and bluetooth - enabling coexistence. IEEE Network, v. 15, n. 5, p. 20-27.

LEE, J.-S. (2005). An experiment on performance study of ieee 802.15.4 wireless networks. In: 10th IEEE Conference on Emerging Technologies and Factory Automation. Catania, Itália: [s.n.], v. 2, p. 451-458.

MALAFAYA, H.; TOMÁS, L.; SOUSA, J. P. (2005). Sensoriação sem fios sobre zigbee e ieee 802.15.4. In: INSTITUTO SUPERIOR DE ENGENHARIA DE LISBOA. Terceiras Jornadas de Engenharia de Electrónica e Telecomunicações e de Computadores. Lisboa, Portugal.

MARSAN, M.; CHIASSERINI, C.-F.; NUCCI, A. (2006). Forming optimal topologies for bluetooth-based wireless personal area networks. IEEE Transactions on Wireless Comunication, v. 5, n. 4, p. 763-773.

MCDERMOTT-WELLS, P. (2004-2005). What is bluetooth? IEEE Potentials, 5, v. 23, n. 5, p. $33-35$.

MICROCHIP. (2006e). PICDEM Z Demonstration Kit User's Guide.

MICROCHIP. (2006a). Site Microchip. Disponível em: < http ://www.microchip.com $>$. Acesso em: 20 mai. 2006.

MICROCHIP. (2006b). PICDEM Z Demonstration Kit. Disponível em: $<$ http://www.microchip.com/stellent/idcplg?IdcService $=S_{G} E T_{P} A G E \&$ nodeId $=$ 1406\&dDocName $=$ en021925 >Acesso em: 20 mai. 2006.

MICROCHIP. (2006c). MPLAB IDE (Integrated Development Environment). Disponível em: $<$ http : //www.microchip.com/stellent/idcplg?IdcService $=S S_{G} E T_{P} A G E \&$ nodeId $=$ 1406\&dDocName $=$ en019469\& part $=S W 007002$ >. Acesso em: 20 mai. 2006. 
MICROCHIP. (2006d). MPLAB C18. Disponível em: <http : $/ /$ www.microchip.com/stellent $/$ idcplg?IdcService $=S S_{G} E T_{P} A G E \&$ nodeId $=$ 1406\&dDocName $=$ en010014\&part $=S W 006011$ >. Acesso em: 20 mai. 2006.

NORRIS, M. (2005). Single-chip zigbee for indoor mobile telemetry. The IEEE Seminar on Telemetry and Telematics, p. 10/1-10/4.

NUGGEHALLI, P.; SRINIVASAN, V.; RAO, R. R. (2006). Energy efficient transmission scheduling for delay constrained wireless networks. IEEE Transactions on wireless communications, v. 5, n. 3, p. 531-539.

ONDREJ, S.; ZDENEK, B.; PETR, F.; ONDREJ, H. (2006). Zigbee technology and device design. In: IEEE International Conference on Networking, International Conference on Systems and International Conference on Mobile Communications and Learning Technologies, ICN/ICONS/MCL. Mauritius: [s.n.], p. 129 - 129.

PETERSON, R. L.; ZIEMER, R. E.; BORTH, D. E. (1995). Introduction to Spread Spectrum Communications. [S.1.]: Prentice Hall.

PROAKIS, J. G. (2001). Digital Communications. 4th. ed. [S.1.]: Mc Graw-Hill.

RONDEAU, T. W.; D'SOUZA, M. F.; SWEENEY, D. G. (2004). Residential microwave oven interference on bluetooth data performance. IEEE Transactions on Consumer Electronics, 3 , v. 50, n. 3 , p. $856-863$.

SAKURAGUI, R. R. M. Sistema de Localização de Serviços para Domínios de Segurança Locias e Remotos. Dissertação (Mestrado) — Universidade de São Paulo, 2006.

SALONIDIS, T.; BHAGWAT, P.; TASSIULAS, L.; LAMAIRE, R. (2001). Distributed topology construction of bluetooth personal area networks. In: IEEE INFOCOM 2001. Twentieth Annual Joint Conference of the IEEE Computer and Communications Societies. Anchorage, Alaska, USA: [s.n.], v. 3, p. 22-26.

STREETON, M.; STANFIELD, C. (2005). Zigbee: the telemetry solution? In: The IEE Seminar on Telemetry and Telematics. Savoy Place, London, UK: [s.n.], p. 8/1 - 8/4.

WIKIPEDIA. (2006a). Harald I of Denmark. Disponível em: $<$ http :

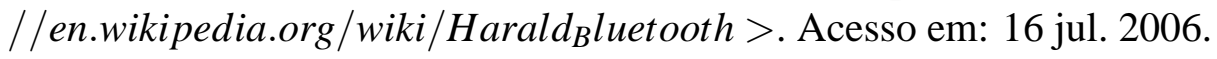

ZHAO, Z.; CUI, L. (2005). Easimed: A remote health care solution. In: 27th Annual International Conference of the Engineering in Medicine and Biology Society. Shanghai, China: IEEE, p. 2145-2148.

ZHENG, Y.; FENG, Z. (2002). Simplifications of the bluetooth radio devices. In: IEEE 4th International Workshop on Networked Appliances, 2002. Gaithersburg, Maryland, USA: [s.n.], p. 107-115.

ZIGBEE-ALLIANCE. (2005)., ZigBee-Specification-v1.0. [S.1.], Junho 2005.

ZIGBEE-ALLIANCE. (2006). Disponível em: < http : //zigbee.org/ > . Acesso em: 16 mar. 2006. 


\section{APÊNDICE A - CÓDIGOS FONTE}

\section{A.1 Coordenador}

\section{A.1.1 Inicialização}

Poucas alterações foram feitas para a implementação. O PORTA inteiro continuou como I/O digital.

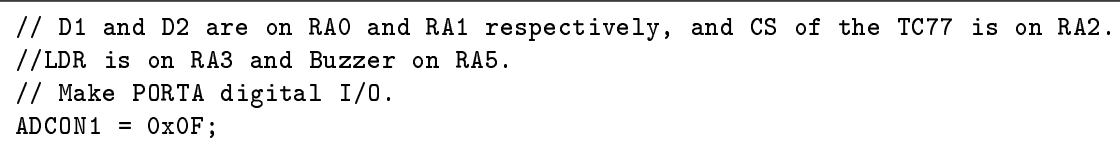

O valor dos pinos do PORTA na inicialização é dado pelo valor da variável LATA. Os valores dos bits equivalentes ao sensor de temperatura (TC77) e do Buzzer foram colocados em nível lógico alto, para que o sensor de temperatura não fosse habilitado e o Buzzer não disparasse na inicialização.

// Deselect the TC77 (RA2) and turn Buzzer off (RA5).

LATA $=0 \times 24 ;$

O TRISA é responsável por definir se um pino do PORTA será uma entrada ou uma saída.

// Make RAO, RA1, RA2, RA4 and RA5 outputs, and RA3 input. TRISA $=0 \mathrm{xC} 8$;

\section{A.1.2 Sensor de Temperatura}

O software do sensor de temperatura pode ser dividido em duas partes, mostrado abaixo. 
1.Leitura do valor de temperatura para ser mostrado na tela.

A função GetTC77String retorna o valor de temperatura já formatado para ser mostrado na tela.

ConsolePutROMString((ROM char*)"Medido: ");

GetTC77String (ptr);

ConsolePutString ( (BYTE*)ptr);

ConsolePutROMString((ROM char*)" $\backslash r \backslash n$ ");

Gerando no hyperterminal algo como:

Medido: $26,0625 \mathrm{C}$

2.Leitura do valor de temperatura para ser comparado com os patamares estipulados.

A função GetTC77HexaValue retorna o valor de temperatura no formato de um número inteiro, de forma a poder ser utilizado para comparar com valores fixos de temperatura.

lui_Temperature_Value = GetTC77HexaValue();

A função GetTC77String faz parte de um exemplo que veio junto com a pilha da Microchip, enquanto que a função GetTC77HexaValue foi implementada. Ambas estão devidamente documentadas no arquivo TC77.c que se encontra no $\mathrm{CD}$ entregue junto com a dissertação.

Como explicado na seção 5.2.1, existem dois patamares de temperatura. Para facilitar a verificação do funcionamento do sensor de temperatura, criou-se uma lógica para os dois leds presentes na placa do kit de desenvolvimento. Cada LED equivale a um patamar. O LED 1 que está no pino RA0 do PIC representa o patamar mais baixo, e o LED 2 que está no pino RA1 do PIC representa o patamar mais elevado. Quando a temperatura está abaixo do primeiro patamar, os dois LEDs estão apagados. Quando a temperatura ultrapassa o valor do primeiro patamar, o LED 1 acende, e quando a temperatura ultrapassa o segundo patamar o LED 2 acende. Abaixo vemos o código implementado. 


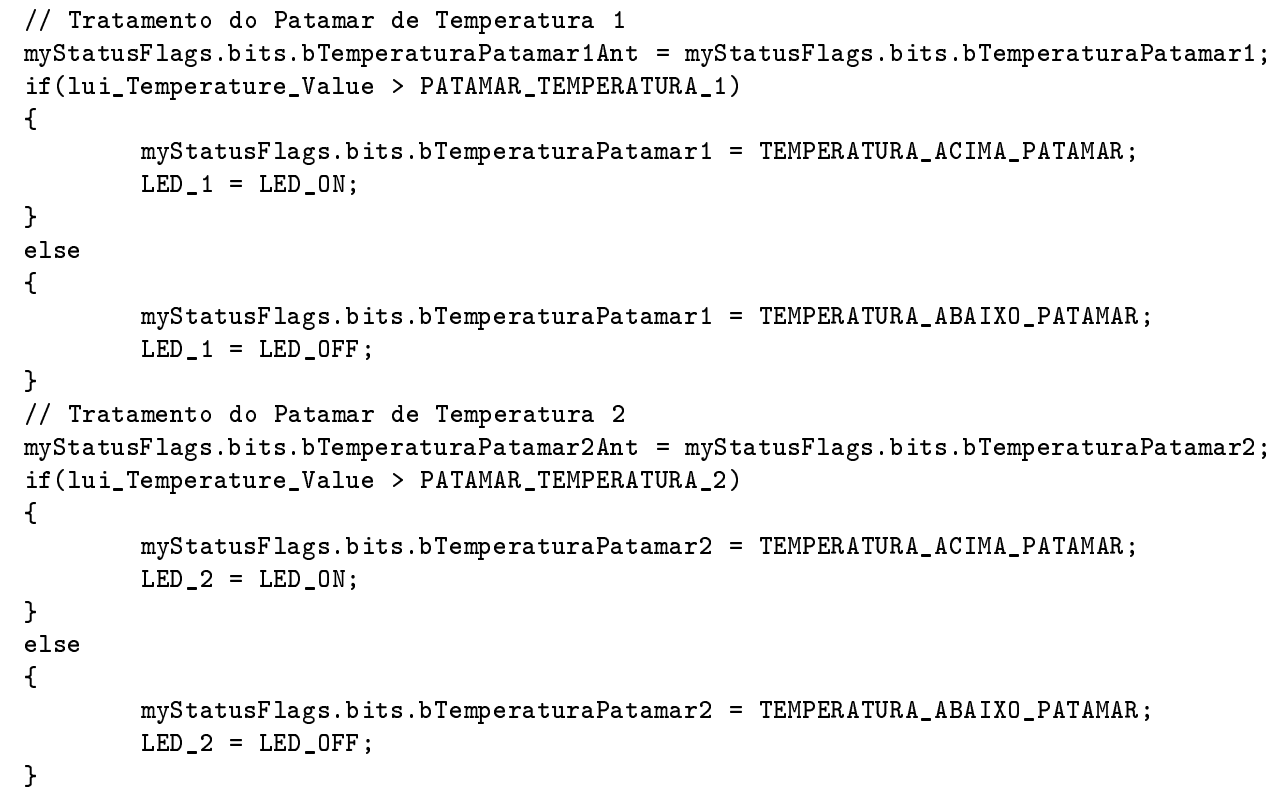

O próximo passo é verificar se o ar condicionado (LED) precisa ser ligado. Essa verificação só é feita se o nó do tipo RFD estiver ativo na rede. Cabe lembrar também que existem dois tipos de tratamento, o do regime permanente e o da inicialização do nó do tipo RFD. O código para essa verificação é apresentado a seguir.

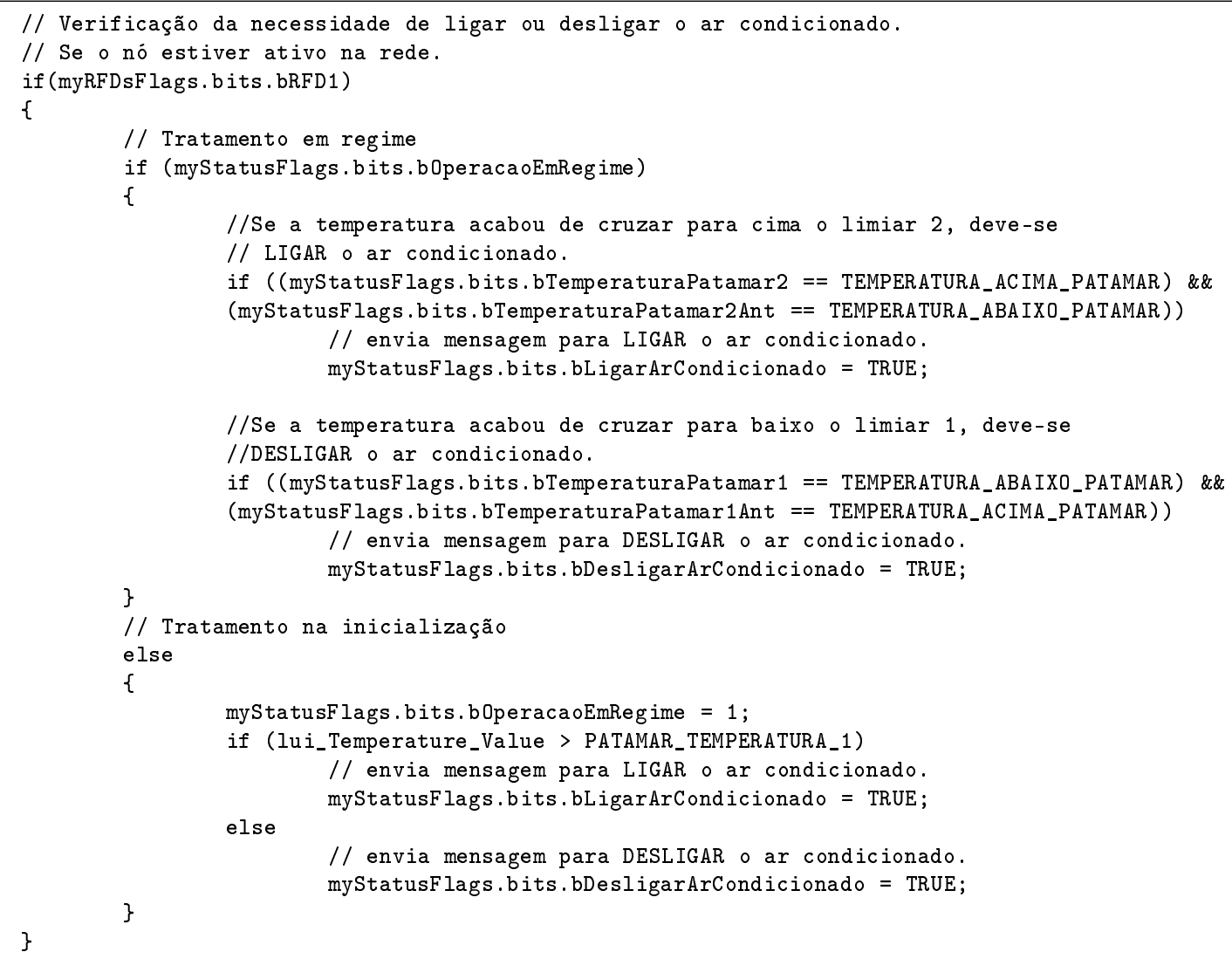


Medido o valor da temperatura e realizadas as verificações quanto à necessidade do envio de mensagens, a última parte referente ao sensor de temperatura é o envio da mensagem, caso seja necessário. Para tal é utilizado o seguinte segmento de software:

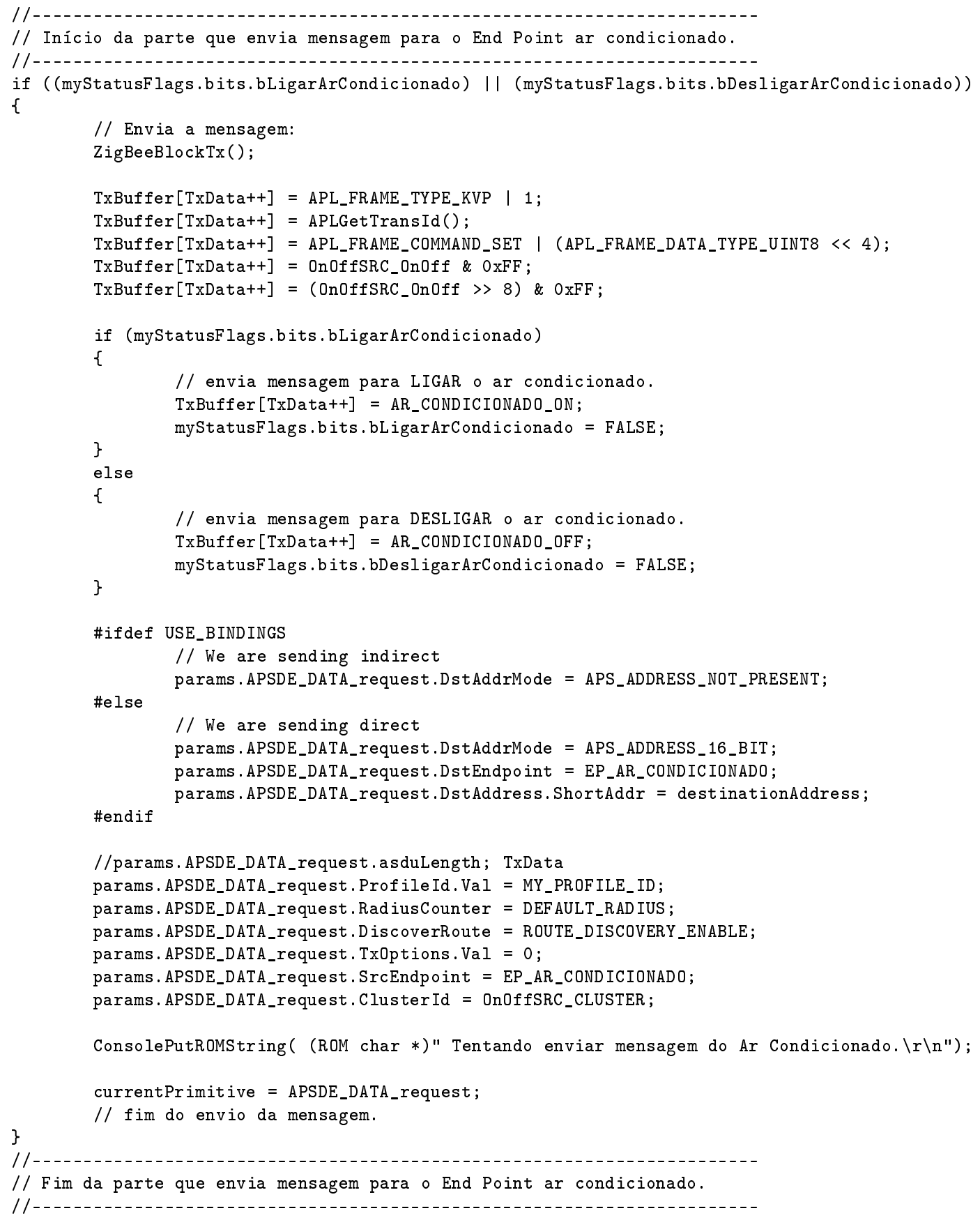




\section{A.1.3 Sensor de Luminosidade (LDR)}

Para realizar a leitura do LDR, deve-se seguir os seguintes passos:

-Inicializar o conversor AD;

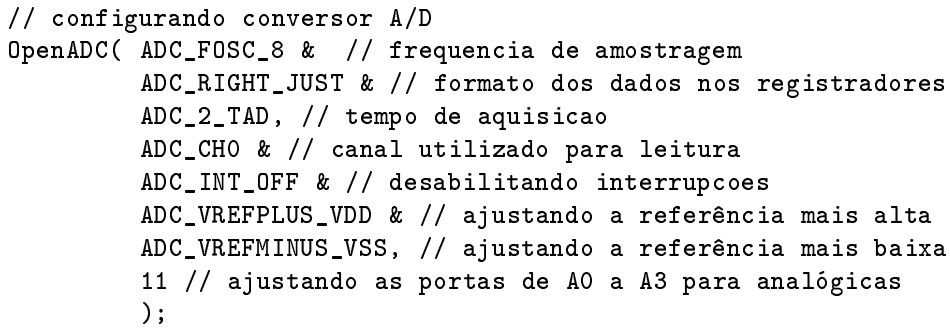

-Determinar a porta do PIC onde será feita a leitura;

SetChanADC ( ADC_CH3 );

- Realizar a leitura.

Valor_Lido_AD = LerDadosAD( );

-Após a leitura do valor do conversor AD, esse valor é enviado via hyperterminal, através das linhas de comando abaixo:

ConsolePutROMString( (rom char*)"Valor medido no AD: ")

ConsolePutString (itoa(Valor_Lido_AD, (char*)Buffer)) ;

ConsolePutROMString((rom char*)".!!! \n\r");

-O efeito no hyperterminal é:

Valor medido no AD: 794.!!!

-Fechar o conversor AD

CloseADC ();

-Habilitar novamente as portas RA0 até RA3 como portas digitais. 
Para realizar a leitura do conversor AD, é necessária a utilização da função int Ler$\operatorname{Dados} A D$ (void), localizada dentro do arquivo LerDadosAD.c, que se encontra no CD que acompanha esta dissertação.

Após a leitura do valor do LDR, o próximo passo é o tratamento do valor obtido. Dependendo do intervalo em que ele se encontra, a lâmpada do nó do tipo RFD deverá ficar apagada, acesa a $40 \%$, acesa a $60 \%$ ou acesa a $100 \%$ da sua carga máxima.

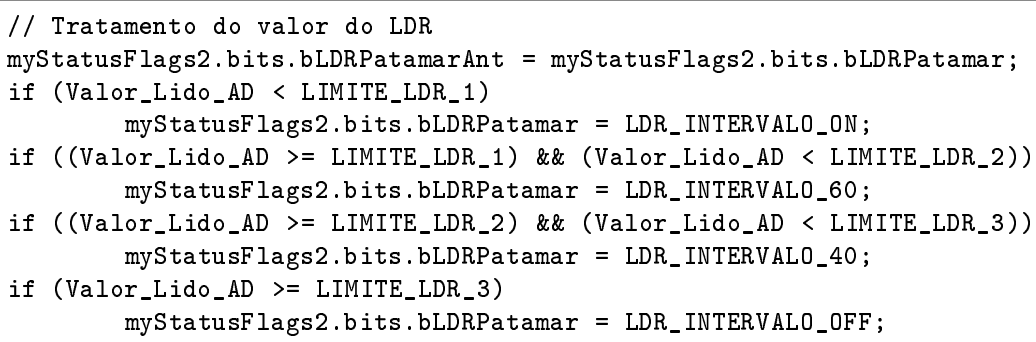

Após o tratamento, é necessário verificar a necessidade de enviar uma mensagem ao nó do tipo RFD alterando o status da lâmpada.

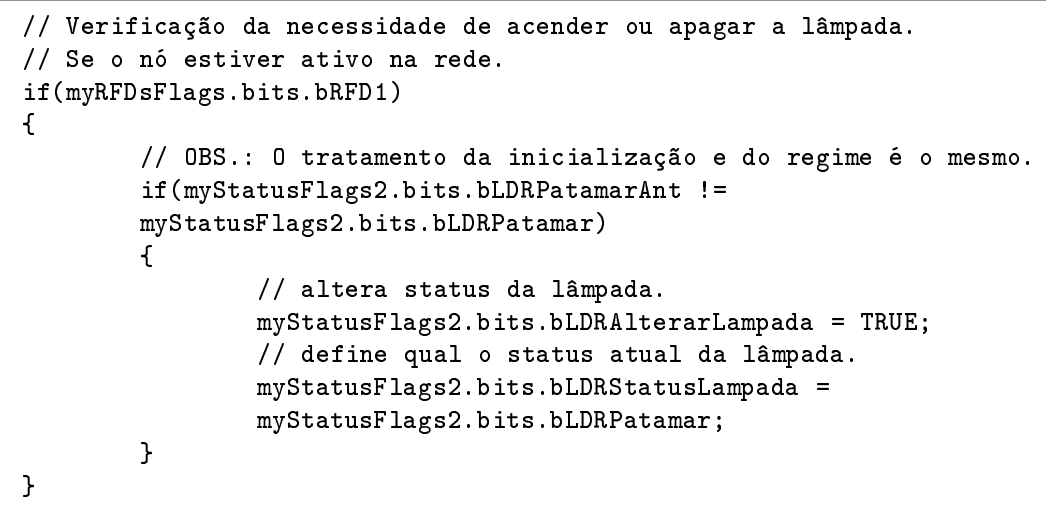

Caso exista a necessidade de se enviar uma mensagem ao nó do tipo RFD, isso será realizado através do seguinte segmento de software:

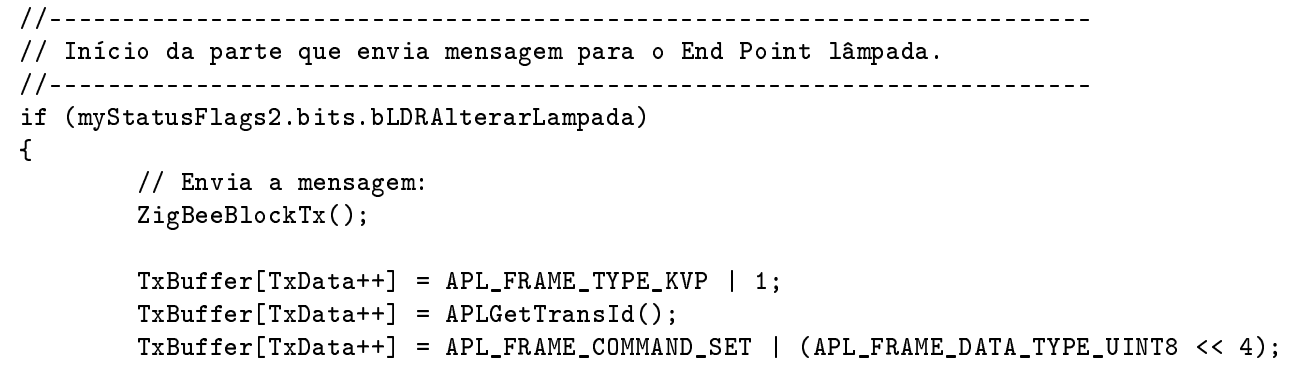




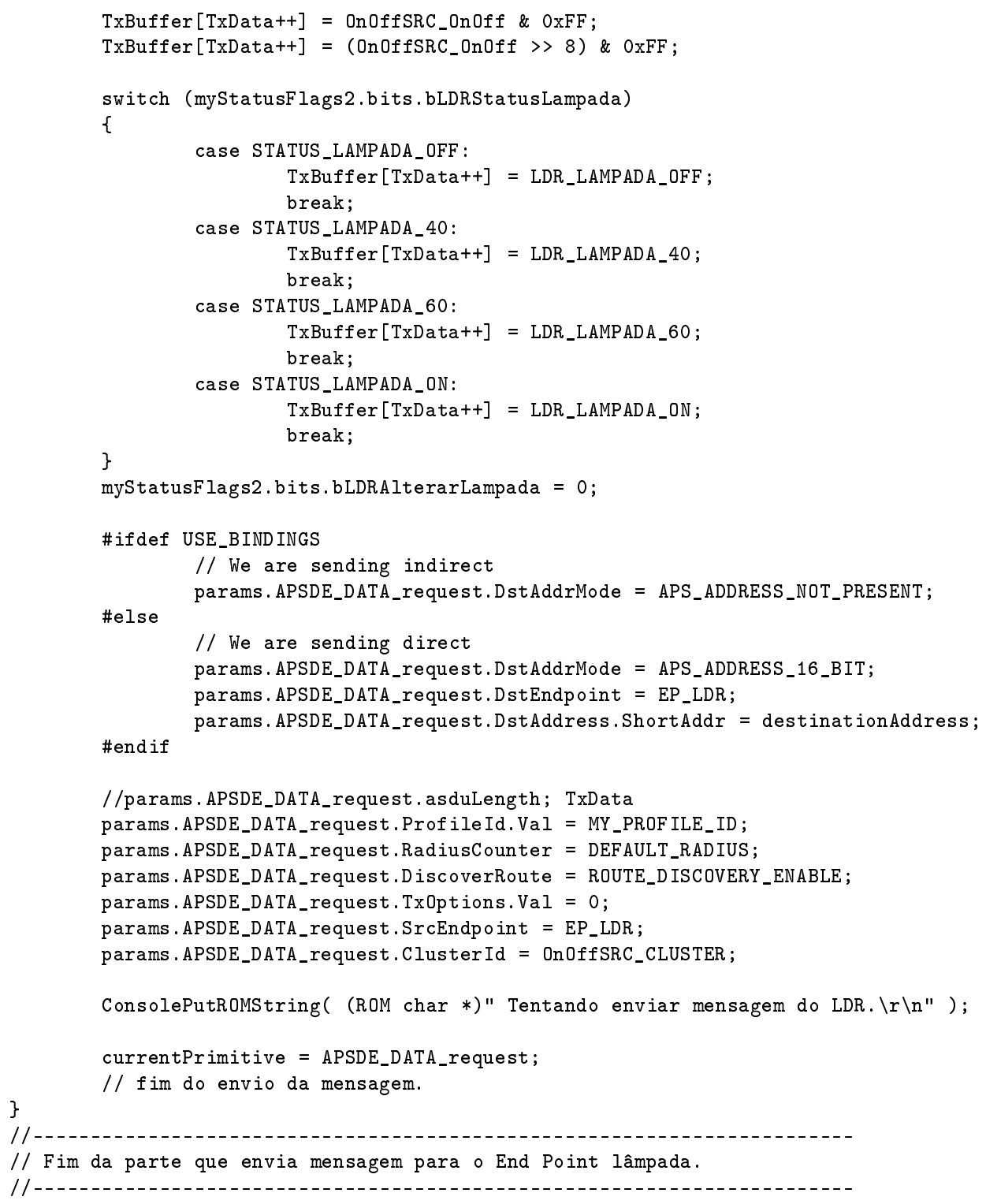

\section{A.1.4 Sinalizador Acústico (Buzzer)}

O estado do Buzzer depende do valor que é recebido via ZigBee. Quando o sensor de movimento do nó do tipo RFD detecta algum movimento, o nó do tipo coordinator recebe uma mensagem indicando que o Buzzer deve ser acionado. Quando o mesmo sensor de movimento não mais detecta movimento, é enviada uma mensagem para o nó do tipo coordinator para que o Buzzer deixe de ser acionado. Segue abaixo a parte do código onde é alterado o estado do Buzzer dependendo da mensagem recebida. 


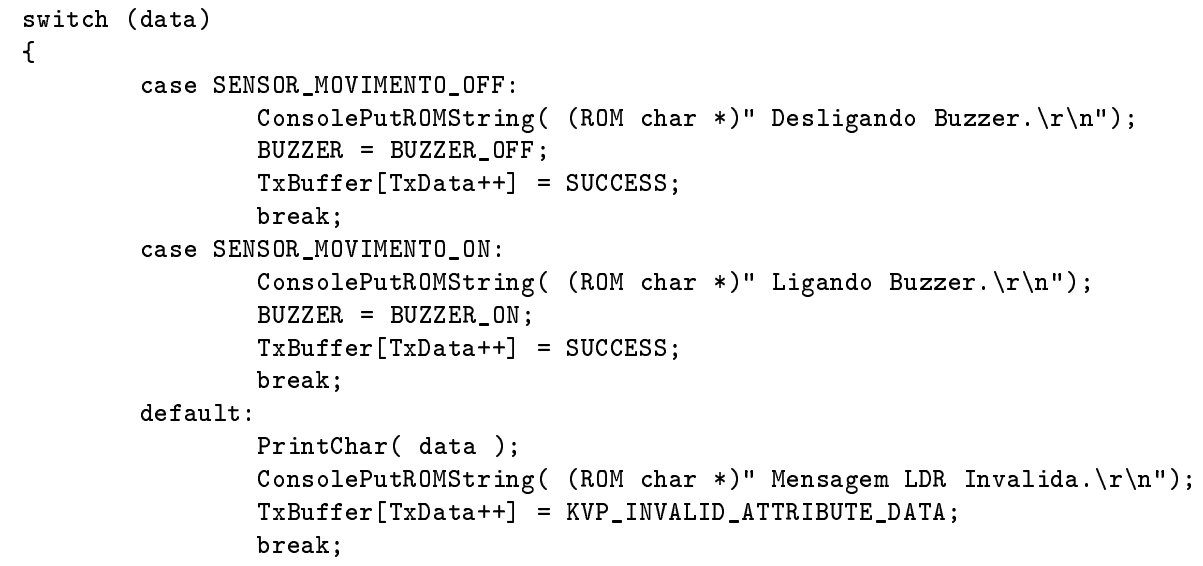

\section{A.2 End Device (RFD)}

\section{A.2.1 Inicialização}

Nessa parte do software foram feitas várias alterações. As portas de RA0 até RA3 do PORTA são utilizadas como entradas analógicas. As portas RA0 e RA3 são utilizadas no comparador e as portas RA1 e RA2 não são utilizadas.

ADCON1 = 11; $\quad / /$ ANO:AN3 analogicas. ANO e AN3 serão utilizadas no comparador.

//Os leds em RAO e RA1 e o TC77 em RA2 não serão utilizados.

O valor dos pinos do PORTA na inicialização é dado pelo valor da variável LATA.

Todos os bits foram inicializados com nível lógico baixo.

// Coloca todas as portas em nível lógico baixo.

LATA $=0 \times 00$;

O TRISA é responsável por definir se um pino do PORTA será uma entrada ou uma saída.

// Make RAO:RA3 and RA5 inputs and RA4 output.

TRISA $=0 \mathrm{XEF}$;

O pino RD0 do PORTD foi utilizado para acionar o LED, que representa o ar condicionado, enquanto que o pino RE1 do PORTE é utilizado para acionar o gate do triac, que acionará a lâmpada. 
//Fazendo de PORTDO e PORTE1 saídas.

TRISDO $=0$

// Led que representa o ar-condicionado.

TRISEbits. TRISE1 $=0$;

// Saida para acionamento do gate do Triac.

É necessário também habilitar os comparadores do PORTA e alterar as interrupções de modo que o comparador funcione corretamente.

\begin{tabular}{ll|}
\hline CMCON $=0 \times 1 ;$ & $/ /$ habilita os comparadores do PORTA \\
PIE2bits.CMIE $=1 ;$ & $/ /$ habilita interrupçao por comparador \\
IPEN $=0 ;$ & // desabilita prioridade das interrupçoes \\
INTCONbits.PEIE $=1 ;$ & // habilita interrupçoes perifericas \\
PIR2bits.CMIF $=0 ;$ & // limpa flag da interrupçao por comparador \\
\hline
\end{tabular}

\section{A.2.2 Sensor de Movimento}

Assim que o nó do tipo RFD entra na rede, a primeira coisa que ele faz é aguardar 60 segundos, para que o sensor de movimento seja inicializado. Para tal é utilizado o timer 1, com uma base de tempo de aproximadamente $50 \mathrm{~ms}$.

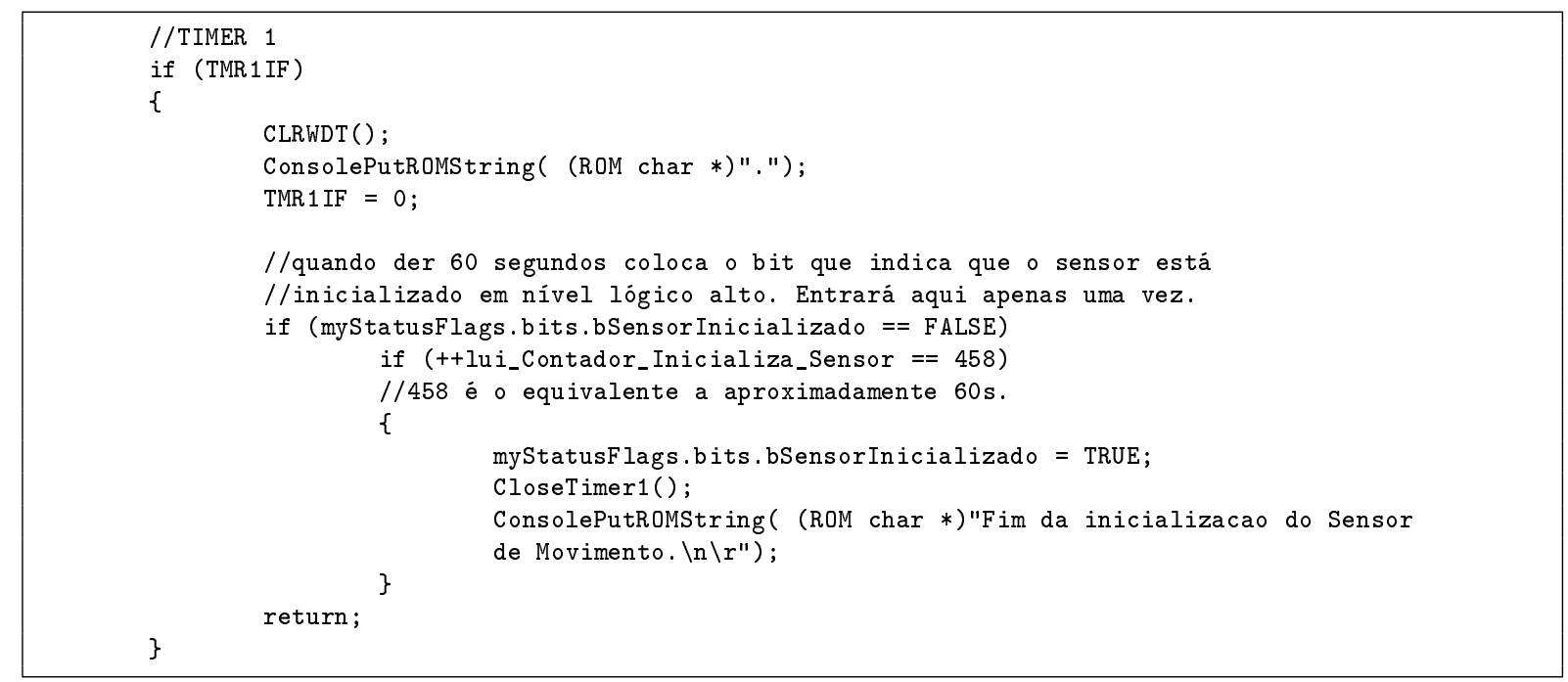

Após a inicialização, o sensor de movimento funciona da seguinte forma: quando acionado envia ao nó do tipo coordinator uma mensagem indicando que o Buzzer deve ser acionado, e quando o sensor de movimento não mais detecta movimento, uma mensagem deve ser enviada ao nó do tipo coordinator para que o Buzzer deixe de ser acionado.

Essa primeira parte de software verifica se o sensor foi acionado. 


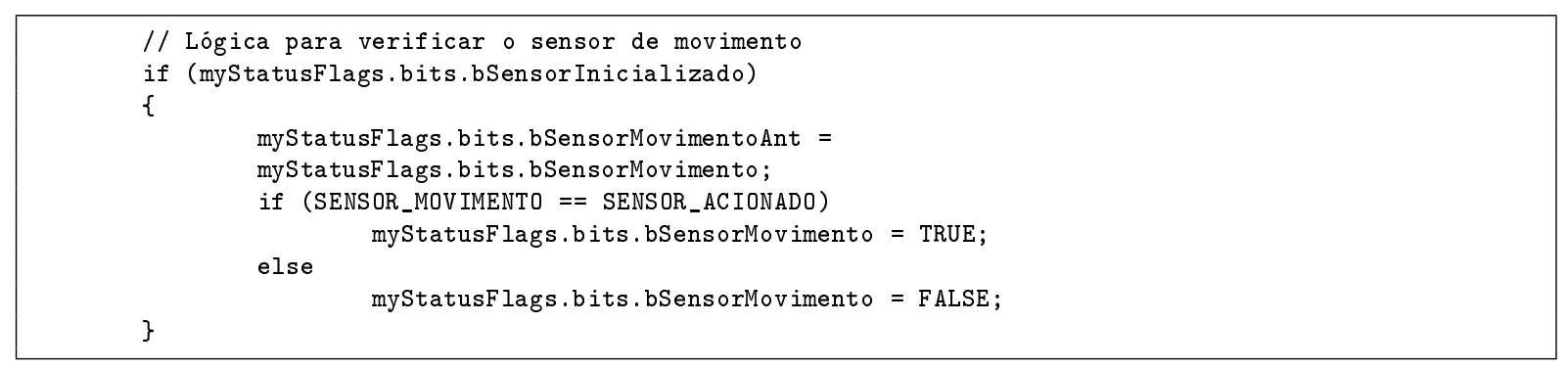

A próxima parte do software é a que verifica a necessidade do envio de mensagem.

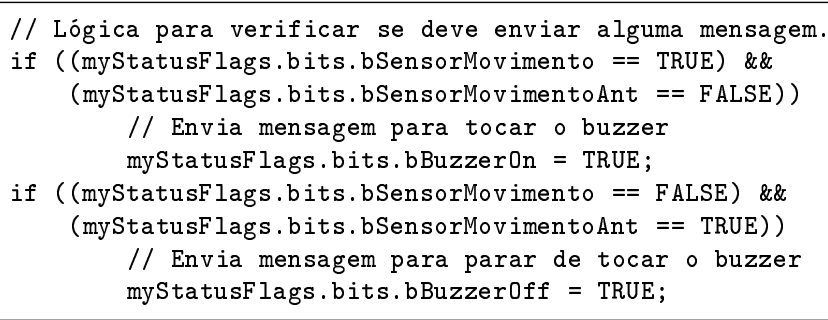

Caso deva ser enviada uma mensagem para alterar o status do Buzzer, o seguinte código é utilizado:

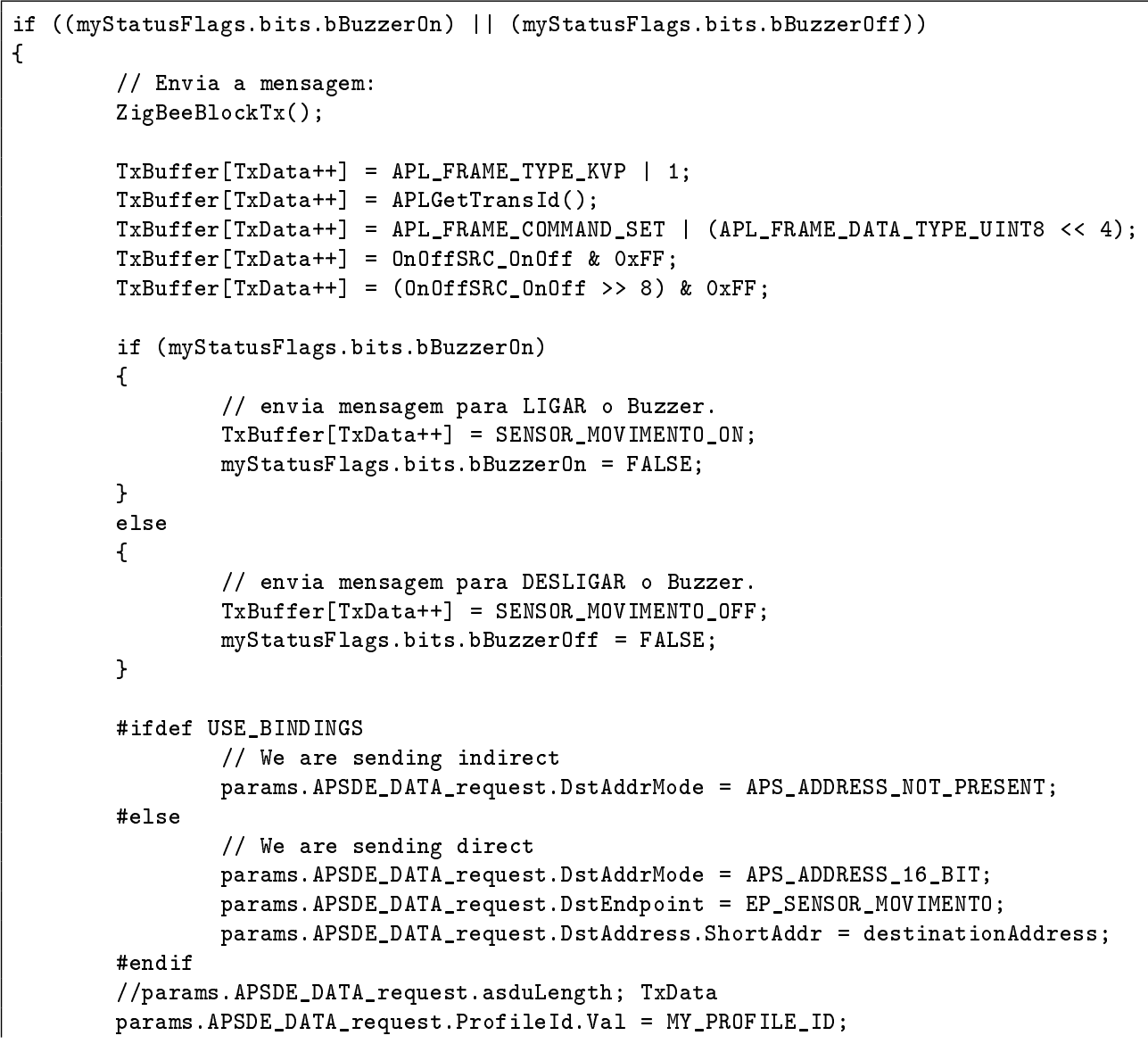




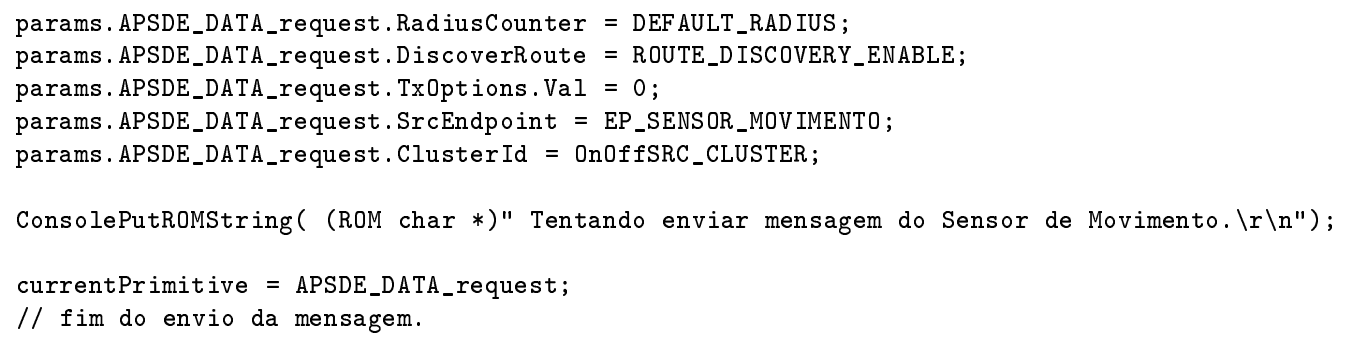

\section{A.2.3 Lâmpada}

A lâmpada é acionada dependendo da mensagem que é recebida do nó do tipo RFD via ZigBee. De acordo com o valor de luminosidade lido pelo LDR, a lâmpada poderá estar apagada, acesa a $40 \%$, acesa a $60 \%$ ou acesa a $100 \%$ de sua carga máxima.

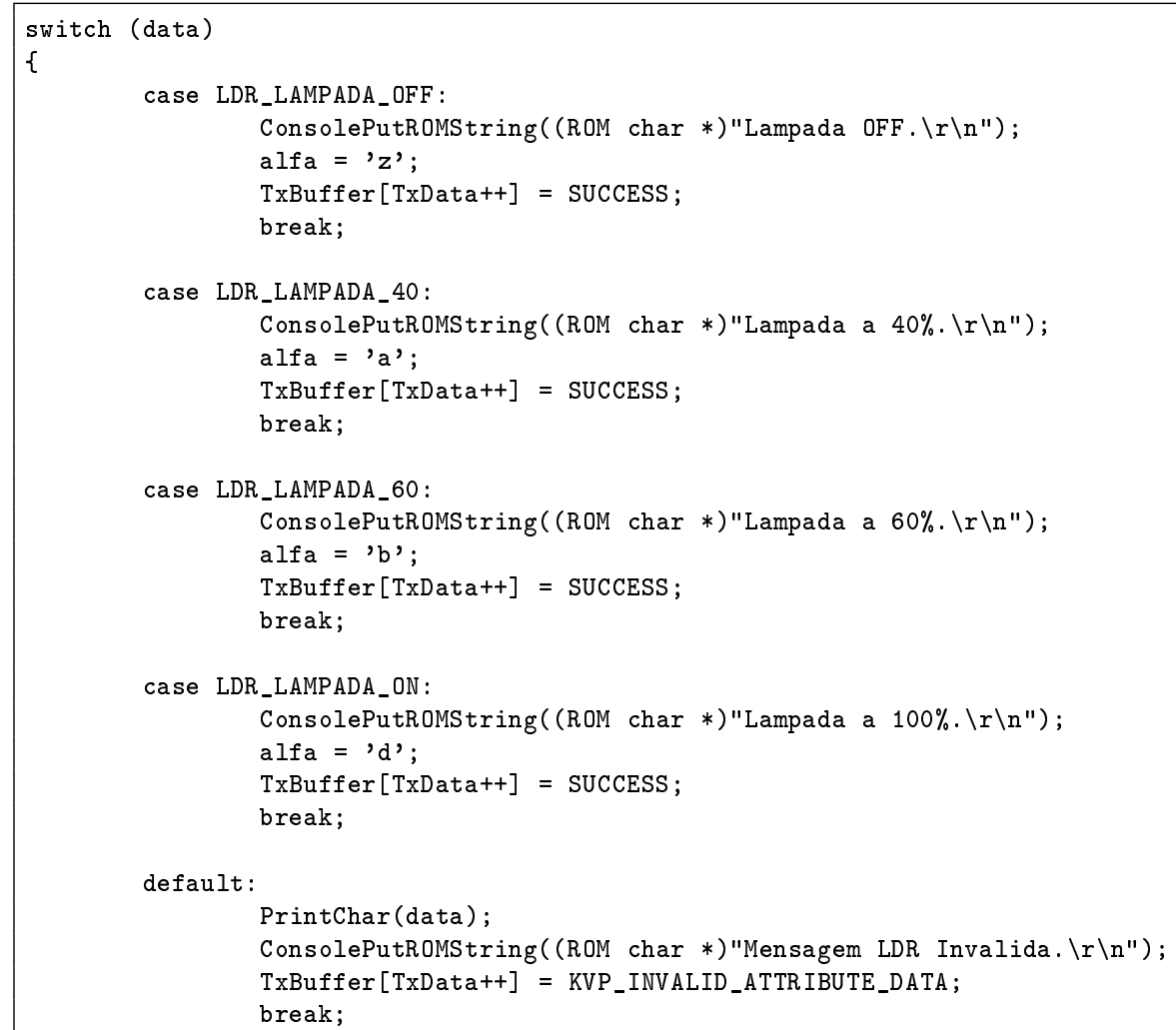




\section{A.2.4 LED}

O status do LED (ar condicionado) depende da mensagem recebida do nó do tipo coordinator. Dependendo da temperatura lida pelo sensor de temperatura (TC77) o ar condicionado deve ser ligado ou desligado. Abaixo pode ser visto o código referente à mudança do status do LED.

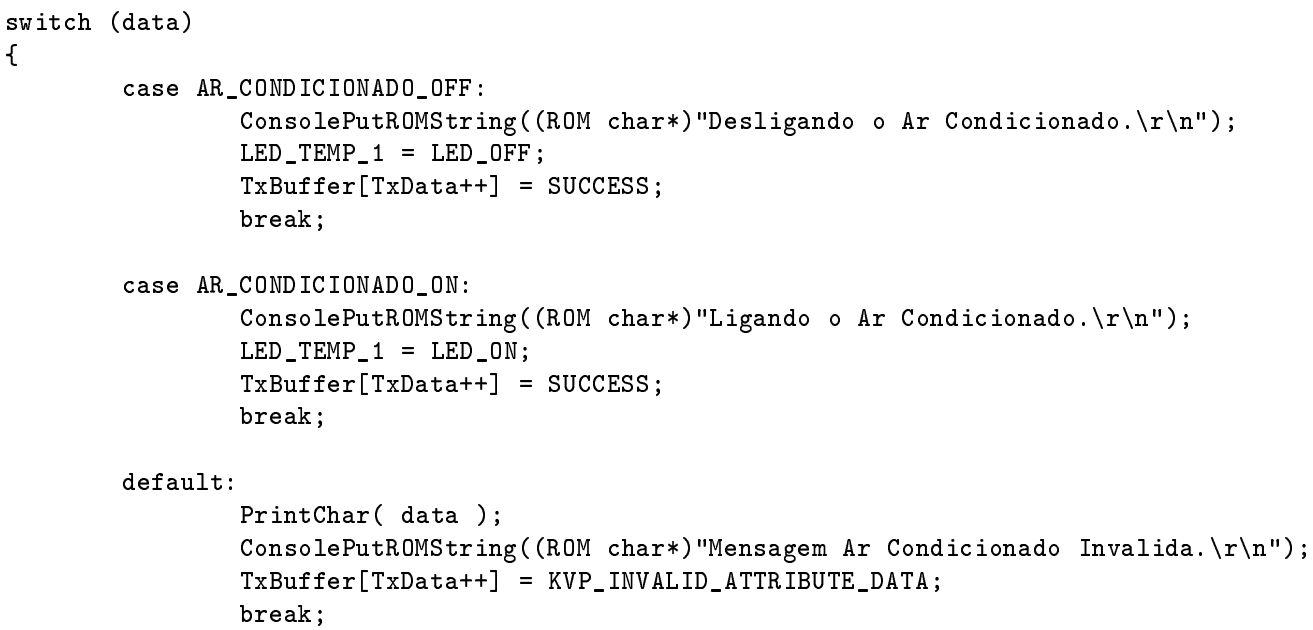

